\title{
Transport Processes in the Gulf of Mexico Along the River-Estuary-Shelf-Ocean Continuum: a Review of Research from the Gulf of Mexico Research Initiative
}

\author{
Dubravko Justić ${ }^{1} \cdot$ Villy Kourafalou $^{2} \cdot$ Giulio Mariotti $^{1,3}$. Songjie He ${ }^{1} \cdot$ Robert Weisberg $^{4} \cdot$ Yannis Androulidakis $^{2}$. \\ Christopher Barker ${ }^{5}$. Annalisa Bracco ${ }^{6}$. Brian Dzwonkowski ${ }^{7}$. Chuanmin $\mathrm{Hu}^{4}$. Haosheng Huang ${ }^{1}$. Gregg Jacobs ${ }^{8}$. \\ Matthieu Le Hénaff ${ }^{9,10}$. Yonggang Liu ${ }^{4}$. Steven Morey ${ }^{11}$. Jeffrey Nittrouer ${ }^{12}$. Edward Overton ${ }^{1}$. Claire B. Paris ${ }^{2}$. \\ Brian J. Roberts ${ }^{13} \cdot$ Kenneth Rose $^{14} \cdot$ Arnoldo Valle-Levinson $^{15} \cdot$ Jerry Wiggert ${ }^{16}$
}

Received: 27 June 2020 / Revised: 4 September 2021 / Accepted: 9 September 2021 / Published online: 4 October 2021

(c) The Author(s) 2021

\begin{abstract}
Estuarine and coastal geomorphology, biogeochemistry, water quality, and coastal food webs in river-dominated shelves of the Gulf of Mexico (GoM) are modulated by transport processes associated with river inputs, winds, waves, tides, and deepocean/continental shelf interactions. For instance, transport processes control the fate of river-borne sediments, which in turn affect coastal land loss. Similarly, transport of freshwater, nutrients, and carbon control the dynamics of eutrophication, hypoxia, harmful algal blooms, and coastal acidification. Further, freshwater inflow transports pesticides, herbicides, heavy metals, and oil into receiving estuaries and coastal systems. Lastly, transport processes along the continuum from the rivers and estuaries to coastal and shelf areas and adjacent open ocean (abbreviated herein as "river-estuary-shelf-ocean") regulate the movements of organisms, including the spatial distributions of individuals and the exchange of genetic information between distinct subpopulations. The Gulf of Mexico Research Initiative (GoMRI) provided unprecedented opportunities to study transport processes along the river-estuary-shelf-ocean continuum in the GoM. The understanding of transport at multiple spatial and temporal scales in this topographically and dynamically complex marginal sea was improved, allowing for more accurate forecasting of the fate of oil and other constituents. For this review, we focus on five specific transport themes: (i) wetland, estuary, and shelf exchanges; (ii) river-estuary coupling; (iii) nearshore and inlet processes; (iv) open ocean transport processes; and (v) river-induced fronts and cross-basin transport. We then discuss the relevancy of GoMRI findings on the transport processes for ecological connectivity and oil transport and fate. We also examine the implications of new findings for informing the response to future oil spills, and the management of coastal resources and ecosystems. Lastly, we summarize the research gaps identified in the many studies and offer recommendations for continuing the momentum of the research provided by the GoMRI effort. A number of uncertainties were identified that occurred in multiple settings. These include the quantification of sediment, carbon, dissolved gasses and nutrient fluxes during storms, consistent specification of the various external forcings used in analyses, methods for smooth integration of multiscale advection mechanisms across different flow regimes, dynamic coupling of the atmosphere with sub-mesoscale and mesoscale phenomena, and methods for simulating finer-scale dynamics over long time periods. Addressing these uncertainties would allow the scientific community to be better prepared to predict the fate of hydrocarbons and their impacts to the coastal ocean, rivers, and marshes in the event of another spill in the GoM.
\end{abstract}

Keywords Estuarine and shelf dynamics · Ocean circulation · Biophysical and ecological connectivity $\cdot$ Oil transport and fate $\cdot$ Gulf of Mexico

Communicated by Kenneth L. Heck

Dubravko Justić

djusti1@1su.edu

Extended author information available on the last page of the article

\section{Introduction}

Transport processes associated with river inputs, winds, waves, tides, and their complex interactions throughout estuaries, shelves, and the open ocean play important roles 
in modulating coastal geomorphology, biogeochemistry, water quality, and food webs. These transport processes are especially important in river-dominated shelf environments, such as the northern Gulf of Mexico (GoM), which seasonally receive an influx of fresh water into their estuaries and shelf. Transport processes control the spatial distribution of fundamental water properties (temperature and salinity) and water constituents (sediments, nutrients, contaminants) over event-driven, seasonal, and interannual time scales. Many organisms are also influenced by transport, in that their advection and dispersal enable ecological connections among different habitats.

In the northern GoM, transport processes control the fate of river-borne sediments (river to estuary), which in turn affect coastal land changes (e.g., Allison et al. 2012). For example, due to decrease in sediment supply from the Mississippi River (Blum and Roberts 2009; CPRA 2017; Mize et al. 2018), activities related to exploration and operations of oil and gas extraction (e.g., Foy 1990; Mendelssohn et al. 2012; Turner and McClenachan 2018), and the high rate of relative sea-level rise (Dixon et al. 2006; Ivins et al. 2007), about $23 \%$ (> $4800 \mathrm{~km}^{2}$ ) of Louisiana's coastal wetlands were converted to open water between the 1930s and 2014 (CPRA 2017). As a method of land building, proposed Mississippi River sediment diversions have received significant attention from state and federal agencies along the Gulf Coast to mitigate Mississippi River Delta land loss (DeLuca 2014; CPRA 2017). The need to design, operate, and maintain efficient sediment diversions has motivated a thorough and quantitative understanding of the processes that control sediment transport. Although land loss along the Louisiana coastline has drawn the greatest attention in the northern GoM, beach erosion also occurs along the sandy barrier islands of Texas, Mississippi, Alabama, and west Florida (Morton et al. 2004; Morton 2008; Anderson et al. 2014; Eisemann et al. 2018).

Freshwater influx from rivers brings nutrients and carbon, and thus influences eutrophication dynamics, including hypoxia, harmful algal blooms, and coastal acidification in the estuaries and on the shelf (e.g., Tester and Steidinger 1997; Goolsby et al. 1999; Rabalais et al. 2007; Cai et al. 2011; Holstein et al. 2016a, b; Weisberg et al. 2016a, 2019; Justić et al. 2007 and 2017). For example, nutrient inputs from the Mississippi and Atchafalaya Rivers into the northern GoM (river to estuary to shelf) promote enhanced phytoplankton production and fuel high respiration rates that, when coupled with water column stratification, result in summer hypoxia of shelf bottom waters. Hypoxia may also occur episodically due to the oxidation of decaying matter under extreme harmful algal bloom events, as happened off the west Florida coast in 2005 (Weisberg et al. 2009). In addition to consuming oxygen, respiration produces $\mathrm{CO}_{2}$, thus lowering water $\mathrm{pH}$ and acidifying bottom waters (e.g., Cai et al. 2011; Laurent et al. 2017).

Delivery and transport of the fresh water affects pesticide, herbicide, heavy metal, and oil pollution in the receiving estuaries and shelves (e.g., Meade 1995; McMillin and Means 1996; Clark et al. 1999; Holm et al. 2003). For example, water samples collected from the Mississippi River at Baton Rouge between 1991 and 1997, and from sites on the upper Mississippi, Missouri, and Ohio Rivers during 1996 and 1997, were analyzed to show that herbicide loading to the GoM from the Mississippi River catchment is comprised of approximately 640 metric tons of atrazine, 320 metric tons of cyanazine, 215 metric tons of metolachlor, 53 metric tons of simazine, and 50 metric tons of alachlor annually (Clark et al. 1999). Even though there are no known studies on human and wetland plant health effects that occur at exposure concentrations, this influx could potentially affect the marsh ecology, given that herbicides have been shown to inhibit growth of wetland plants (Langan and Hoagland 1996), in addition to possible adverse impacts on human health (Lynch et al. 2006; Boffetta et al. 2013).

Transport processes along the river-estuary-shelf-ocean continuum regulate the movement of organisms, including individuals, materials, or genes, between distinct subpopulations (e.g., Cardona et al. 2016; Holstein et al. 2016a, b; Bracco et al. 2019b). For example, a modeling study showed that gag grouper (Mycteroperca microlepis) larvae are transported to the nearshore via the bottom Ekman layer and that such transport is facilitated by remote forcing associated with GoM Loop Current (LC) interactions with the shelf slope near the Dry Tortugas (Weisberg et al. 2014). Similarly, the delivery of Karenia brevis from its bloom initiation region to the coastal regions of southwest Florida, where "red-tides" are most frequent, follows the same pathway (Weisberg et al. 2019), helping to explain why both gag juveniles and $K$. brevis share similar epicenter distributions.

The above transport processes are largely controlled by circulation within rivers, wetlands, estuaries, deltas, and shelves, extending from nearshore shallow areas to offshore shelf slope areas. Within the shelf-break region, farther offshore transport is possible, toward the GoM interior and beyond. Local and remote interactions affect the material fluxes across the shelf-slope break (e.g., Weisberg 2003; Walsh 2003), and these fluxes can further propagate landward influencing the coastal zone (Weisberg et al. 2004). Mississippi waters moving along the LC front can reach the Straits of Florida and the Atlantic Ocean (Ortner et al. 1995; Hu et al. 2005; Schiller and Kourafalou 2014; Androulidakis et al. 2019).

The Deepwater Horizon (DwH) oil spill that occurred offshore of the Mississippi Delta beginning in April 2010 and lasting for 3 months was the largest offshore oil spill in US 
history. The Gulf of Mexico Research Initiative (GoMRI), a 10 -year (\$500 million) research program formed in response to this incident (Shepherd et al. 2016), has provided unprecedented opportunities to study transport processes along the river-estuary-shelf-ocean continuum and facilitated many discoveries. For this review, we focus on five specific transport themes: (i) wetland, estuary, and shelf exchanges; (ii) river-estuary coupling; (iii) nearshore and inlet processes; (iv) open ocean transport processes; and (v) river-induced fronts and cross-basin transport (Fig. 1). We also discuss the relevance of transport processes for ecological connectivity and oil transport and fate. We focused on these topics because they are fundamental for understanding transport in the GoM and are not only critical for future responses to oil spills but have broad implications on many aspects of the physics and ecology of the GoM. We conclude with a section on legacy of the GoMRI research program and recommendations to inform future research and successful future management strategies in the region.

\section{Transport Processes in the Gulf of Mexico}

\section{Wetland, Estuary, and Shelf Exchanges}

\section{Overview}

The exchange of water and materials between wetlands, estuaries, and the shelf is critical for many physical, geological, biochemical, and ecological processes in river-dominated environments. These exchanges are driven by estuarine circulation, river-induced currents, meteorological forcing such as wind and atmospheric pressure related to fronts and storms, surface and internal waves, and astronomical tides (Rozas 1995; Hiatt et al. 2019).

We present examples from the northern and eastern GoM, where most estuaries consist of relatively large water bodies in the lower reaches, some connecting to the upper reaches with sinuous natural bayous and straight segments of navigational and pipeline channels, interspersed with lakes and bays of various sizes and large expanses of freshwater, brackish, and salt marshes. Because the majority of the estuaries in the northern GoM are separated from the open ocean by barrier islands (Schroder and Wiseman 1999), the exchanges with the shelf mostly take place through tidal inlets ( $\mathrm{Li}$ et al. 2011). Astronomical tides in this region are diurnal and small (i.e., less than $0.6 \mathrm{~m}$, Marmer 1954; Feng and Li 2010). Nevertheless, tidal currents can maintain high velocity, especially in inlets (1-2 m/s, Murphy and Valle-Levinson 2008; Murphy et al. 2009; Li et al. 2011; Valle-Levinson et al. 2015), and in narrow channels inside estuaries $(0.5-0.7 \mathrm{~m} / \mathrm{s}$, Snedden et al. 2007). Within the estuaries, the exchanges between open waters and marshes occur through channel flow and intermittent sheet flow over the marsh platform. Winds associated with the recurrence of cold fronts dominate during November-May, causing significant rapid water level variations (up to $1 \mathrm{~m}$, Chuang and Wiseman 1983; Perez et al. 2000) and prolonged inundation of adjacent marshes.

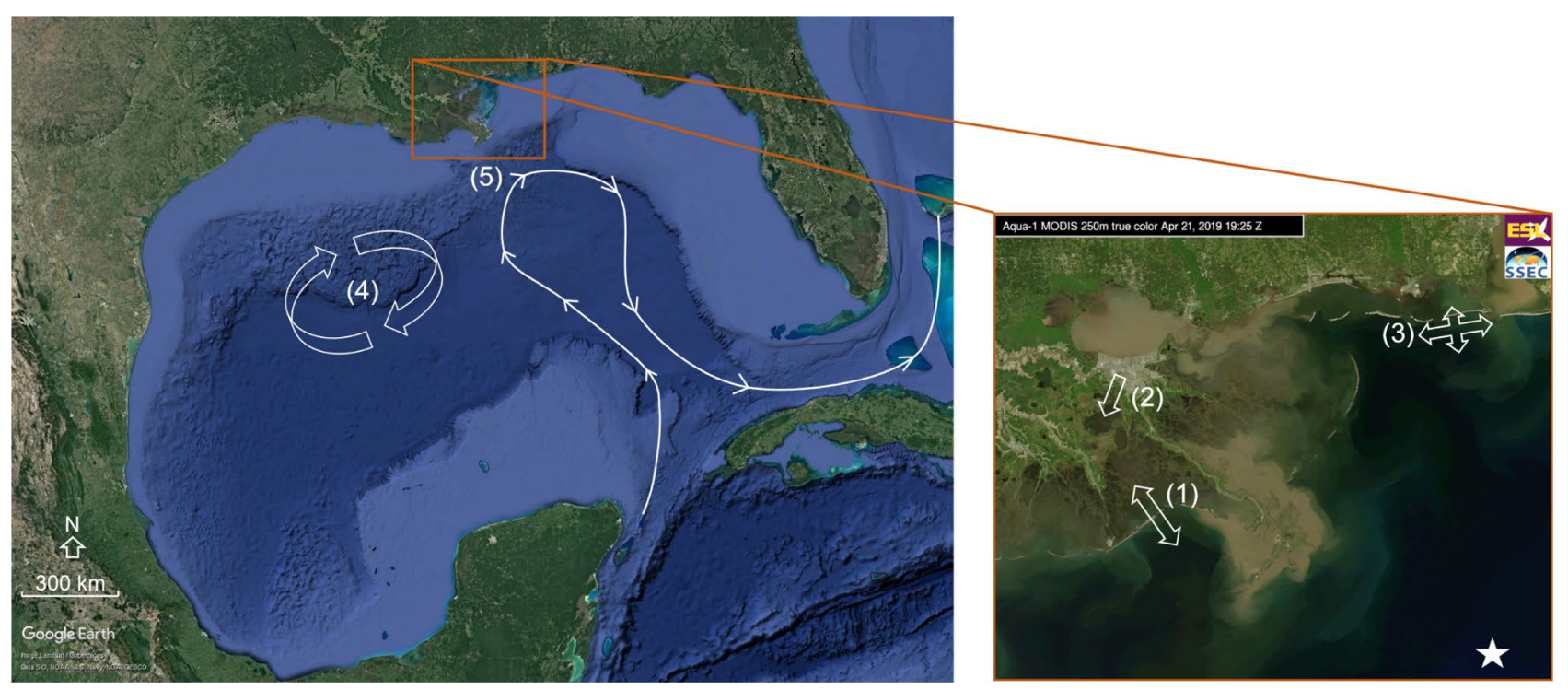

Fig. 1 Key transport processes in the Gulf of Mexico (GoM): (1) wetland, estuary, and shelf exchanges; (2) river-estuary coupling; (3) nearshore and inlet processes; (4) open ocean transport processes; and (5) river-induced fronts and cross-basin transport. The site of the
Deepwater Horizon oil spill (DwH) is denoted by a white star symbol on the inset panel. The placement of symbols representing the five processes is arbitrary 
The baseline understanding of transport processes in these systems before GoMRI was extensive and included both observational and modeling studies. For example, there were several long-term water quality sampling efforts that spanned freshwater and brackish regions, including a transect of 37 stations in Barataria Bay from 1994 to 2016 (Wissel et al. 2005; Turner et al. 2019), and a transect of 16 stations in the Breton Sound Estuary between 1988 and 2010 (Lane et al. 1999, 2007; Wissel et al. 2005; Lundberg et al. 2014). In addition, shorter-term research efforts with field measurements of sediment, nutrients, and carbon were carried out in wetlands (e.g., Marton and Roberts 2014; Schutte et al. 2020), rivers and estuaries (e.g., Roberts and Doty 2015; He and Xu 2017), and coastal and shelf waters (e.g., Rabalais et al. 2007; Lehrter et al. 2013).

It should be noted, however, that field measurements were mostly carried out during calm weather conditions, except for a few continuous studies that encompassed low frequency storm conditions (e.g., Perez et al. 2000). The measurements were generally compartmentalized, with only limited integration across the river-estuary-shelf-ocean continuum. In addition, field measurements were typically focused on water quality variables (such as salinity, turbidity, and nutrient concentrations), whereas direct current measurements were rare (e.g., Li et al. 2011). During most field surveys, water samples were collected only at the surface or some assumed mid-depth without any further vertical profiling because of the assumption that water column in these shallow (2-3 m deep) estuaries is always well mixed. The assumption of a well-mixed water column favored the development of numerical frameworks that were either simple box models (e.g., Das et al. 2010), or 2-dimensional (horizontally resolved) models (e.g., Inoue et al. 2008; Das et al. 2011, 2012).

\section{Findings of the GoMRI Research Program}

As a result of the GoMRI Research Program, progress in the understanding of wetland, estuary, and shelf transport processes has been made using field measurements and models, and the integration of both. For example, measurements in tidal inlets have indicated a bathymetric control on exchange flows and atmospherically forced flows whose magnitude may exceed that of tidal flows (e.g., Li et al. 2011; Olabarrieta et al. 2017). Exchange flows tend to be laterally sheared under weakly stratified (top-to-bottom density differences $<2 \mathrm{~kg} / \mathrm{m}^{3}$ ) or vertically mixed conditions, and vertically sheared otherwise (Valle-Levinson 2011; Huguenard et al. 2015; Valle-Levinson et al. 2015; Cui et al. 2018). Deep ship channels were also shown to be a critical pathway by which offshore subsurface material could be rapidly transported into estuarine systems (Coogan et al. 2019).
Another important finding was the effect of meteotsunamis that can develop during both winter and summer seasons, and preferentially during El Niño years and hurricane conditions (e.g., Olabarrieta et al. 2017). These are waves like storm surges, with periods $<1.5 \mathrm{~h}$, produced by atmospheric forcing and wind stress (e.g., Shi et al. 2019). Meteotsunamis can trigger horizontal currents $>1 \mathrm{~m} / \mathrm{s}$ and therefore are one of the effective forcing mechanisms for transporting oil, and particularly important as they can be of the same magnitude as tidal currents (and reverse the forecast tidal currents), but far less predictable. Also, more systematic GoMRI studies have shed light on how the bay geometry and bathymetry affect the relative roles of remote and local wind effects on transport, possibly augmenting the risk of nuisance flooding associated with river diversions (Payandeh et al. 2019).

From the modeling perspective, use of unstructuredgrid models, such as the Finite-Volume Community Ocean Model (FVCOM), has enabled more realistic simulation of complex coastline geometries, the inclusion of sinuous bayous and channels, and the capability to simulate periodic inundations over the low-lying wetlands (e.g., Chen et al. 2003). These advances built upon the earlier work of Weisberg and Zheng (2006) for Tampa Bay and Zheng and Weisberg (2010) for Rookery Bay. As an example, FVCOM was used to study how Tampa Bay responded to Hurricane Irma (Chen et al. 2018), where water was first transported out of the bay and then it was replaced by a different water mass entering the bay. High-resolution, three-dimensional nested modeling with flooding and drying revealed where the water that exited Tampa Bay flowed and where the replacement water eventually came from (Fig. 2). FVCOM simulations also revealed the along- and cross-inlet circulation features at the main inlet (Barataria Pass) of Barataria Bay (Cui et al. 2018), the tidal and wind modulation of the estuarine plume (Cui 2018), sediment erosion, transport and deposition patterns (Sorourian 2019), dynamics of coastal hypoxia (Justić and Wang 2014) and oil transport and fate (Huang et al. in review).

Advances have been made in modeling of marsh morphodynamics, which is a key step to understand and quantify the impact of oiling on marsh erosion (e.g., Beland et al. 2017) and compare it to other (either natural or anthropogenic) causes of marsh loss. For example, a theoretical model was developed to simulate the dynamics of ponds on the marsh platform (Mariotti 2016), and a 2D model was developed to simulate wave-driven marsh edge erosion in Barataria Bay (Valentine and Mariotti 2019).

Progress has also been made in modeling of meteorological forcing. Most coastal ocean circulation simulations now adopt operational meteorological analysis or reanalysis products (such as the North American Regional Reanalysis, NARR) to drive numerical models. We have also learned 

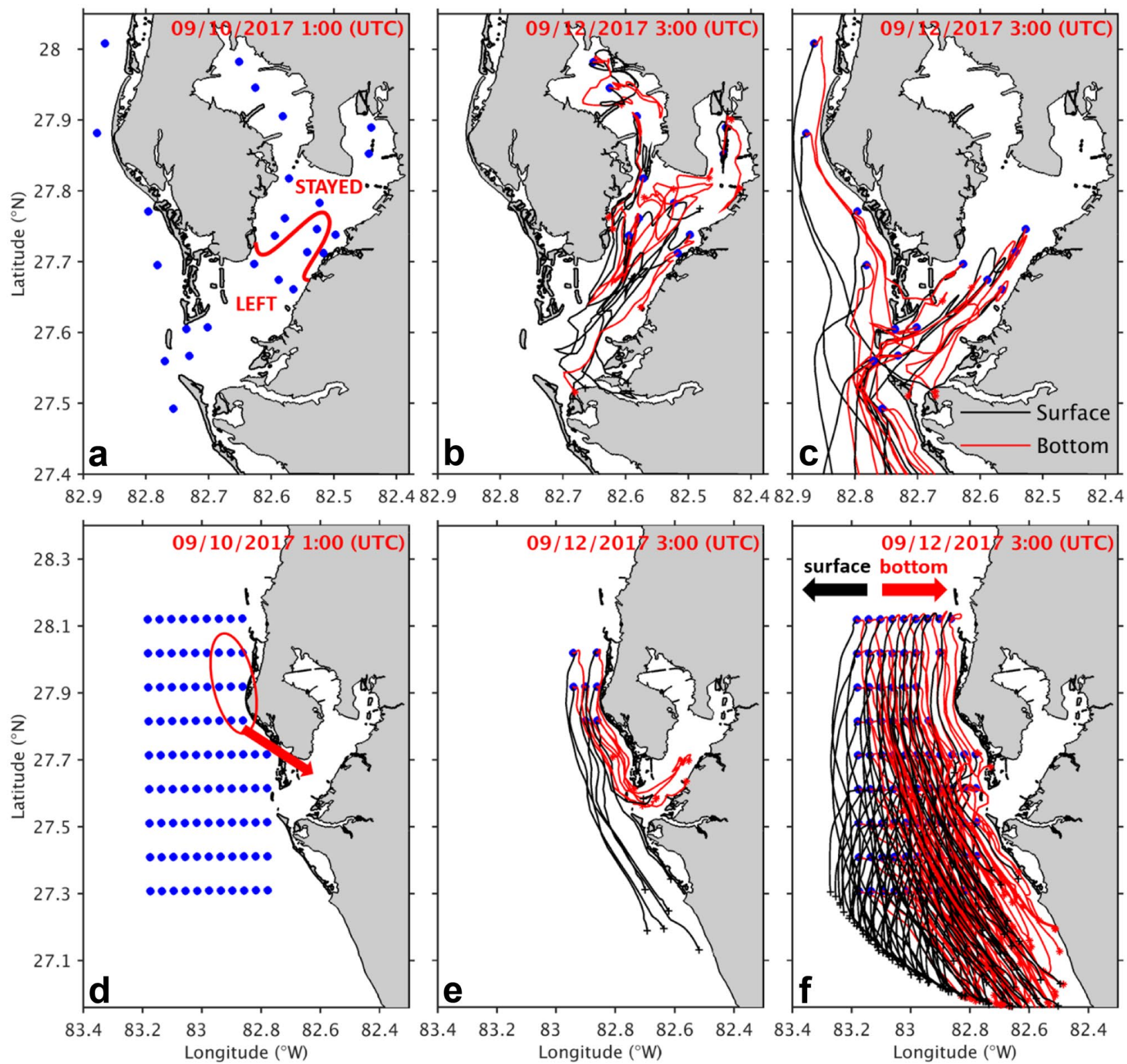

Fig. 2 Simulated Lagrangian drifter trajectories in the Tampa Bay during Hurricane Irma. All the drifters were released at 1:00 UTC, 10 September 2017. (a) The blue dots represent the initial locations of the drifters for the inside bay experiment. The red line shows the boundary between the old and renewed water in the Tampa Bay during Hurricane Irma. (b) The trajectories of drifters that stayed in the bay (black, surface; red, bottom). (c) The trajectories of drifters that left the bay. (d) The initial locations of the drifters for the outside bay experiment. (e) The trajectories of drifters that went into the bay. (f) The trajectories of drifters that did not go into the bay (from Chen et al. 2018)

sediment concentrations are relatively high. This effort has recently led to the development of a coupled ocean-oilsediment-biology model (Dukhovskoy et al. 2021). The Marine Oil Snow Sedimentation of Flocculent Accumulation (MOSSFA) triggered by DwH has also been tracked by analyzing sediment cores collected on the continental slope and abyssal plain within $\sim 100 \mathrm{~km}$ of the blowout (Larson et al. 2020). 


\section{Identified Uncertainties and Challenges}

In terms of field measurements, considerable challenges exist in implementing integrated sampling campaigns across the entire river-estuary-shelf-ocean continuum. A crucial aspect is the monitoring of sediment, carbon, dissolved gasses, and nutrient fluxes during extreme weather events (e.g., strong storms and hurricanes) that, despite being relatively rare, might contribute a large fraction of the annualized transport. Deployed instruments (e.g., current meters and multi-parameter sondes) are capable of collecting data during extreme weather events but their use remains challenging as they often fail or are lost at sea, and because they can simultaneously be deployed at only a few locations. In addition, deployed instruments are unable, or not fully capable, to measure all relevant parameters (e.g., sediment composition, organic carbon, nutrients, oil).

Given that remote sensing is often not possible during extreme events (for example, due to cloud cover), the development of more robust, more reliable, and possibly cheaper deployable instruments constitutes a crucial need. Promising results are expected to come from network-based technological advances such as the Internet of Things (IoT). Also, drones and unmanned aerial vehicles (UAV) are expected to become more common and accessible, thus facilitating monitoring during fair weather conditions.

Remaining challenges include the quantification of various external forcings, such as winds, incident solar radiation, latent and sensible heat fluxes, precipitation, evapotranspiration, freshwater inflows, tidal propagation, and availability of high-resolution bathymetry/topography data. Accurate measurements of these variables are particularly challenging in these complex deltaic estuaries because of distortion and reduction of wind stress (due to presence of woodlands, spoil banks, and wetland vegetation), reflection and absorption of short and long wave radiation (due to tree shading, shallow depths, and variable sediment types), small temporal and spatial scales of rainfall, heterogeneous nature of evaporation and plant transpiration, and rapid changes in geomorphology.

A striking example of the limited knowledge associated with both field measurements and modeling is the net exchange of water and sediments (as well as carbon and nutrients) through tidal inlets. For example, at the main inlet of Barataria Bay (Fig. 3), there are large uncertainties in the estimates of net estuarine outflow (i.e., $127-380 \mathrm{~m}^{3} / \mathrm{s}$ ), and the magnitude and the direction of sediment flux (import or export) (Payandeh et al. 2021; Mariotti et al. 2021).

Promising advances are expected to come from remote sensing, both from the continuation of long-lasting programs such as LANDSAT, and from the launch of new programs, such as the Surface Water and Ocean Topography (SWOT) program. In addition, the improvements in cloud computing, such as GoogleEarthEngine, are expanding the capabilities to perform analysis of remote sensing data at the regional and global scale.

In terms of numerical modeling, a major challenge identified as part of the GoMRI analyses is the development of efficient numerical algorithms to speed up model simulations. Undoubtedly, high-resolution model grids (on the order of $10 \mathrm{~m})$ and small integration time steps $(0.1-1 \mathrm{~s})$ pose a considerable computational burden even for the current state-of-the-art supercomputers. Moreover, it is still being intensely debated how to realistically incorporate open ocean influences in estuarine simulations (see "Open Ocean Transport Processes"). Finally, in terms of fundamental physical processes, wind waves and their interaction with tidal currents remain an understudied component of estuarine dynamics. This is especially true with respect to water column mixing and sediment resuspension, deposition, and transport.

\section{River-Estuary Coupling: River Diversions}

\section{Overview}

The Mississippi River drains $\sim 40 \%$ of the conterminous United States and carries approximately $65 \%$ of all suspended solids and dissolved solutes that enter the ocean from it (Milliman and Meade 1983; Meade 1996; Milliman and Farnsworth 2011). Deltaic Mississippi River estuaries historically received Mississippi River water but are now largely devoid of its influence because of closure of active distributaries and artificial flood control levees constructed along the Mississippi River over the last 100 years (Day et al. 1997; Turner 1997). Due to various flood control measures along the Mississippi and Atchafalaya Rivers, currently the rivers deliver fresh water and sediment to the shelf break, where buoyant surface plumes emanate from the distributary channel outlets (see "River-Induced Fronts and Cross-basin Transport" for more details). Interdistributary basins (deltaic estuaries), including Barataria, Terrebonne, and Timbalier estuaries to the west, and Breton Sound and Lake Pontchartrain to the east, receive only intermittent Mississippi River input, primarily by way of diversions and spillways.

Diverting water from the Mississippi River back into the estuaries and coastal wetlands was proposed decades ago (Gagliano et al. 1971; Chatry et al. 1983). The primary motivation at the time was to prevent increased salinities in the oyster-producing regions adjacent to the Mississippi Delta. The use of river diversions was later expanded to include marsh nourishment via riverine sediment and nutrient additions, even though the effectiveness of such measures varies among different studies (Gagliano et al. 1971; Day and Templet 1989; Swarzenski et al. 2008; Deegan et al. 2012), 


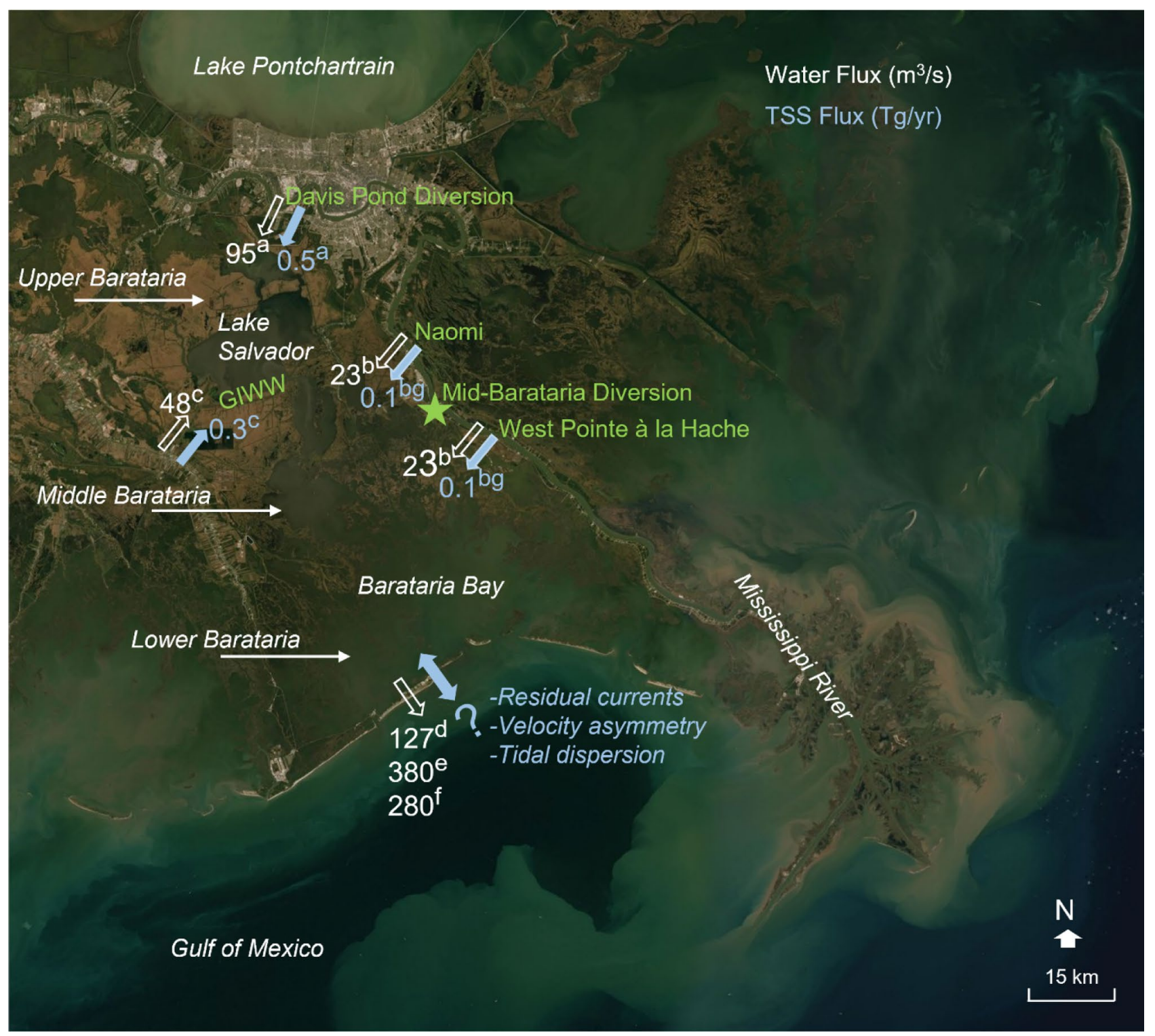

Fig. 3 Water and sediment fluxes in Barataria Bay inferred from observations and modeling. Solid white arrows denote geographical regions. Solid blue arrows and hollow white arrows represent water fluxes and sediment fluxes, respectively. Legends in green indicate inflow sites (GIWW, Gulf Intracoastal Waterway). The site of the proposed future mid-Barataria sediment diversion is represented by a green star symbol. Mean water discharge at Naomi from 2006 to 2019 was used to infer mean discharge for both Naomi and West Pointe à

as well as a possible method to control nutrient loading from the Mississippi River to the GoM (Mitsch et al. 2001).

Sediment diversions on the Lower Mississippi River play a central role in the proposed \$50-billion, 50-year strategy for restoring the Louisiana's coast. The strategy, as outlined in the Louisiana's Comprehensive Master Plan for a Sustainable Coast (CPRA 2012, 2017), includes diversions of the Mississippi and Atchafalaya River water and sediments into the estuarine basins of the Louisiana Deltaic Plain. The la Hache siphons. Total suspended solids (TSS) measurements at Pointe à la Hache $(0.3 \mathrm{~km}$ away from West Pointe à la Hache) were used for TSS flux calculation at Naomi and West Pointe à la Hache. Superscript letters on flux estimates refer to literature sources used for calculation: ${ }^{\mathrm{a}}$ Allison et al. 2012; ${ }^{\mathrm{b}}$ United States Geological Survey; ${ }^{\mathrm{c}}$ Swarzenski and Perrien 2015; ${ }^{\mathrm{d}}$ Das et al. 2011; ${ }^{\mathrm{e}} \mathrm{Li}$ et al. 2011; ${ }^{\mathrm{f}}$ Marmer 1948; ' ${ }^{\mathrm{L}}$ ouisiana Department of Environmental Quality

key objective is to mitigate the loss of coastal wetlands and achieve biophysical and socio-economic sustainability of the State's coastal resources. In the past three decades, the State, together with its federal and local partners, has constructed and operated several river diversions, the Caernarvon Diversion (maximum discharge of $\sim 220 \mathrm{~m}^{3} / \mathrm{s}$ ) in Breton Sound Estuary and the Davis Pond Diversion (maximum discharge of $\sim 300 \mathrm{~m}^{3} / \mathrm{s}$ ) in Barataria Estuary, as well as the West Bay Sediment Diversion (maximum discharge of $\sim 700 \mathrm{~m}^{3} / \mathrm{s}$ ) and 
several smaller siphons. The latest update to the Coastal Master Plan (CPRA 2017) proposed the construction of four large-scale sediment diversions into the Barataria and Breton Sound estuaries whose discharge capacity would be one order of magnitude higher (e.g., $\sim 990-2120 \mathrm{~m}^{3} / \mathrm{s}$ ) than the Caernarvon and Davis Pond Diversions.

Field and modeling studies have demonstrated that river diversions affect many environmental factors of significance to the structuring and functioning of coastal and estuarine ecosystems, including salinity, turbidity, residence times, stratification, nutrient loads, concentrations, and ratios (e.g., Peyronnin et al. 2017; White et al. 2018; Bargu et al. 2019; Huang et al. 2020).

\section{Findings of the GoMRI Research Program}

Since the establishment of GoMRI, progress has been made in both field observations and modeling efforts related to river diversions. In response to the $2010 \mathrm{DwH}$ spill, all river diversions in Louisiana were operated at or near their maximum discharge level for an extended period to attempt to prevent offshore oil from moving landward and threatening coastal wetlands. For instance, the Davis Pond Diversion was operated at six times the normal discharge level for nearly 4 months. Riverine freshwater discharge and the associated river-induced density fronts in the coastal ocean indeed influenced the oil transport pathways during the DwH incident but not with the same protective effect for all coastal areas around the Mississippi Delta (Kourafalou and Androulidakis 2013; see "River-Induced Fronts and Crossbasin Transport"). Nevertheless, these efforts proved ideal for testing the effects of high river discharge rates on deltaic estuaries and wetlands.

The effects of river diversions on wetland-estuarinecoastal exchanges in Barataria and Breton Sound estuaries were studied using high-resolution coupled estuarine-coastal models (e.g., FVCOM, Huang et al. 2011; Cui et al. 2018). Model simulations suggested that the peak discharge from the Caernarvon diversion $\left(\sim 200 \mathrm{~m}^{3} / \mathrm{s}\right)$ into Breton Sound enhances water exchange between wetlands and adjacent water bodies, substantially increasing water velocity in the bayous and channels within $20-25 \mathrm{~km}$ of the diversion structure (Huang et al. 2011; Huang et al. in review). However, the peak diversion discharge has no influence on hydrodynamics $>30 \mathrm{~km}$ from the diversion sites. Consequently, it can be inferred that the operation of river diversions at full capacity in the aftermath of the DwH incident was not effective in preventing the offshore oil slicks from drifting into Barataria and Breton Sound estuaries (Huang et al. 2011; Huang et al. in review).

The modeling efforts supported by GoMRI also explored how estuarine flushing characteristics change under hypothetical future large diversion scenarios (CPRA 2017). The results suggest that large sediment diversions can affect estuarine flushing $>60 \mathrm{~km}$ from diversion structure and therefore could have significant effects on surface oil transport, albeit with important ecological tradeoffs due to estuarine freshening. For example, a hypothetical constant discharge of $850 \mathrm{~m}^{3} / \mathrm{s}$ from a Mid-Barataria sediment diversion (Fig. 3) for 3 months is predicted to greatly reduce estuarine residence times, especially in the lower reaches of Barataria Bay, with the average salinity exhibiting a $\sim 12$ point reduction near the Barataria Pass compared to a scenario with no diversion (Cui 2018). Furthermore, the area experiencing decreased salinities is larger along the bottom (near the bed) than at the surface, suggesting that the density gradients in the estuary would also change if a large-scale Mid-Barataria diversion is implemented (Cui et al. 2018).

An important finding associated with the river-estuaryshelf-ocean continuum is the occurrence of a region of salinity maxima inside an estuary. This region, known as a "salt plug" was also observed in Barataria Bay (e.g., Juarez et al. 2020). A salt plug occurs when an embayment receives relatively fresh water at the landward end (head) and at its mouth. The effects of buoyancy at both ends of the embayment create a region of surface convergence where maximum salinity waters are trapped. Barataria Bay is influenced by Mississippi River waters both at its head (intensified by the Davis Pond diversion) and its mouth, and exhibits saltplug conditions especially in winter (Juarez et al. 2020). It is likely that under low wind conditions, spilled oil drifting into deltaic estuaries receiving diverted freshwater inputs will accumulate at these salt plug regions.

\section{Identified Uncertainties and Challenges}

GoMRI studies pointed out that better quantification of various forcing functions and boundary conditions would greatly improve the accuracy of model-predicted transport. Important forcing functions and boundary conditions include winds, incident solar radiation, latent and sensible heat fluxes, precipitation, evapotranspiration, diversion discharge rates, tides, and bottom bathymetry. Accurately measuring most of these variables is challenging because of their highly variable nature and complex geomorphology and ecology of deltaic estuaries. Examples include variations in wind stress, reflection and absorption of short- and long-wave radiation due to changing wetland vegetation cover, spatiotemporal variability in rainfall events, heterogeneity in evaporation and plant transpiration, and dynamic changes in geomorphology. Some of the uncertainties, however, could be easily reduced. For example, diversion discharge rates, typically inferred through the rating curve method, would be more accurate if directly measured. 


\section{Nearshore and Inlet Processes}

\section{Overview}

Accounting for the transport of oil along beaches and barrier islands is perhaps one of the most important aspects of an emergency response to an oil spill, as this is where the public tends to be most impacted. Such transport is not a local phenomenon; rather, it entails many aspects of ocean circulation, including the effects of waves. For ocean circulation, both deep-ocean/continental shelf interactions (locally and remotely) and the effects of local forcing (by tides, winds, rivers, and heat and mass fluxes) must be considered. Inclusion of wave effects involves consideration of Stokes drift, which is aligned with the direction of the wave propagation. Both ocean circulation and waves show depth-dependent anisotropy. Their influence can therefore change depending on the depth of the water. Shoaling isobaths constrain the Eulerian currents to flow along the isobaths, whereas refraction tends to turn the wave propagation normal to the shoaling isobaths. Thus, Stokes drift, when added to the currents, facilitates the deposition of oil on the beach, as shown for the DwH oil spill by Weisberg et al. (2017). Surf zone dynamics create another complication - once oil enters the surf zone it is subject to rapid mixing, and is transported by processes such as littoral drift and rip currents. These processes are generally absent from both circulation models and oil spill models.

A requisite for tracking oil as it approaches the beaches and barrier islands is a numerical circulation model with the following: (1) a construct complete enough to account for both remote and local forcing, (2) horizontal and vertical resolution fine enough to include the shoreline and barrier island intricacies, and (3) the ability to include flooding and drying, without which a physically reasonable set of beaches and barrier islands cannot be included. This is usually done by nesting a coastal ocean model in a larger scale ocean model (see review in Kourafalou et al. 2015). Such approach has been beneficial for detailing the transport of waters from the Mississippi Delta: e.g., Schiller et al. (2011), Androulidakis et al. (2015) and Androulidakis and Kourafalou (2013) for the Northern GoM; He and Weisberg (2003), Weisberg et al. (2009, 2017) and Zheng and Weisberg (2012) for the West Florida Shelf; and Kourafalou et al. (2009) and Kourafalou and Kang (2012) for South Florida coasts and the Florida Keys. These models used boundary conditions from data-assimilating outer models such as the Hybrid Coordinate Ocean Model (HYCOM; hycom.org; Chassignet et al. 2009) applied in the GoM at $1 / 25^{\circ}$ resolution (GoM-HYCOM 1/25).

Along a similar line, the Coupled Ocean-AtmosphereWave-Sediment Transport (COAWST) Modeling System has been widely used in the last decades, especially to simulate hurricanes (Warner et al. 2010; Zambon et al. 2014; Warner et al. 2017). This model has been particularly successful at simulating not only the inner shelf and surf zone regions (Kumar et al. 2012), but also backbarrier estuaries (Defne et al. 2019).

\section{Findings of the GoMRI Research Program}

As highlighted in the previous sections, the coastal areas around barrier islands and their inlets have complex circulation patterns owing to the interaction of multiple processes. Significant GoMRI research efforts went into improving the understanding of these regions through observational and modeling efforts. Of particular interest were buoyant discharge plumes as there was uncertainty about whether these features would provide some measure of natural protection for beaches and estuaries during the DwH oil spill. A consistent finding of the observational work suggested that plumes from smaller scale river/estuary systems (relative to the Mississippi River), e.g., Mobile Bay and Choctawhatchee Bay, can be protective, but this effect is variable and strongly dependent on wind conditions determining plume position (Dzwonkowski et al. 2015; Roth et al. 2017). A conceptual diagram of such protective capacities was developed in Roth et al. (2017) (Fig. 4). These observational findings were expanded with a numerical model of the Choctawhatchee River plume which demonstrated that the protective effect of plumes degraded as wind speeds increased and the protective capacities changed significantly with tidal forcing (Kuitenbrouwer et al. 2018). Furthermore, Huguenard et al. (2016) found that the frontal features associated with the Choctawhatchee tidal plume were accompanied by intense mixing that could entrain surface material, potentially oil, throughout the water column. Thus, frontal features associated with river plumes represent a complicating factor for oil spill response and prediction (i.e., a 2-D surface problem can become a 3-D issue in these regions) as these small-scale structures are not typically included in regional modeling efforts.

Advances were made in improving the resolution of regional modeling to better resolve coastal areas and tidal inlets. An example is the data-assimilating GoM HYCOM model at $1 / 50^{\circ}$ resolution (GoM-HYCOM 1/50, Le Hénaff and Kourafalou 2016; Androulidakis et al. 2019; Androulidakis et al. 2020a, b) that, in addition to doubling the resolution of GoM-HYCOM 1/25, included detailed river plume dynamics and contained topographic details around estuaries and islands. Unstructured grid models continued to evolve to provide even more details in such topographically complex areas. An example of a high-resolution, unstructured grid model is the West Florida Coastal Ocean Model (WFCOM). This was first done as FVCOM nested in the Global HYCOM (Zheng and Weisberg 2012) and then nested in the GOM-HYCOM 
Fig. 4 The effects of buoyant discharge plumes on surface oil transport; depending on the wind conditions, the plume position and the relative shielding effect on a given region can be highly variable (from Roth et al. 2017)

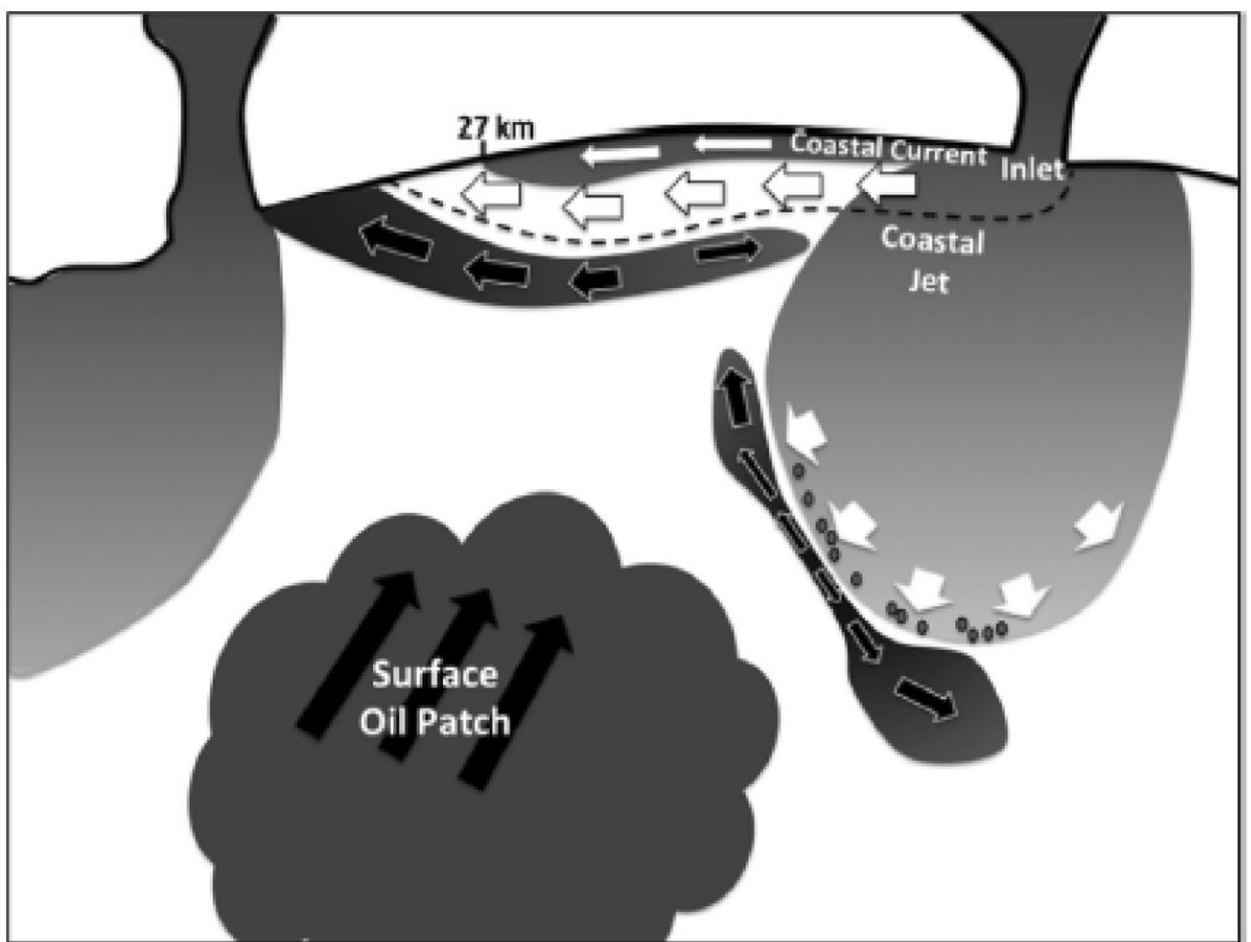

(Weisberg et al. 2014). The importance of high horizontal resolution was made evident, as the Global HYCOM neither includes the barrier islands nor the sounds or estuaries behind them, while the GoM-HYCOM 1/25 omits the inlets. Only with high enough resolution (as in WFCOM) can all these features be incorporated. High vertical resolution is also important. By resolving the surface and bottom Ekman layers, the three-dimensional nature of the flow field can be included, mitigating the need for adding an arbitrary wind factor. The vertical coordinate must also include flooding and drying to avoid the requirement for an arbitrary and unrealistically large minimum depth.

\section{Identified Uncertainties and Challenges}

Several model uncertainties resulting from initial conditions, surface (winds, heat, and freshwater fluxes, SST), and open boundary forcing were identified during GoMRI-supported analyses. For example, the quality of the wind forcing is well-known to be critical to the success of regional-coastal modeling (e.g., He et al. 2004), since the winds are often underestimated by meteorological models in coastal regions (e.g., Mayer et al. 2017; Mariotti et al. 2018). Challenges remain regarding how to improve the surface forcing by assimilating observations, particularly during extreme meteorological events (e.g., Chen et al. 2018; Liu et al. 2019).

The coordination between coastal ocean observing (data) and modeling should be encouraged and sustained. In situ observations provide a basis for model veracity testing and improvement (e.g., Liu and Weisberg 2011). With scientifically designed and justified observation platforms (e.g., Weisberg et al. 2015; Liu et al. 2015), future coordinated efforts will benefit from the assimilation of these diverse data sets into models to improve simulations and forecasts (e.g., Barth et al. 2008; Pan et al. 2014).

Additional effort toward fully coupled current and wave models will better represent the coastal dynamics of material transport for the nearshore beaches and barrier island areas. For these shallow areas, a major challenge is how to include the relevant coastal ocean processes over long time scales. Coupling models and long-term simulations of fine-scale dynamics raise issues about the computational aspects of such analyses and the need for efficient algorithms and innovative use of the ever-changing field of advanced computing.

Inclusion of wave effects would ideally utilize a fully coupled wave and circulation model, but this is precluded both by computational limitations and by the lack of a universally accepted way to include Lagrangian transport (Stokes drift) in an Eulerian modeling framework (e.g., Brostrom et al. 2014). Linearly adding Stokes drift from a separate wave model, despite being an approximation, does provide an expediency with demonstrated value (e.g., Rohrs et al. 2012; Le Hénaff et al. 2012b; Curcic et al. 2016; Weisberg et al. 2017).

Improvements in model accuracy and numerical efficiency would increase the ability to forecast oil transport in case of another oil spill. Equally important, such 
improvements would be useful for many other nearshore applications such as responses to major storm events (e.g., Liu et al. 2019), search and rescue operations, harmful algal blooms (e.g., Weisberg et al. 2019), studies of fish recruitment (e.g., Rose et al. 2015), and environmental awareness for recreation boating and fishing.

\section{Open Ocean Transport Processes}

\section{Overview}

It was well known by 2010 that the circulation of the surface ocean boundary layer in the GoM is strongly influenced by the interaction of large mesoscale (horizontal scale of $\mathrm{O}(100) \mathrm{km})$ circulation features. The key mesoscale pattern is the LC (Fig. 5) that, at irregular intervals of several months, sheds large anticyclonic (clock-wise) mesoscale eddies (200-300 km in diameter), also known as LC eddies or Rings. The LC eddies are, in turn, often surrounded by smaller vortices, both cyclonic and anticyclonic, and intense vorticity filaments (Sturges and Leben 2000). Cyclonic (counter-clockwise) eddies, called LC frontal eddies, move around the periphery of the LC and play a role in the detachment of the LC eddies (Le Hénaff et al. 2012a; 2014; Androulidakis et al. 2014). LC eddies generally move
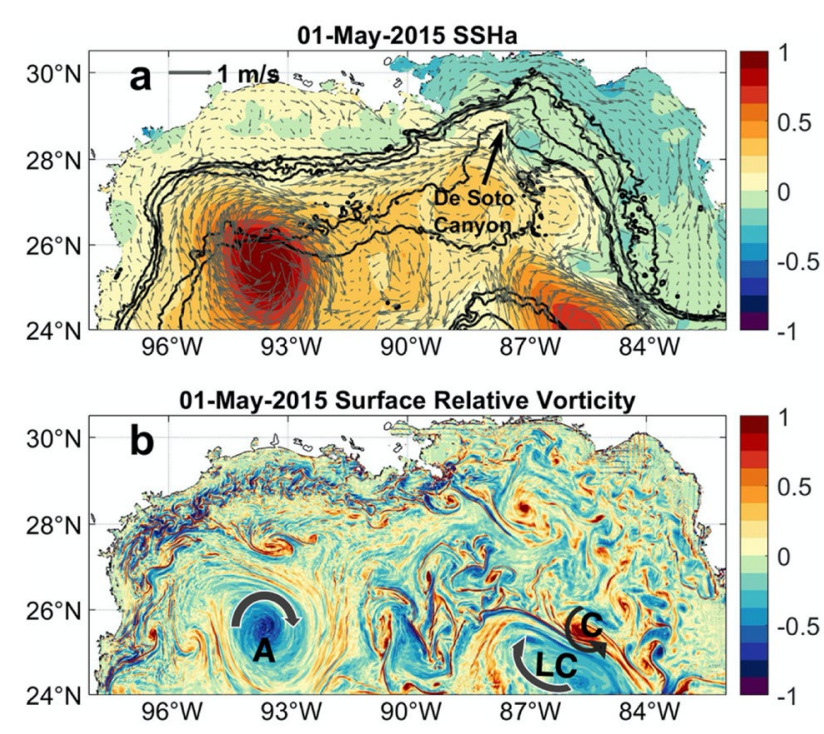

Fig. 5 (a) Sea surface height (SSH) field in the northern Gulf of Mexico with superposed geostrophic currents in a submesoscale permitting regional ocean simulation of May 1st, 2015 (in gray). Bathymetric contours ( $200 \mathrm{~m}, 500 \mathrm{~m}, 1000 \mathrm{~m}, 2000 \mathrm{~m}$, and $3000 \mathrm{~m}$ ) are indicated in black, together with the location of the De Soto Canyon (marked by a thin black arrow). (b) Corresponding surface relative vorticity field normalized by the Coriolis parameter (nondimensional). The anticyclonic Loop Current (LC), a cyclonic frontal eddy (C), and an anticyclonic LC eddy (A) are indicated by thick black arrows highlighting their spinning direction westward with a velocity of about $\sim 2-5 \mathrm{~km} \mathrm{day}^{-1}$ and have lifetimes from a few months to about 1 year (e.g., Vukovich 2007). Following the shedding of a Ring, the LC changes from a northward extending position that approaches the continental slope of the northern GoM to a southward retracted position. The LC system (the Loop Current, LC eddies, and LC frontal eddies) influences processes on the continental slope and on the shelf break in the northern GoM in all seasons (Schiller et al. 2011; Cardona and Bracco 2016) and causes persistent, strong, cross-isobath currents with dipolar structures acting as an efficient mechanism for offshore transport of river waters and materials (Hamilton and Lee 2005; Schiller et al. 2011; Androulidakis et al. 2018; 2019).

\section{Findings of the GoMRI Research Program}

The role of the mesoscale circulations on advection in the GoM has been further investigated during GoMRI, identifying the role of specific structures in both transporting mass (Kourafalou et al. 2018; Drouin et al. 2019) and acting as barrier to onshore transport (Gough et al. 2019).

Following the DwH oil spill, it was realized that mesoscale structures alone did not explain the distribution of pollutants: smaller submesoscale (scale of $\mathrm{O}(1) \mathrm{km}$, Rossby number of $\mathrm{O}(1)$ ) circulations have to be accounted for in any hindcast or forecast effort related to tracer mixing. Through modeling and observational studies, especially the drifter experiments Grand LAgrangian Deployment (GLAD; Poje et al. 2014) and LAgrangian Submesoscale Experiment (LASER; D'Asaro et al. 2018), the role of the submesoscale circulations (Fig. 6) in relation to the mixing within the surface boundary layer has been elucidated, at least in part. In this regard, a review of submesoscale circulations can be found in McWilliams (2016) and a partial review of applications to advective processes in the GoM is contained in Bracco et al. (2019a, b).

Furthermore, models and analysis of observations have revealed the key modulation of advective processes exerted by the discharge of the Mississippi River System (and other smaller rivers entering the basin). The freshwater influx interacts with mesoscale eddies and modifies the density gradients and stratification that control submesoscale instabilities (Luo et al. 2016; Barkan et al. 2017a).

The juxtaposition of mesoscale eddies and filaments in waters with very different densities contributes to frontal and baroclinic instabilities and to the formation of submesoscale lateral convergence zones (Luo et al. 2016; Barkan et al. $2017 \mathrm{a}, \mathrm{b})$. These convergence zones are where fresh water, nutrients, and pollutants (including oil) accumulate (Zhong et al. 2012; Zhong and Bracco 2013; Huntley et al. 2015; Poje et al. 2014; Choi et al. 2017; D'Asaro et al. 2018; Bracco et al. 2019a). The effect of riverine discharge is, 


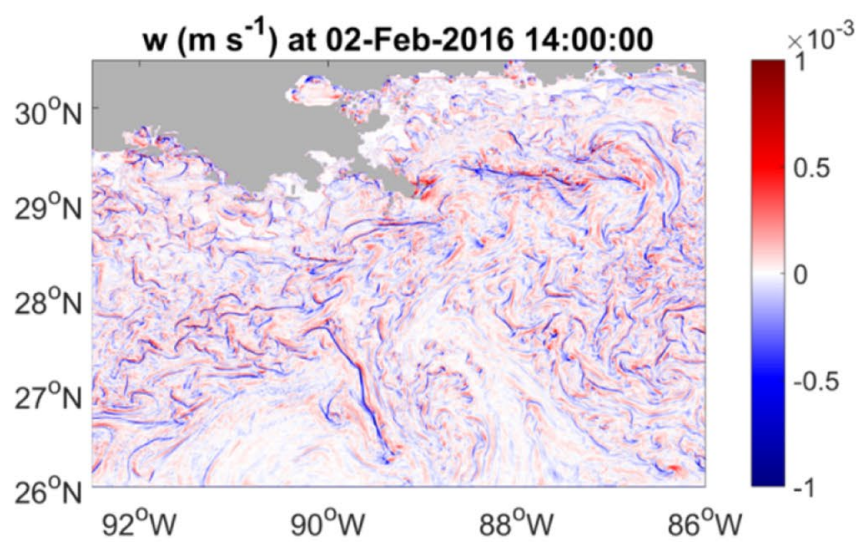

Fig. 6 Simulated surface vertical velocities (left) and relative vorticity normalized by the Coriolis parameter (right) in a submesoscale permitting run at $500 \mathrm{~m}$ horizontal resolution on February 2, 2016, while the LASER experiment was underway. The figure shows

on one hand, to enhance submesoscale currents by providing lateral buoyancy gradients, and, on the other hand, to suppress submesoscale currents by increasing stratification near the surface. In the GoM, suppression is predominant in winter when baroclinic instabilities are most abundant around and inside the LC and its rings, but their strength and number is somewhat limited by the freshwater input, due to the increased stratification near the surface (Barkan et al. 2017a). In late spring and early summer, when the riverine discharge is commonly at its maximum, submesoscale enhancement by river discharge prevails in the offshore GoM, because the generation of submesoscale fronts is amplified by the density gradients induced by the freshwater fluxes, despite the shallow mixed layer (Luo et al. 2016). Analyses related to the DwH spill showed that the freshwater volume in De Soto Canyon (marked on Fig. 5) increased from the second half of May, increasing the frontogenetic tendency of the flow with the consequent generation of fronts that were partially responsible for the convergence of oil. These fronts became clearly visible in the Synthetic Aperture Radar (SAR) images of the surface oil collected from the end of May onward (see e.g. Walker et al. 2011).

The modulation of submesoscale circulations by low salinity waters is partially controlled by the LC and its detached eddies. During the summer months, a northward extending LC can efficiently transport low-salinity water southward to the Florida Straits (Schiller and Kourafalou 2014; Androulidakis et al. 2019), while a LC eddy near the Louisiana-Texas shelf would promote the recirculation of low-salinity water within the central Gulf (Brokaw et al. 2019). In a retracted LC state, the riverine water remains close to the northern coasts (Brokaw et al. 2019).

A key consequence of the existence of an energetic submesoscale field in the offshore GoM throughout the year is

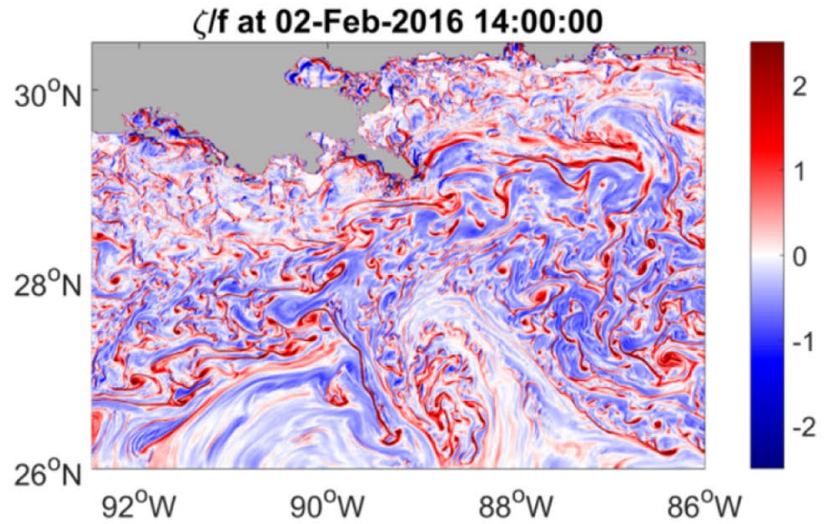

numerous submesoscale eddies and vorticity filaments associated to large vertical velocities and submesoscale fronts (simulation analyzed in Sun et al. 2020)

that the Lagrangian sampling of the current field is biased toward regions characterized by strong convergence or elevated positive vorticity in the upper turbulent boundary layer. This preferential sampling affects any Lagrangian (passively buoyant) or quasi-Lagrangian surface-confined tracers, such as drifters, plastic, Sargassum, oil or other pollutants, and is relevant to the flow around and within the mesoscale eddies (Zhong et al. 2012; Haza et al. 2016). The impact of such preferential sampling has been quantified using models through the analysis of probability density functions (Choi et al. 2017) and structure functions (Pearson et al. 2019) and can greatly affect the interpretation of Lagrangian observational studies at scales less than $10 \mathrm{~km}$. Drifters, for example, rapidly converge into submesoscale coherent structures, such as eddies and fronts (D’Asaro et al. 2018). As shown by Pearson et al. (2019), the surface drifter statistics for separations below $10 \mathrm{~km}$ consistently exhibit scaling laws close to $2 / 3$ because of convergence, which are shallower than the Eulerian second-order statistics. As a result, no conclusions on Eulerian energy statistics can be directly drawn from Lagrangian measurements.

Through studies following the 2010 oil spill, it also became clear that transport of material (e.g., oil) on the surface of the open and coastal ocean alike can differ substantially from that inferred from currents at depths of decimeters to meters. Traditional methods of measuring and modeling currents used to estimate surface transport provide currents at some depth below the surface. Waveinduced Stokes drift, Langmuir circulation, and the turbulent vertical flux of wind-driven momentum (e.g., Wenegrat et al. 2014) all can contribute to substantial vertical shear of currents within the upper meter and influenced the evolution of the oil patch in 2010 (Le Hénaff et al. 2012b). The effects of 
this shear on the transport of surface material using currents measured or modeled at some depth are typically parameterized as a "wind drift," particularly in the case of oil spill modeling (e.g., Samuels et al. 1982).

Recently, new methods of observing currents directly at the ocean surface, both in situ (e.g., Morey et al. 2018) and using remote sensing technology (Rodriguez et al. 2018), provided novel insight into the relation of surface currents to near-surface currents. For example, Morey et al. (2018) reported that during a drifter study in the GoM the magnitude of surface velocity measured by ultra-thin $(5 \mathrm{~cm})$ surface-following drifters was approximately $35 \%$ greater on average than that measured by typical surface drifters with drogues centered at the depth of $1 \mathrm{~m}$. Shear associated with the estimated Stokes velocity profile accounted for much of this difference. Using near-field remote sensing and surface drifting instruments, Laxague et al. (2018) reported current speeds at $1 \mathrm{~cm}$ depth twice that of the average speed over the upper $1 \mathrm{~m}$.

These new measurement capabilities can be applied with other concurrent observations to improve the parameterization of surface wind drift, with the goal of better accounting for sea state and stratification in ocean and climate circulation models. Developing a better understanding of the structure of the near-surface current shear is not only important for estimating the total surface current from current data at some depth below the surface, but also for accurately simulating the physics involved in the transport of buoyant material such as oil. In particular, breaking waves fragment surface oil into droplets that are mixed into the subsurface layer where they are advected by the ambient current (which differs from that directly at the surface) before the larger droplets resurface (e.g., Johansen et al. 2015).

Much progress has been made as a result of GoMRIrelated research in simulating the mesoscale circulation of the GoM and developing capabilities for forecasting its evolution (Wei et al. 2014; Carrier et al. 2014; Jacobs et al. 2014; Coelho et al. 2015; Dukhovskoy et al. 2015; Cardona and Bracco 2016; Iskandarani et al. 2016; Putrasahan et al. 2017). Furthermore, the scientific community has advanced the understanding of the role of circulations at scales between few hundreds of meters and $10 \mathrm{~km}$. Theoretical developments and process modeling continue to thrive (see for example Barkan et al. 2019), with recent observational campaigns at unprecedented resolution. These included deployment of hundreds of biodegradable satellite-tracked surface drifters and drift cards, and simultaneous surface current mapping by aerial, optical remote sensing systems, and ship-mounted radars (D'Asaro et al. 2020), as well as high-resolution mapping of river-induced fronts with in situ, aerial, and remote sensing platforms (Androulidakis et al. 2018; Garcia-Pineda et al. 2020).

\section{Identified Uncertainties and Challenges}

Analyses highlighted fundamental uncertainties that remain open related to the advection mechanisms across different spatiotemporal flow regimes. For example, Mariano et al. (2011) identified as dominant periods for the surface velocity field in the open GoM " $1-2$ days due to inertial oscillations, tides, and the sea breeze; 5-6 days due to wind forcing and submesoscale eddies; $9-10$ days and two weeks or longer periods due to wind forcing and mesoscale variability, including the period of eddy rotation." However, the available information does not allow quantification of the multiscale interactions, potential feedbacks and energy transfers between inertial waves, tides, sea breeze, submesoscale and mesoscale circulations in different seasons and under different winds, heat fluxes, and freshwater conditions. A recent GoMRI-funded study, for example, showed the existence of diurnal cycling of submesoscale circulations that extended to the horizontal divergence and vertical velocity field (Sun et al. 2020).

The coupling between oceanic meso- and submesoscale circulations and the atmosphere is another important topic that has received attention in western boundary systems but should be further pursued in the GoM (see e.g. Byrne et al. 2016 and Renault et al. 2018 for a mesoscale and submesoscale example). Furthermore, the recent discoveries on the relation of surface currents to near-surface currents question our parameterizations and vertical discretization choices at the ocean surface, which are key to providing reliable boundary conditions to unstructured models for simulating coastal dynamics in shallow shelves and inlets.

\section{River-Induced Fronts and Cross-basin Transport}

\section{Overview}

Mesoscale and submesoscale fronts due to river discharge are common in the GoM, especially in the northern shelf areas that receive large river inputs (see "Open Ocean Transport Processes"). In contrast to the saltier waters of the GoM interior, strong fronts are induced as the river plumes carry low-salinity waters and associated materials (such as nutrients, sediments, and pollutants) offshore. Discharge from large rivers also induces buoyancy-driven currents that move brackish water and associated substances along the northern GoM. The processes controlling river plume dynamics and associated transport processes were known prior to GoMRI (Walker 1996; Walker et al. 2005; Schiller et al. 2011). Schiller et al. (2011) and Androulidakis and Kourafalou (2013) discussed the development and evolution of the Mississippi River plume that has major pathways both westward (along the Texas-Louisiana shelf) and eastward (along the Mississippi-Alabama-Florida shelf). This is based on river 
plume considerations for buoyancy-driven currents, which have two major pathways, based on the direction of Kelvinwave propagation (Kourafalou et al. 1996): "downstream" and "upstream" (which for the Mississippi is to the right of the Delta and toward northeast of the Delta, respectively); these pathways are further modified due to wind influence. Schiller et al. (2011) also elucidated the processes that initiate riverine fronts not only on the shelf areas but also offshore, toward the GoM interior due to the influence of the LC and its associated eddies. These fronts create offshore branches of waters of river origin that are unique to the GoM and have been found to reach the Florida Straits and farther to coastal waters off Georgia following the Gulf Stream (Ortner et al. 1995; Hu et al. 2005; Schiller and Kourafalou 2014; Le Hénaff and Kourafalou 2016). These fronts can influence the optical, physical, and chemical properties of remote waters.

When Mississippi River water travels eastward, three pathways emerge, by which this water moves to and around the Florida Keys (Weisberg et al. 2005): (1) direct and (2) indirect LC and eddy pathways, and (3) a wind- and buoyancy-driven West Florida Shelf pathway. Thus, along with the Mississippi River plume, wind-driven currents and the LC system largely impacted the transport of hydrocarbons associated with the $2010 \mathrm{DwH}$ blowout (e.g., Liu et al. 2011a, d; Walker et al. 2011; Weisberg et al. 2011; 2016b).

\section{Findings of the GoMRI Research Program}

New findings during the GoMRI decade of sponsored research built upon the previous studies, establishing that the river-induced fronts play an important role in along-shore and cross-shore transport, acting both as barriers on material transport and as convergence zones that guide transport along frontal lines. Based on satellite- and model-derived surface fields of oil patches and GoM salinity, Kourafalou and Androulidakis (2013) illustrated the influence of riverinduced fronts on hydrocarbon transport during the 2010 DwH incident. They showed that the distinct river plume domains to the east and west of the Mississippi Delta influenced the variability of the observed Surface Oil Patch (SOP), as they were guided by the variability in river discharge and wind stress. As seen in Fig. 7, the Mississippi plume front kept the oil away from the Delta during the spring discharge maximum on 5/20/2010 (as deeper circulation also advected thin jets of plume and oil offshore). The SOP was still offshore on 6/20/2010, pushed away from the shelf areas east of the Delta, where the plumeinduced currents turned clock-wise (offshore). The pattern was very different on $7 / 6 / 2010$, when prevailing winds from the East advected plume waters westward, along a narrow coastal jet, which also entrained oil along the coast west of the Delta. These results were further investigated with a multi-platform observational study (Androulidakis et al. 2018) that measured the impact of river-induced fronts on the transport and fate of waters in oil-covered areas near the Mississippi Delta, where oil patches were observed by satellite and in situ methods. Drifters released in such waters were well aligned with the river plume fronts and traveled in three distinct areas: downstream (westward) along the Louisiana-Texas shelf, upstream (northeastward) along the Mississippi-Alabama-Florida shelf and offshore (southward), toward the GoM interior. These regimes correspond to the major buoyancy-driven currents, modified by other shelf flows (especially wind-driven circulation) and offshore influence (LC and associated eddies), as discussed in "Overview" under "River-Induced Fronts and Cross-basin Transport."

The riverine fronts that extend into the GoM interior and the related cross-basin transport processes were further elucidated in GoMRI studies. Schiller and Kourafalou (2014) analyzed several cases of combinations in coastal, shelf, and offshore circulation that influenced the offshore transport of Mississippi waters and their removal from the shelf to the basin interior. Le Hénaff and Kourafalou (2016) showed that Mississippi waters can reach the Florida Keys, traveling not only along the LC but also along the edge of the West Florida Shelf, following a transport pattern also discussed by Weisberg et al. (2005). Androulidakis et al. (2019) used ship survey profiles, satellite observations, and high-resolution model fields (GoM-HYCOM 1/50, Le Hénaff and Kourafalou 2016) to quantify the three-dimensional structure of offshore (southward) branches of Mississippi plumes, concentrating on the double episode of 2015 (branches west and east of the LC). The surface signal of the offshore Mississippi water export in the summer of 2015 was also described by Chen and $\mathrm{Hu}$ (2017) to evaluate their method for estimating Sea Surface Salinity (SSS) from satellite ocean color observations (MODIS). Figure 8 shows examples of such episodes during both extended $(a, b)$ and retracted (c, d) phases of the LC. The color patterns revealed in the MODIS Color Index (CI) images (Fig. 8a-d) are consistent with those inferred by Sea Surface Salinity (SSS) patterns derived both from the GoM-HYCOM 1/50 model and from MODIS data, based on a novel algorithm to estimate SSS from multi-band ocean color data (Chen and Hu 2017).

Several GoMRI studies focused on the smaller estuaries, showing that river-induced fronts are important locally, while they can also contribute to regional transport. An example is the cross-shore transport of brackish waters in the Northwestern GoM, including from small local rivers after spring floods in 2016 (Le Hénaff et al. 2019). This transport of waters of high nutrient content had significant ecological implications, as it played a key role in the episode of coral mortality in the Flower Garden Banks National Marine Sanctuary (offshore Texas). 

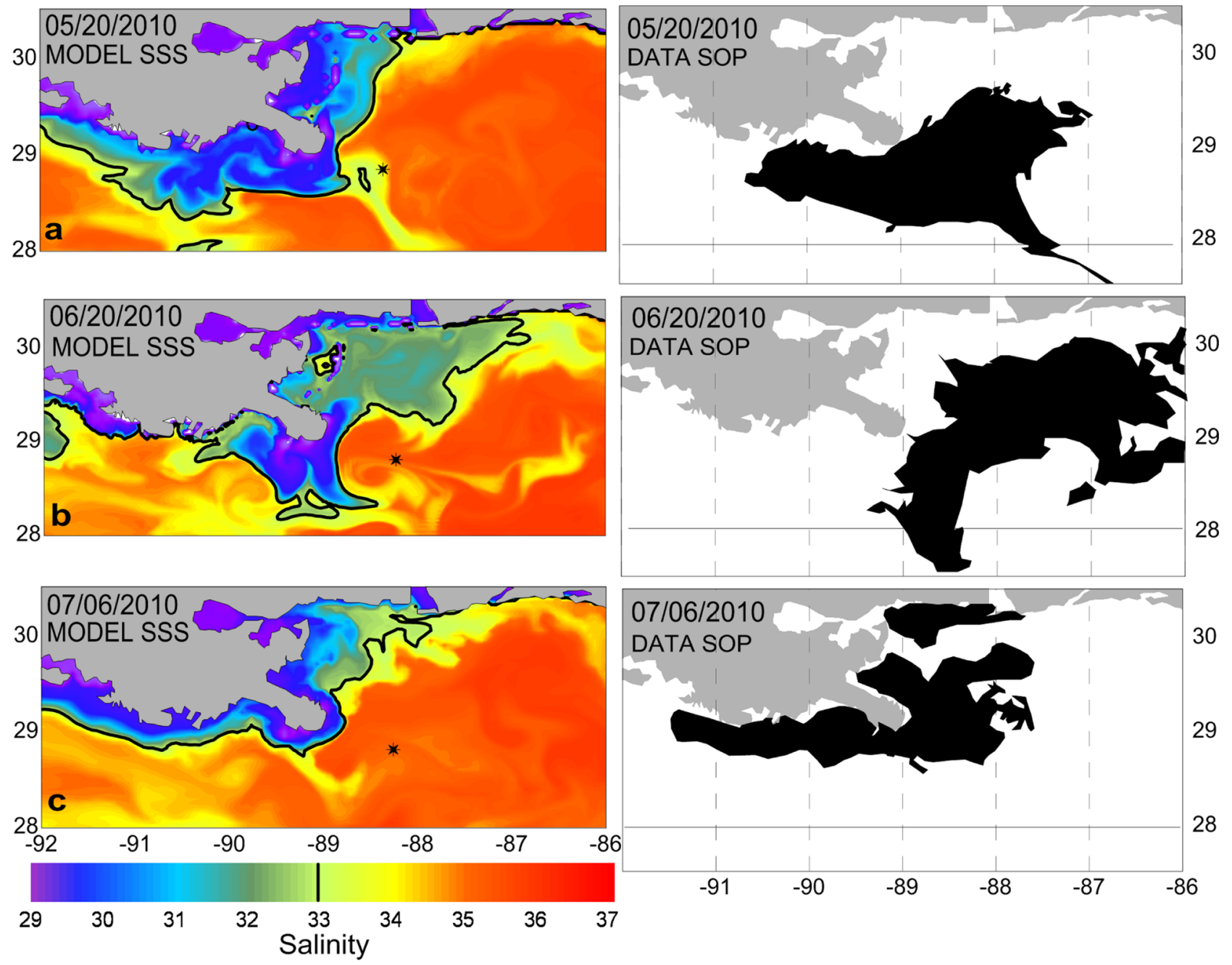

Fig. 7 (Left) Model-computed Sea Surface Salinity (SSS) and (right) data-derived (NOAA surveys and satellite composites) Surface Oil Patch (SOP), on characteristic days during the DwH incident: (a) May 20, 2010; (b) June 20, 2010; and (c) July 6, 2010; the black star at the left panels denotes the location of the Macondo well (MC 252).

Another example is a low-tide front from a Florida estuary that moved material seaward near the surface, which could prevent buoyant material from entering the estuary during the full tidal cycle (Valle-Levinson et al. 2015).

\section{Identified Uncertainties and Challenges}

Going forward, the monitoring and reliable modeling of river-induced circulation and associated fronts, as well as the related influence on material transport, are fundamental for the understanding of the GoM ecosystem, the management of its marine resources, and the response planning for both natural disturbances and man-made hazards. Recent studies have shown the importance of accurately representing
The black SSS lines indicate the 33 salinity contours, taken as the frontal boundary of brackish waters. The thin horizontal lines in the SOP plots mark the southern model domain at $28^{\circ} \mathrm{N}$ (adapted from Kourafalou and Androulidakis 2013)

the transport of riverine waters in models and their forecasts, not only from the Mississippi and other major rivers, but also from smaller estuaries that can, under some conditions, influence both local and remote environments. Le Hénaff et al. (2019) highlighted the challenge of predicting complex interactions across the ocean continuum, from estuarine to basin scales, as key to manage marine resources. Such reliable forecasts require assimilation of data in both deep and coastal waters. The latter remains challenging and requires the advancement of sustained coastal observatories with appropriate spatial resolutions. Developing efficient protocols and software infrastructure for coupling among estuarine, coastal/shelf, and ocean models will be required to further our capabilities for simulating river-induced fronts 

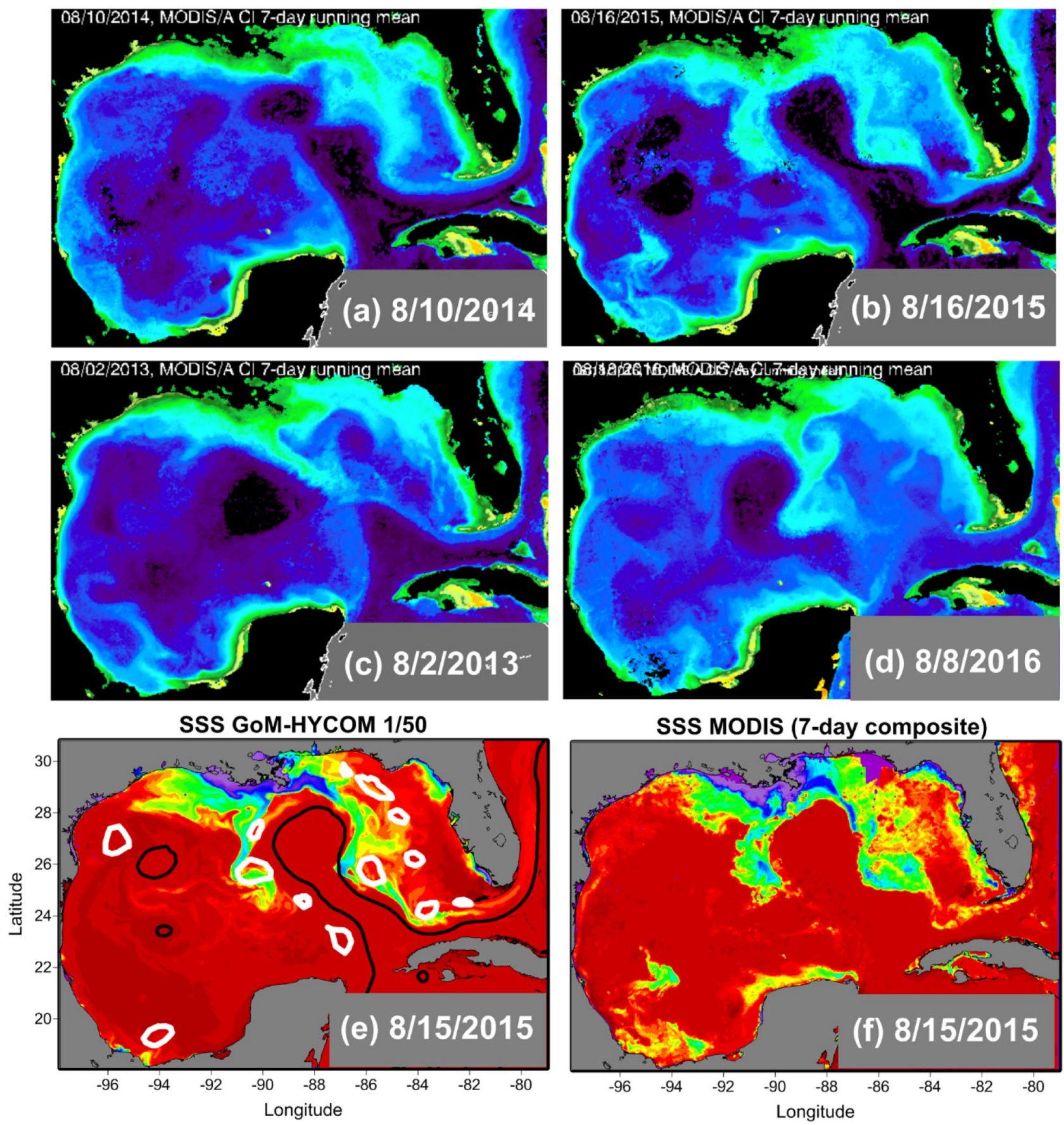

Fig. 8 Typical fronts related to GoM river inflows at selected dates. Offshore pathways of the Mississippi River plume reaching southern GoM and the Florida Keys are evident during both extended Loop Current (LC) phase (a, b) and retracted LC phase, when the LC eddy helps the offshore removal of riverine waters $(\mathbf{c}, \mathbf{d})$. The (a-d) images are derived from MODIS satellite observations using a color index algorithm (Hu 2011), with different colors representing relative concentrations of particulate and dissolved materials. The

and their effects on transport. Such dynamic couplings are either not presently explicit or are approximated by parameterizations (e.g., Verri et al. 2020). river-induced fronts and offshore pathways of the Mississippi River plume are also evident on the horizontal distribution of (e) simulated Sea Surface Salinity (SSS) from the GoM-HYCOM 1/50 model and the (f) MODIS-derived SSS (7-day composite) (Chen and Hu 2017; Androulidakis et al. 2019). The white and black lines in (e) mark the major cyclonic eddies and anticyclonic circulation features, respectively

Another challenge is to advance observational methodologies in realistic settings of oil spills, toward a comprehensive set of tools that combine appropriate in situ and satellite 

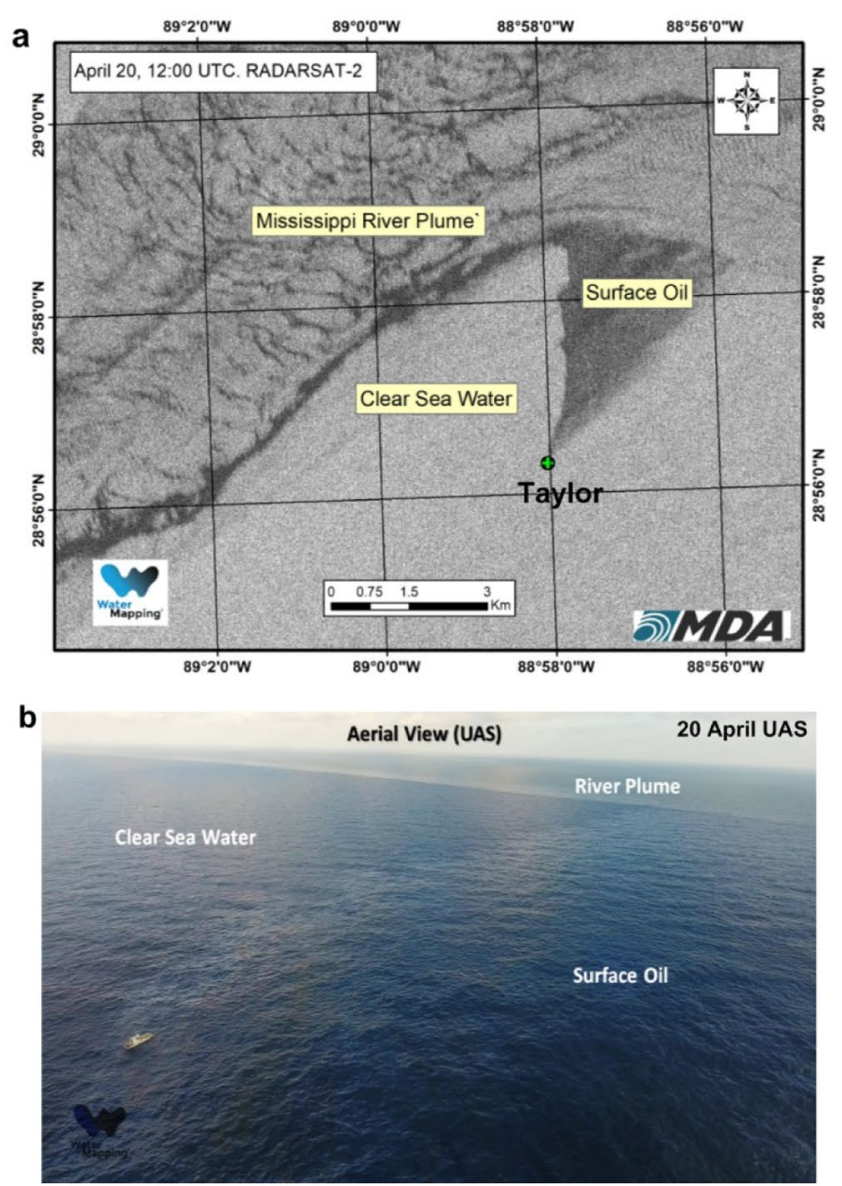

Fig. 9 Images collected from (a) RADARSAT-2 satellite (04/20/17), (b) Unmanned Aerial Systems (UAS) aerial view (04/20/17), and (c) TerraSar-X satellite with four drogued (DR, black and magenta lines) and un-drogued (UN, purple and green lines) drifter tracks (04/25/17) over the Taylor oil spill (Androulidakis et al. 2018). The Mississippi River plume, the Taylor Energy Site, the clear sea water, and the surface oil are marked. (d) Radar imagery snapshot containing the related surface currents (red vectors, $\mathrm{m} / \mathrm{s}$ ) measured over an

measurements. This is especially challenging in the presence of river plumes, where intense coastal to offshore interactions may occur and impact the accurate documentation of oil transport and fate. Several novel observational and numerical techniques were used and tested during the last decade to describe the river-induced plume dynamics and especially the effects of the accompanying density fronts on the hydrocarbons fate. An example is a multi-platform observational study around the Taylor platform near the Mississippi Delta, where vast amounts of oil were present over several years (Sun et al. 2018). Satellite radar (Fig. 9a; Garcia-Pineda et al. 2020) and ocean color images (Fig. 9d; Androulidakis et al. 2018) showed that when oil reaches the ocean surface, it can be trapped and travel along the river fronts. Field observations (i.e., Unmanned Aerial Systems - UAS, drifters and marine radars) confirmed the contribution of the river plume on the
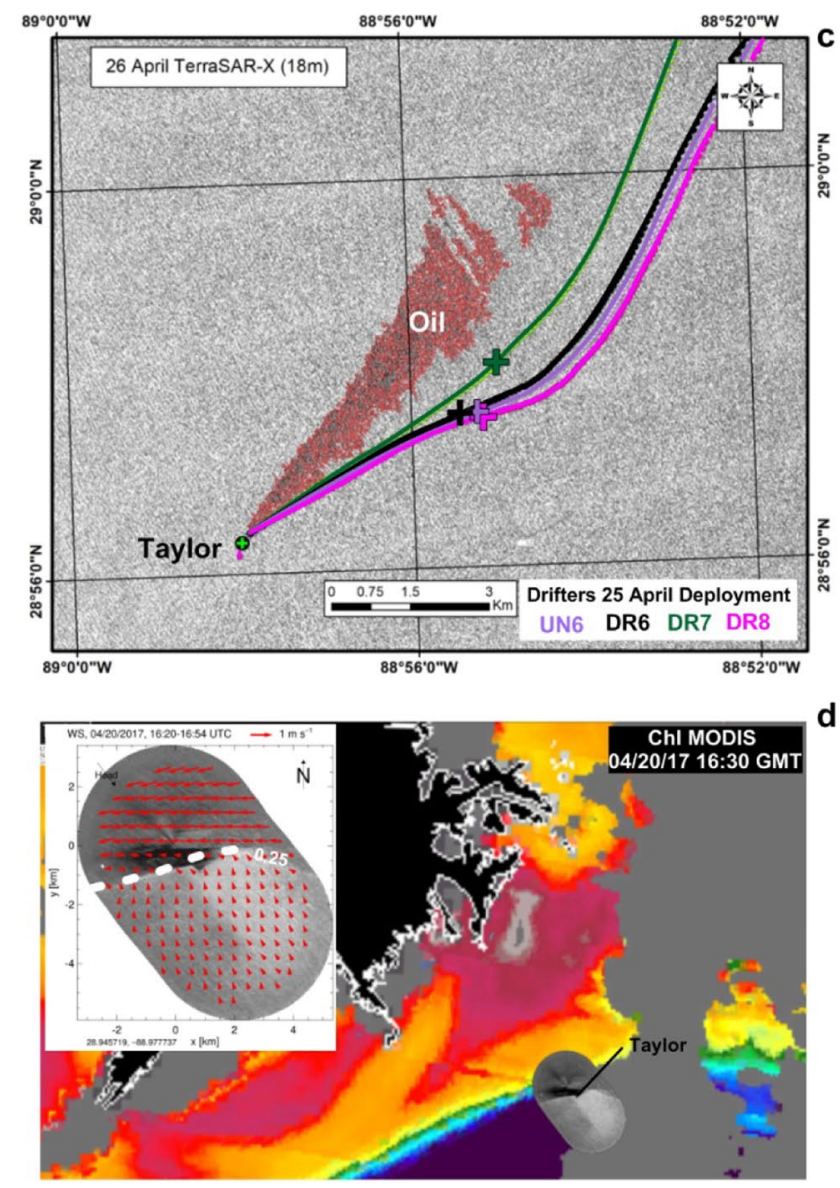

area ( $\sim 3 \mathrm{~km}$ radius) with respect to the respective MODIS chl-a concentration $\left(\mathrm{mg} / \mathrm{m}^{3}\right)$ map in the vicinity of the Mississippi Delta on $04 / 20 / 17$. The dark gray areas in the background are characterized by oiled waters and the dashed line indicates the $0.25 \mathrm{mg} / \mathrm{m}^{3}$ derived from the MODIS chl-a concentrations. RADARSAT-2 Data and Products ${ }^{\circledR}$ MDA (2017) - All Rights Reserved. TerraSAR-X data ${ }^{\odot}$ 2017 DLR e.V., Distribution Airbus DS

oil spill spreading. Drogued and un-drogued drifters (Novelli et al. 2017) examined the transport differences of surface and suspended oil in the water column related to wind-induced and sub-surface currents, respectively (Androulidakis et al. 2018). Garcia-Pineda et al. (2020) combined UAS (Fig. 9b), drifters (Fig. 9c), and Synthetic Aperture Radar (SAR; Fig. 9a and c) images to investigate the wind effects on oil residence time along river-induced fronts. Sea-surface roughness imagery derived from shipboard marine X-band radars may provide high-resolution information of oil patches, river plume, surface currents, and the concentrated oil along the density fronts. The marine radar mapping technique was validated with more than 4000 radar-drifter pairs in the GoM (Lund et al. 2018) and efficiently used during a multi-platform (in situ and satellite) observational experiment at the Taylor oil spill site (Fig. 9d; Androulidakis et al. 2018), located in the vicinity of 
the Mississippi Delta. Such detailed observations and related analyses provide a roadmap for obtaining data sets that can reduce uncertainty by advancing the understanding of the dynamics controlling oil transport and fate, while providing models with suitable tools for improved predictions.

\section{Relevance of Transport Processes for Ecological Connectivity and Oil Transport and Fate}

\section{Ecological Connectivity}

\section{Overview}

Most ecologically and commercially important fish and shellfish species, including those of the GoM, have complex life cycles (Wilbur 1980) that often involve the transport of a pelagic larval stage and include behavioral movement and migration of juveniles and adults among habitats (Petitgas et al. 2013). Advancements in modeling of both the coastal ocean and estuary circulation and a better understanding of juvenile and adult behavioral movement have allowed further investigation into the exchanges and pathways of organisms that result in the interconnections among habitats and between the estuaries and the shelf. Such information is needed to predict how environmental variation, as well as many stressors such as dispersed oil (e.g., Liu et al. 2011a; Paris et al. 2012), which are themselves inherently spatial, will affect dynamically moving individuals. Management of fisheries, protection of species (e.g., endangered), and coastal and ocean planning are also becoming increasingly spatially oriented (Fogarty and Botsford 2007; Crowder and Norse 2008; Katsanevakis et al. 2011).

Pelagic larvae may be locally retained when spawning and nursery habitat are co-located (Paris and Cowen 2004) or transported over longer distances when spawning occurs on the shelf and the embryos and larvae must recruit to distinct nursery areas or ingress into estuaries (Weisberg et al. 2014; Teodosio et al. 2016). The transport, range of dispersion, and exchange with areas are determined by the combination of the larva's physical environment (passive transport), and by their own physical-chemical characteristics (e.g., buoyancy) and biological traits (e.g., vertical movement, starting locations, larval stage duration) (Johnson et al. 2009; Vaz et al. 2016). Larval transport is often modeled using a Lagrangian framework (Olson and Paris 2019) where virtual particles representing individual larvae are released in Ocean General Circulation Models (OGCMs) and tracked in time based on hydrodynamic fields and other outputs (e.g., temperature) and with a wide variety of behaviors (Paris et al. 2013;
Faillettaz et al. 2018) often with relatively simple representations. Such coupled biophysical models of larval transport (particle-tracking models or PTMs) may also include a random component to resolve the sub-grid scale motion of the OGCMs and to mimic the effects of turbulent diffusivity (Griffa 1996). These PTMs are sometimes referred to as "stochastic particle-tracking models" or STPMs. The evolution of the hydrodynamics modeling toward finer resolution, nesting of grids and coupling of models, and increased skill has carried over to improved larval transport modeling. PTMs have a long history of application (Gabric and Parslow 1994; Limouzy-Paris et al. 1997; Gallego et al. 2007; Metaxas and Saunders 2009; Lett et al. 2009; Hawkins et al. 2019). However, their use for simulating larval transport in the GoM is relatively new and experienced a surge of activity as a result of research triggered by the DwH oil spill.

In contrast to the long history of research on modeling larval transport, field data and modeling of juvenile and adult fish movement is a more recent area of research (Nathan et al. 2008; Hays et al. 2016; Fraser et al. 2018). The accelerating development of empirical and modeling approaches that predict fish movements and resulting spatial distributions have been also driven by the increasing skill of hydrodynamics modeling and, more importantly, by the rapid developments in the data collected on the movement patterns of individuals. The recent upsurge of research includes an emerging new field termed "movement ecology" (Nathan et al. 2008). Measurement capabilities for tracking the movement of individuals are also rapidly expanding (Ropert-Coudert et al. 2012; Hussey et al. 2015).

\section{Findings of the GoMRI Research Program}

Research as part of the GoMRI effort has advanced both the biophysical modeling of larval transport and our understanding of spatial distributions and patterns of movement of the juvenile and adult stages of organisms. Wallace et al. (2014) measured stable isotopes in fish eyes as a possible way to infer individual macro-level habitat shifts and their broadscale movement patterns. For juveniles and adult stages, the simple representations of behaviors imposed on "particles" for larval PTMs are typically expanded for juvenile and adult fish (e.g., Watkins and Rose 2013) and movement is represented in both Lagrangian and Eulerian modeling approaches (e.g., Rose et al. 2015; Ainsworth et al. 2018).

Three general issues related to biophysical modeling of larval transport have been investigated by GOMRI studies: connectivity of subpopulations and metapopulations through larval exchange, likely pathways for larvae to get from spawning to nursery areas, and how more complicated movement behavior would affect larval stage dynamics. Connectivity is a major long-standing issue for marine 
populations that are comprised of local concentrations of adults (sub-populations) because of its influence on population dynamics and the resulting stability and resiliency of the overall population (Botsford et al. 2009; Cowen and Sponaugle 2009). The relevant GoMRI studies under these three categories related to connectivity are described below, as well as how these studies also specifically assessed overlap of the larvae with oil from the DwH spill.

GoMRI research related to the second general topic of the movement of juveniles and adults (i.e., post-larval stages) involved data analysis and modeling to determine short- and long-range movement patterns, assess habitat quality, and map the spatial distributions of the organisms. Tracking the movement trajectories of individuals with data and modeling results in the spatial distributions of organisms that provides the basis for assessing habitat quality and quantity and their exposure to spatially and temporally varying stressors. Resolving exchanges among habitats and documenting spatial distributions are necessary for effective management of the populations and fisheries.

For both topics of connectivity and movement of juveniles and adults, the DwH spill and associated managementrelated responses will further complicate analyses going into the future. A major response to the spill was to impose fisheries closures, which then affected, to varying degrees, many aspects of the ecosystem (Murawski et al. 2016, 2020). Organism responses were species-specific, life-stage specific, and geographically localized (Murawski et al. 2020). These responses were the combined effects of exposure to the oil (direct), indirect responses to other affected organisms (e.g., prey), and reduced mortality to fisheries closures, and they affected the long-term monitoring data differently across monitoring programs (Ward et al. 2018; Martin et al. 2020). Because fish are long-lived, the event will need to be considered in analyses of data and modeling for decades into the future.

Particle Tracking Models (PTMs) and Larvae Jones et al. (2015) simulated the transport of larval blue crabs in the northern GoM and their overlap with oil from the DwH spill. Connectivity among estuaries was highest for the estuaries adjacent to the Mississippi Delta. They showed that of the larvae that settled within the domain, approximately $38 \%$ were potentially exposed to oil from the spill; this varied from 0 to $93 \%$ across released cohorts with exposure typically occurring for 1-day and for young ( $<15$ days old) larvae. Cardona et al. (2016) used a PTM to quantify the connectivity of deep water black coral larvae in the northern GoM and showed that there was limited exchange among sites to the east and west of the Mississippi Fan, suggesting that deep local populations were relatively isolated. Zeng (2019) simulated bonefish larvae transport in the NW Atlantic that included the GoM and determined how the spatial regions treated as independent areas in management were, to varying degree, connected and their exchanges depended on larval retention versus dispersal. Their PTM was imbedded within the Regional Ocean Modeling System (ROMS) circulation model, rather than the more typical approach of averaging hydrodynamics output for use in off-line analyses (Paris et al. 2013; Putman and He 2013a). Finally, Paris et al. (2020) used a PTM to examine the relationship between oceanography (Miron et al. 2017), fish community structure (Murawski et al. 2018), and larval patterns based on over 20 years of Southeast Area Monitoring Assessment Program (SEAMAP) data. They identified ecological regions that were influenced by Lagrangian patterns derived from Argos drifters (Miron et al. 2017) and controlled larval retention and self-recruitment levels; fish community structure similarity among these ecological regions was mostly driven by larval connectivity.

Important to assessing impacts on populations is also knowing how larvae get from spawning areas to nursery areas. Weisberg et al. (2014) addressed the gag grouper conundrum, originally posed by Fitzhugh et al. (2005), regarding how gag juveniles, spawned near the shelf break, arrive at settlement locations along the shoreline and in the estuaries. Using a high-resolution nested model (FVCOM nested in the GoM-HYCOM 1/25), they tested both nearsurface and near-bottom routes of transport and found that the bottom Ekman layer (under protracted upwelling conditions) accounted for the specific observations of 2007 and the more general distribution of gag juveniles along Florida's west coast. Thus, the historical spatial order found for gag juvenile settlement agrees with the expectation from coastal ocean circulation. The modeling was supported by stable isotope data showing that settled juveniles had an isotopic signature consistent with macroalgae identified as being part of hard-bottom (spawning site) that persists throughout a near-bottom larval migration route. Todd et al. (2014), using a hydrodynamic model of the region, identified an onshore transport mechanism on the northern West Florida Shelf linked to the asymmetry in oscillating wind patterns associated with synoptic weather patterns during the late winter and early spring, a critical time period for gag spawning. Lagrangian trajectories originating in known gag spawning areas in the northeastern Gulf were associated with the highest likelihood of reaching inshore nursery habitat.

Staaterman et al. (2012) examined how adding directed movement toward the settlement habitat in a PTM not only affected how much time larvae had to travel before successful settlement, but resulted in reduced dispersal distances. They found that early onset of orientation and large maximum detection distances increased settlement and resulted in an increase in larvae settling near their starting (home) reef. 
Putman and He (2013a) used a PTM to assess how different spatial and temporal averaging of the physics (transport) affected model skill simulating transport of larvae relative to drifters, and then simulated (albeit passive only) transport of young turtles escaping the shelf to reach the better habitat of the oceanic waters. They showed how over-averaging the hydrodynamics output can cause results that were inconsistent with observations of in situ drifter trajectories, and that cross-shelf transport of virtual juvenile turtles moving to better ocean habitat depended on the release site. The results apply to a variety of organisms because of the focus on passive transport (which affects all species although to varying degrees), but they are only relevant to long-range movements (fine-scale behavior is not considered) for which net transport plays a dominant role. Putman et al. (2013b) further focused on simulating the distribution of the oceanic stage of Kemp's Ridley sea turtles. Assuming survival increases with water depth and allowing for going in an offshore direction when very young, they predicted that the turtles would occur mostly in the western GoM, with some rare events of rapid eastward transport so the turtles sometimes occurred on both coasts of Florida.

Many of the PTM analyses made innovative use of field data collected in the GoM to support or parameterize the models. For example, PTM results were corroborated or contrasted with genetic data (Cardona et al. 2016), stable isotopes (Weisberg et al. 2014), or survey data (Paris et al. 2020). Combining field data with modeling enabled quantification of the results with higher confidence and should serve as template as PTM and data collection continues in the GoM.

Movement of Juveniles and Adults Movement of juveniles and adult stages of fish and other taxa was incorporated into a comprehensive food web model of the GoM (Ainsworth et al. 2018). The model simulated the growth, mortality, recruitment, and movement of 91 functional groups on a $12 \mathrm{~h}$ time step in a coarse 3-D grid comprised of 61 horizontal polygons (up to 7 vertical layers). It also concurrently simulated the spatial-temporal dynamics of the DwH oil spill using a deep-sea blowout model developed as part of GoMRI research (Paris et al. 2012; Le Hénaff et al. 2012b; Perlin et al. 2019). The oil spill effects were imposed on growth and mortality and the food web response was quantified. The modeling results of Ainsworth et al. (2018) showed major local declines in many functional groups in areas most impacted by the DwH spill, with recovery times ranging from 10 to 50 years depending on life history. Some impacts were predicted far from the spill source due to reduction in prey and the subsequent transport of the prey (and their pelagic larvae) to other regions on the grid, which in turn affected higher order predators. Movement was simulated as seasonal redistributions of biomass among major habitat types, and as long-range migrations of some species represented via specified fractions of biomass entering and leaving the model domain.

GoMRI research examined the connectivity of the wetlands in estuaries with the shelf habitats using field data analyses. For many coastal fish species, including many species in the GoM (e.g., Shaw et al. 1985; Rogers et al. 1993), eggs and larvae are transported into the estuaries (and associated wetlands and other habitats) from adults spawning on the shelf (Epifanio et al. 2001). In general, for species that use both the shelf and estuaries, one would expect to see reduced fish in their estuarine environment if their eggs and larvae were exposed to oil on the shelf. Yet, Fodrie and Heck Jr. (2011) used long-term monitoring data of juvenile fishes in seagrass habitat and did not detect a reduction in juveniles nor changes in species distribution following the DwH spill. Moody et al. (2013) used monitoring data of fishes on salt marshes as part of ongoing oyster-reef restoration project and compared trajectories of the abundances of resident and transient species before and after the spill. While two resident species declined after the spill, they recovered by the next year and there were no declines in transient species, which are most likely to be impacted because their eggs and larvae would be exposed on the shelf. Able et al. (2015) studied marsh fish assemblages 2 years after the spill and no detectable differences were observed in oiled versus unoiled marshes. A recent paper by Martin et al. (2020) looked at 20 years of fisheries-independent data from Mississippi and Alabama on fishes and invertebrates and showed differences in community composition, abundances, etc. during the intra-spill period (2010-2012) compared to pre- and postspill time horizons.

A precursor to assessing connectivity is to define subregions with similar ecology and species composition and communities that can provide the basis for examining connectivity among spatial sub-units in the GoM. Murawski et al. (2018) collected adult demersal fish using long-line sampling in a transect design that covered the 40 to $300 \mathrm{~m}$ depth strata throughout the GoM. They identified 6 zones of similar fish community structure. Miron et al. (2017) used surface drifter observation data to delineate 5 subregions of high retention in the Gulf. Such physics-based identification of subregions is very useful to compare to sub-units based on biological considerations to infer how biological considerations combine with circulation to result in the realized connectivity among eco-regions.

\section{Identified Uncertainties and Challenges}

Future efforts should focus on collecting behavioral data on fish swimming modes and capabilities, responses to 
environmental variables, movement strategies (e.g., hiding, cruising), and degree of specificity and fidelity to different conditions and habitats, in order to expand the coupling between coastal ocean circulation modeling and fish ecology. Great promise exists for identifying transport pathways and ascertaining the underlying movement patterns that lead to observed spatial distributions. Obtaining the data to refine larval and adult movement in circulation, population, and food web models will lead to better predictions of the spatial and temporal trends of organisms and quantification of the degree of connectivity within the GoM subregions and habitats. A critical issue for the movement of early life history stages, as well as juveniles and adults, is how multiple cues determine behavioral movement on short and long time and space scales. For many species, these cues are time-dependent and vary in two and often three dimensions. In addition, the idea of linking the movement trajectories to the bioenergetics and survival (i.e., fitness and food limitation) of the individual is just recently gaining attention. This was limited until recently by little field data on finescale movement trajectories. Telemetry data are becoming available on enough individuals to determine patterns in trajectory pathways, and the technology now permits for the recording of the environmental conditions experienced by the individuals over time (e.g., temperature) as the fish travel along these trajectories (Hussey et al. 2015). The rapidly advancing monitoring methods merging genetics, telemetry, and other emerging technologies (Danovaro et al. 2016), with observing systems (Liu et al. 2015), will provide the empirical basis for these model developments and their validation.

Associated with modeling is the need for continued monitoring and synthesis of existing field data. Such information is needed to provide spatially resolved biological inputs to models and for assessing the overall skill of the combined physical and ecological modeling. With the GoMRI efforts as initial steps, continued systematic analysis of connectivity pathways of key species at local and Gulf-wide scales is needed for effective management of the GoM's habitats and resources. Many of the economically and ecologically important fish and shellfish species have early life stages (egg and larvae) that rely on transport ranging from a $1 \mathrm{~km}$ scale (within the shelf and within estuaries) to hundreds of km's (shelf to estuaries) for successful completion of their life cycles (Chen 2017). Recruitment (defined as survivors to an age or size after which mortality rate is relatively constant) determines population abundances and therefore sustainable harvest levels (Plagányi et al. 2019). Recruitment is greatly influenced by the dynamics in the early life stages (Fogarty and O'Brien 2016; Lorenzen and Camp 2019) when transport plays an important role in growth and survival of individuals.

\section{Oil Transport and Fate}

\section{Overview}

The fate of oil spilled into the ocean depends on many factors, including transport and dispersion by the ocean circulation (sections "Wetland, Estuary, and Shelf Exchanges" to "River-Induced Fronts and Cross-basin Transport"), physical weathering (evaporation, emulsification), photochemical degradation, other chemical transformations, and biological consumption (e.g., Spaulding 1988; Yapa 1996). These physical/chemical/biological processes may have different time scales, ranging from hours to years. To inform response activities (e.g., booming, skimming, in situ burning, and applying dispersant), what is needed are short-term forecasts on time scales of hours to days, for which physical oceanography plays an important role. Therefore, information on ocean currents, winds, and waves is essential at those scales.

Prior to the DwH incident, and partly due to a paucity of high-quality numerical ocean circulation models, many oil spill models relied on low-accuracy ocean circulation modules which propagated large uncertainties into forecasts of oil transport. Commonly added was a wind-age term to account for either unresolved Ekman layer effects, or simply to make an empirical correction to align observed and modeled oil spill trajectories (e.g., Abascal et al. 2009). Also, due to the lack of open-access to operational ocean circulation nowcast/forecast model results, most oil spill modeling was performed in a hindcast mode, despite the availability of satellite-inferred oil slick location information.

Differing from prior oil spills, during the DwH event crude oil rose from the ocean bottom in approximately $1500 \mathrm{~m}$ water, much deeper than any previous oil spill. The amount of hydrocarbons released remained uncertain throughout the spill, and mitigation activities, such as dispersants use, containment, collection and burning at sea, affected the composition and trajectory of released oil, complicating trajectory modeling efforts. Such uncertainty was compounded by errors in both the velocity fields generated by the suite of extant ocean circulation models and the trajectory model algorithms. Many regional ocean models did not represent the details of the transport of river waters from the estuaries to the shelf and beyond and none resolved submesoscale dynamics. Kourafalou and Androulidakis (2013) showed that the correct representation of the evolution of river-induced fronts is fundamental for the transport and fate of oil for a spill near a river-dominated coastal environment, such as the DwH incident. All these factors complicated traditional oil spill forecast (Liu et al. 2011a). How to effectively model transport pathway and fate of the DwH hydrocarbons remains a challenging research question. 


\section{Findings of the GoMRI Research Program}

As a rapid response to the DwH oil spill, surface trajectory forecasts were implemented to provide information for mitigation activities (e.g., Liu et al. 2011a). To reduce the uncertainties and the errors that increase with time, the trajectory models were frequently re-initialized with satellite inferred and observed oil locations (Liu et al. 2011b, c; Mariano et al. 2011). New virtual particles were added to the trajectory models to simulate the continuous release of oil from the wellhead. An ensemble of multiple models was used to generate the short-term forecast of surface oil (e.g., Liu et al. 2011 b, c). Subsurface oil trajectories were also simulated based on the virtual particles released at individual vertical levels (Weisberg et al. 2011) and directly from the spewing wellhead in three dimensions (Paris et al. 2012). These initial simulations were consistent with the observations of the southwest trending plume of dissolved natural gas and dispersed oil droplets at $1200 \mathrm{~m}$ depth (Camilli et al. 2010).

After these rapid response trajectory simulations, hindcast simulations were eventually performed (e.g., Dietrich et al. 2012; Le Hénaff et al. 2012b; Paris et al. 2012), and some considering oil droplet size variations (Paris et al.
2012; North et al. 2015; Perlin et al. 2019) or subsea chemical dispersant applications (Paris et al. 2012). By nesting a high-resolution, unstructured grid, coastal ocean model (WFCOM) in coarser resolution deeper GoM models (either the Global or the GoM HYCOMs), Weisberg et al. (2017) showed that the ocean circulation appeared to control the transport of surface oil from the deep ocean to the continental shelf and that as the water depth decreased, the waves, via Stokes drift, were responsible for the actual beaching of the oil. This finding had an intuitive basis in that the circulation in shallow water is increasingly constrained to flow along isobaths upon approaching the coastline, whereas the Stokes drift is not. Figure 10 compares the results without and with Stokes drift, and while not shown, the results with Stokes drift are in qualitative agreement with the locations where beached oil was observed.

Stokes drift was also found important for the transport of oil both toward the coasts and toward the GoM interior. Le Hénaff et al. (2012b) showed that model simulations without Stokes drift were the main reason for erroneous forecasts indicating that large amounts of oil would travel southward, along the LC in May 2010. Although such a transport scenario is dynamically possible, the wind conditions during

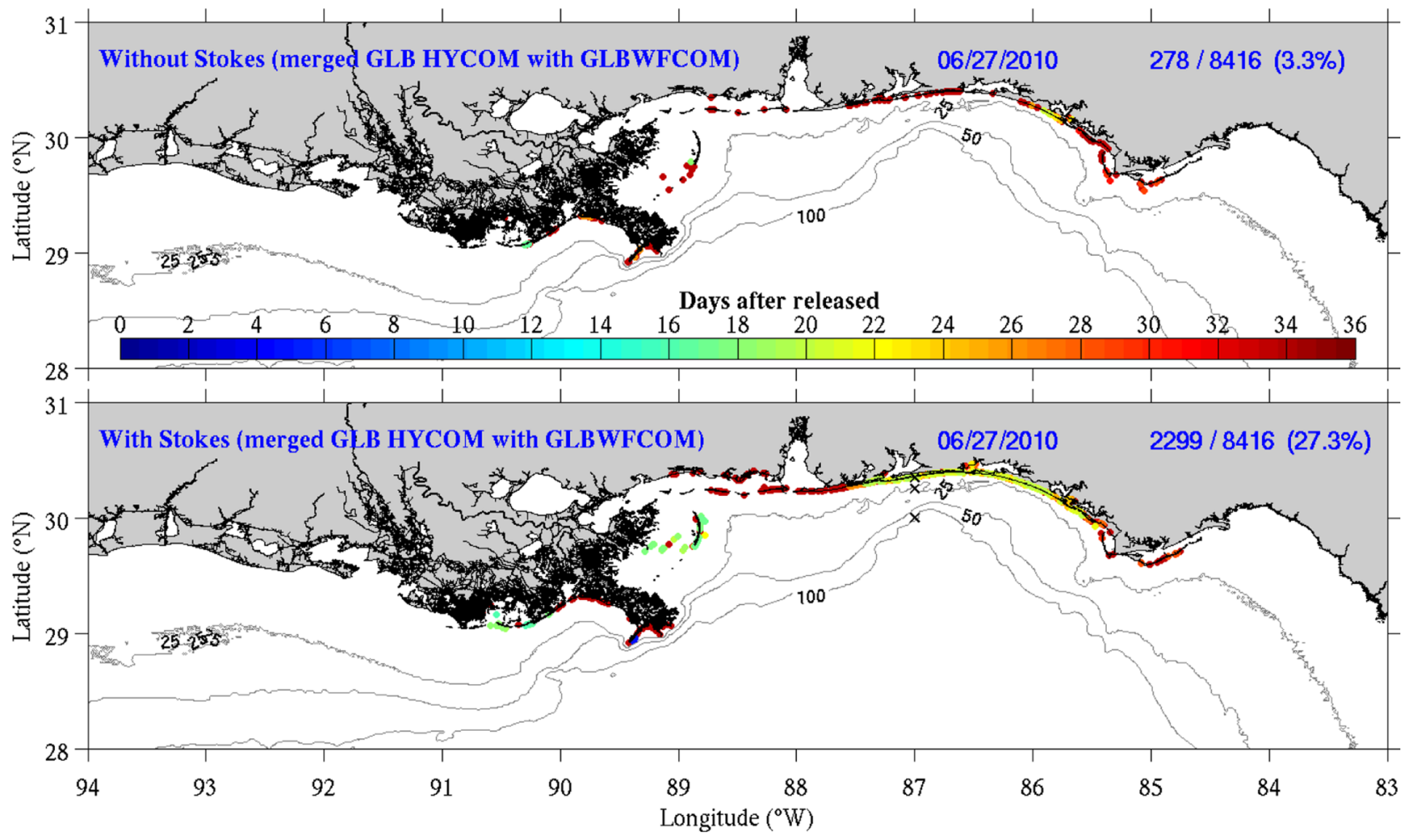

Fig. 10 Distributions of beached particles and their ages on June 27, 2010, simulated without (upper panel) and with (lower panel) the inclusion of Stokes drift. The simulation period was from May 24, 2010 (when the observed surface oil was still over deep water, except near the Mississippi Delta), through June 27, 2010 (when most of the oil had reached the shoreline). The simulation used the highresolution West Florida Coastal Ocean Model (WFCOM) nested in the Global HYCOM. Of the 8416 particles used in the simulation, 27.3\% reached the shoreline with Stokes drift, versus only 3.3\% without Stokes drift (from Weisberg et al. 2017) 
that spill period prevented the massive export of oil from the immediate area of DwH toward the Straits of Florida. These results point to the importance of including a Stokes drift parameterization, in addition to using accurate wind forcing fields.

Whereas particle tracking demonstrated successes over the many studies discussed, the use of scalar concentrations to represent the oil was also successful. For example, Weisberg et al. (2016b) tracked a subsurface scalar concentration plume from the northern GoM coastal region where surface oil abounded to the west Florida continental shelf and around the Dry Tortugas as driven by the protracted upwelling circulation that existed from May 2010 through the end of 2010. The near bottom plume footprint closely coincided with the locations of reef fish lesions found a year later in a survey by Murawski et al. (2014). It was argued that DwH hydrocarbons did permeate the West Florida Shelf, albeit sight unseen beneath the surface. Although the concentrations were largely diluted along the route, these hydrocarbons were potentially toxic according to Murawski et al. (2014) and Berenshtein et al. (2020).

Other hindcast modeling of the oil movement included a stochastic approach to represent unresolved sub-grid scale variability that may affect oil transport (Srinivasan et al. 2010; Mariano et al. 2011; Abascal et al. 2015) and simulations of oil transport using several different ocean circulation models (e.g., Jolliff et al. 2014; Khade et al. 2017). For a longer-term outlook of what a future spill might bring, a Monte Carlo simulation was performed to statistically predict where the oil might go, with a focus on the probabilities of oil beaching (e.g., Barker 2011).

Oil entered some estuaries of the northern GoM between May and September 2010 (Michel et al. 2013). Once inside the estuary, the oil deposited on the marsh shorelines over a total length of $1105 \mathrm{~km}$ (Nixon et al. 2016). The deposition of the oil was largely concentrated to the first $\sim 10 \mathrm{~m}$ from the marsh edge, where it caused acute effects such as plant mortality and accelerated marsh edge erosion (Silliman et al. 2012).

Numerical modeling for oil transport was able to correctly simulate the entrance of oil into Barataria Bay, provided that surface transport was included (see "Nearshore and Inlet Processes" on the parametrization of Stokes drift). These models, however, were unable to simulate the detailed redistribution of oil within the estuary itself, likely due to a combination of factors that included inadequate spatial resolution and imprecise model bathymetry. Nevertheless, it was recognized that this redistribution is strongly affected by wind-driven transport, especially on low-frequency events such as cold fronts (Payandeh et al. 2019). Other important factors were density gradients by neighboring river inputs and tidal fronts. Furthermore, given the settings of estuaries in the northern GoM, south-facing marshes are more likely to experience incoming wave transport when the water level is high (i.e., when the marsh is inundated), and thus are more susceptible to getting covered by oil (Valentine and Mariotti 2019).

Model results indicated that the existing river diversions have a limited flushing potential and are not effective in preventing the offshore oil slicks from drifting into coastal estuaries (e.g., Barataria and Breton Sound) (Huang et al. 2011; Huang et al. in review). The results further suggest that proposed large sediment diversions would have much larger flushing potential, albeit in association with significant ecological tradeoffs associated with estuarine freshening.

The Mississippi plume buoyancy-driven effects on oil transport were different east and west of the Mississippi Delta. Although the downstream westward currents entrapped oil close to the Louisiana coasts in early July 2010, the anticyclonic circulation within the upstream plume region (east of the Delta, extending over the MississippiAlabama-Florida shelf) created a front that restrained onshore transport in late May 2010. The effects of the river plume dynamics and the accompanying fronts on oil transport and especially on oil stranding during the DwH accident were also discussed by Hole et al. (2019). Oil spill simulations, based on the OpenOil model (Dagestad et al. 2018), covered specific periods of characteristic river plume spreading and showed consistent river effects on the amount and location of stranded oil and a considerable impact on the location of the surface oil. Modeling results in tandem with satellite observations in 2010 showed that periods of large river discharges reduced the potential presence of oil stranding by $50 \%$ in comparison with periods without river plume spreading.

Some of the oil buried in the marsh soil was subsequently re-mobilized during Hurricane Isaac in 2012 (Zengel et al. 2015). Precise measurements of this remobilization are not available, but there were qualitative observations of oil presence tens of meters from the original location where the oil was deposited (Zengel et al. 2015). Noticeably, this remobilization was such that sites initially classified as "un-oiled" eventually got contaminated, thus confounding subsequent analyses (Turner et al. 2014a, b, 2019). Furthermore, the occurrence of re-oiling was confirmed by various ecological studies that, in addition to a partial ecosystem recovery in the 2 years after the oil spill, also found increased areas of oil-induced side effects after 2012 (Snyder et al. 2015; Bam et al. 2018; Perez-Umphrey et al. 2018).

\section{Identified Uncertainties and Challenges}

Challenges remain to better understand and model the transport and fate of spilled oil. The reactive terms in the oil transport equation may impact oil droplet size and composition, biological feedbacks via consumption, and 
aggregation of heavily weathered oil residues with biogenic and mineral components (e.g., MOSSFA), and these changes, in turn, affect the transport pathways. Reactive terms were generally not included in the abovementioned oil spill models. Properly accounting for these terms remains a major source of uncertainty in the context of oil transport, fate, and effects. Regardless of the chemical and biological complexities, the transport and dispersion of oil finds its underpinnings in ocean circulation, including river input, waves, and tides. Because spilled oil makes its largest impact in coastal waters and on beaches, there is a need for downscaling from the deep ocean, across the continental shelf, into the estuaries and onto the marshes and beaches. No single model is adequate for this task. Accurate deep ocean models are required for representing the deep ocean currents (including baroclinicity and waves) and how these deep ocean currents project onto the continental shelf (Bracco et al. 2020). Increasing resolution plus incorporation of flooding and drying is required approaching the coastline, and even higher resolution is needed to include the inlets through which water enters the estuaries and the Gulf Intracoastal Waterway. Equally important are the observations that are necessary for either data assimilation or for determining model veracity. Adding (and sustaining) new observations to the limited ones that existed prior to the $\mathrm{DwH}$ event remains a major challenge.

In summary, requirements for improved oil spill trajectory and fate modeling are as follows: (1) a suite of appropriately scaled, preferably coupled, circulation models, supported by (2) a well-designed observing array for both data assimilation and model veracity testing (e.g., Weisberg et al. 2015), and (3) improved formulations for the non-conservative (physical weathering and biological and chemical transformations/decay) aspects of oil tracking (e.g., Adcroft et al. 2010). Whereas the models themselves may be designed to be portable (e.g., Weisberg et al. 2017), the observing system must be distributed and sustained. Such observing systems should be complemented by fine-scale measurements of sediment and water quality during high-energy events. Such observations have a myriad other applications besides oil tracking, such as improved marine weather forecasting, search and rescue, and water quality and resource management.

Additional challenges occur in the case of deep oil spills, such as the $\mathrm{DwH}$, where up to $50 \%$ of the oil released remained below the surface, entrained into subsurface plumes that traveled at depth along the continental slope. This motivated the scientific community to better understand and model transport and mixing processes in sub-surface and deep waters, as recently reviewed in Bracco et al. (2020). The deep Gulf remains a major challenge due to the sparseness of available observations and the limited predictability of the circulation below $1000 \mathrm{~m}$ depth in the absence of continuous monitoring systems. Limited knowledge of mixing processes along the continental slope and shelves continues to halt progress, as tracer dispersion is both spatially inhomogeneous and temporally intermittent, as confirmed by the deep tracer release experiment conducted by the GOMRI-funded Gulf of Mexico Integrated Spill Response (GISR) Consortium (Ledwell et al. 2016).

\section{GoMRI Legacy}

After more than four decades of research (e.g., Odum et al. 1979; Nixon 1980), much has been learned and much remains to be learned, regarding the transport of sediments, nutrients, carbon, organisms, pollutants, and other constituents along the river-estuary-shelf-ocean continuum. To this end, the GoMRI program has significantly advanced the scientific understanding of the transport processes in the GoM and their relevance for ecological connectivity and oil transport and fate. In general, advances have been focused on the open ocean and the water surface. This focus partly reflects the offshore orientation of the projects proposed and funded by GoMRI, but also the availability of information. Satellite products contribute an almost continuous generation of observations concerning surface conditions (Devi et al. 2015), and modeling was designed to inform oil fate and therefore focused on transport in the shelf-ocean environments. In addition, the available field data are generally more representative from the shelf-ocean as compared to the highly dynamic and complex estuarine environment. Nonetheless, through GoMRI and other research of the last 10 years, our understanding of surface convergence, Stokes drift, LC intrusions, and river-induced fronts, and their impacts on the transport of oil and organisms, has improved dramatically. An indication of this burst of activity is the large number of post-2010 peer-reviewed publications cited in this review, including over 70 funded, wholly or partially, by GoMRI.

Progress in our understanding and quantification of transport resulting from the GoMRI effort involved many individual studies that included aspects of methods development, new analyses, and data synthesis. Targeted multiplatform observational studies were made possible, due to the variety of co-funded research groups that were working both individually and in synergy; an example was given in section "Identified uncertainties and challenges" under "River-Induced Fronts and Cross-basin Transport" and Fig. 9. Methods development included improved 
data collection, analysis of synthesized datasets, and expanded and improved models, which can be transferred and applied to other systems (e.g., Hole et al. 2019; 2021; Androulidakis et al. 2020a, b; Ainsworth et al. 2021). Process understanding helps guide future research and sets up a framework for determining the relative importance of processes influencing transport at multiple spatial scales (submeso- and meso-scale to regional to Gulf-wide) within the GoM and positions us to compare the importance of these factors to other large river-dominated coastal systems. New methods, synthesized data, and increased understanding all coalesce to improve forecasting capabilities that prepare us for dealing with, and responding to, future events, including episodic events such as oil spills, local and regional responses to large-scale restoration, and long-term changes anticipated under climate change scenarios.

Advances in modeling methods were mostly focused, but not limited to, refinement and coupling of models to better simulate transport across various linkages in the river-estuary-shelf-ocean continuum. In the past decade, 3-D hydrodynamic models that had highly refined representations of the complex coastlines began to converge on a consistent use of data products for specifying boundary conditions and forcings, and advanced computing aspects of coupling and nesting of different resolution models were developed and implemented. Examples of the application of these modeling advances were improved capabilities for quantifying bay-ocean exchanges of water under extreme weather conditions (e.g., Chen et al. 2018) and increased skill in simulating oil fate (e.g., Weisberg et al. 2017). A major effort was also centered in examining how freshwater inputs influence transport across the river-to-ocean continuum, as illustrated by the modeling analyses that examined how river diversions affect hydrodynamics (and therefore transport) in the near-field (estuarine) and how those effects propagate onto the shelf (Huang et al. 2011; Cui 2018). These types of simulations have broad implications on the transport dynamics, and the associated fate and distribution of carbon, nutrients, sediment, and other constituents in the GoM. The extensive particle-tracking modeling also built on the improved transport representation to look at ecological connectivity of particles and organisms across the continuum (e.g., Paris et al. 2020).

On finer spatial scales, model developments included allowing for inundation and drying of low-lying areas and marshes (e.g., Weisberg et al. 2014) and the inclusion of sufficient resolution and process formulations to simulate transport along barrier islands and within island passages (e.g., Weisberg et al. 2017). Predictive tools that allow for accurate simulation of transport across temporal and spatial scales will enable more informed assessment of the fate of oil, and the accessibility of these habitats to organisms and their resilience to anticipated future events and climate conditions (McKee et al. 2012; Kemp et al. 2016).

Transport involving the open ocean used both modeling and data analysis to further resolve the role of mesoscale and finer-scale phenomena on advection (Barkan et al. 2019; Bracco et al. 2019a). The additional role played by the influx of riverine fresh water modifying the density gradients and stratification, and thereby affecting the formation of sub-mesoscale lateral convergence zones, is important for predicting and understanding where nutrients concentrate and the fate of pollutants. Furthermore, transport involving the open ocean was linked to the LC via the LC's role in the dynamics of low salinity water of river origin within the GoM (Androulidakis et al. 2019; Brokaw et al. 2019). These results have important implications for interpreting tracer and drifter studies (e.g., D'Asaro et al. 2018) and for understanding the transport of material at the surface versus the conditions measured at depth (Wenegrat et al. 2014). Riverine waters also influenced transport involving the shelfopen ocean via their plume fronts. The role of river plumes on along-shore and cross-shore transport, including oil, was established via modeling and data analysis (Kourafalou and Androulidakis 2013; Schiller and Kourafalou 2014; Androulidakis et al. 2018, 2019).

As part of these advances, there were concentrated activities in synthesizing the available information and the field data for both their own analyses and for use in model formulation and testing. Examples are the use of data assimilation with high-resolution $\left(1 / 50^{\circ}\right)$ HYCOM (Le Hénaff and Kourafalou 2016), and the use of synthetized survey data (e.g., Paris et al. 2020) and genetics data (e.g., Cardona et al. 2016) for development and testing of PTMs for larval transport. New technologies were also developed, such as the use of remote sensing to measure currents at the surface (Laxague et al. 2018; Rodriguez et al. 2018). As part of GoMRI, all data are documented, archived, and available through the GoMRI Information and Data Cooperative (GRIIDC). These data and model products provide a secure mechanism for using the information in subsequent analyses to continue to further our understanding beyond GoMRI.

All these advances, when viewed together and from the lens of transport along the river-estuary-shelf-ocean continuum, improved our understanding and forecasting capabilities for simulating oil fate and for modeling, assessing, and quantifying the transport and connectivity of organisms on the scale of the Gulf. Multi-scale research, such as that illustrated here and made possible by the GoMRI effort, positions us to better respond to future events and projected conditions for the GoM. 


\section{Recommendations for Future Research}

GoMRI, and other DwH oil spill-related funding, provided an unprecedented opportunity to build upon prior knowledge in studying the functioning of the GoM. The accumulation of many studies advanced a holistic view of transport across the river-estuary-shelf-ocean continuum. While each study stands alone, a remaining challenge is to maximize the usefulness of the collection of the individual studies and maintain the momentum of the burst in research provided by GoMRI. Many of the studies, as part of the process of advancing the science, identified specific uncertainties. These uncertainties provide the initial fodder for informing post-GoMRI research. Our accumulation of the uncertainties is not intended as a comprehensive listing of the most critical ones; rather, these arose in the context of specific analyses based on the judgment of the specific investigators. They are worth considering as potential areas of research that, if addressed, would further advance the science.

Several major topics emerged as important in multiple settings. These include the quantification of sediment, carbon, dissolved gasses and nutrient fluxes during extreme weather events, consistent specification of the various external forcings used in analyses, methods for smooth integration of multiscale advection mechanisms across different flow regimes, dynamic coupling of the atmosphere with sub-mesoscale and mesoscale phenomena, and methods for simulating finer-scale dynamics over long time periods. Addressing them will involve data collection, analyses, and model developments, such as using nested models with downscaled inputs. Regarding the understanding of specific processes, particular effort should be devoted to (1) advance the parameterization of turbulence, especially at the air-sea interface and in the bottom boundary layer, and (2) understand and quantify the transport of oil-sediment aggregates. Continued advances in the simulation of transport along the river-estuary-shelf-ocean continuum will permeate into improved skills for simulating oil fate and, with the addition of better data and behavioral considerations, additional insights into the connectivity of organisms across multiple temporal and spatial scales.

With this integrated approach relying on both deep-ocean and land-derived inputs, it is imperative that these be better defined. Key to this are sustained observations and improved models, accommodating the broad range of scales that control circulation and transport. Advancing the understanding of fundamental processes that control such a complex system is an on-going task. For instance, understanding the impact of the LC and associated eddies on shelf circulation has advanced substantially, but improving upon these advances also requires well-designed and sustained observations, and reliable model simulations and analyses.
Addressing the above gaps and uncertainties would allow the scientific community to be better prepared to predict the fate of hydrocarbons and their impacts to the coastal ocean, rivers, and marshes in the event of another spill in the GoM. It would also dramatically improve our understanding of the physical, biological, and chemical functioning along the land-ocean continuum, with long-lasting implications, in and outside the GoM. To achieve these objectives, future research efforts should focus on developing a reliable, continuous, and sustainable observing system using different platforms and instruments, and on advancing data-assimilating models that couple rivers and estuaries to the coastal and shelf seas, and then to the adjacent open ocean. The new platforms should take advantage of emerging technologies for "smart" observational networks that are driven by stakeholder needs and can deliver intelligent adaptive sampling that is suitable for integration in traditional modeling systems, as well as systems based on Artificial Intelligence and Machine Learning. Such developments should cover the sampling of coastal hazards from extreme events and climate change, leading to solutions that are required for coastal sustainability, resilience, and adaptation.

Achieving better capabilities for understanding the interconnected GoM system and better preparations for future contingencies will require the continuous synergy of multiscale studies from the wetlands, rivers, and estuaries to the coastal, shelf, and open seas. It is important to promote such an integrated approach, in contrast to the fragmentation of disciplines that have dominated GoM science. A better coordination between research communities will reduce risks and costs of the required measurements and will advance comprehensive models that address not only environmental, but also socioeconomic and health effects (Solo-Gabriele et al. 2021). Coordination is also necessary between the scientific, management, and policy communities to make sure that scientifically informed measures and decisions are developed. The engagement of all interested stakeholders must be promoted, so that research is guided and co-designed with stakeholder needs in mind. Such an approach will greatly benefit the management of the Gulf's vast marine resources, provide tools for preparedness and response to hazards, and ensure a healthy and economically viable environment.

Acknowledgements We acknowledge the help of Christopher M. Swarzenski, who provided useful comments on an earlier version of the manuscript. The information in this paper reflects the views of the authors and does not necessarily reflect the official positions or policies of NOAA or the Department of Commerce.

Funding Much of this research was made possible by grants from the Gulf of Mexico Research Initiative (GoMRI). Other grants, too numerous to list, also contributed substantially. M. Le Hénaff received partial support by NOAA/AOML and was supported in part under the 
auspices of the Cooperative Institute for Marine and Atmospheric Studies (CIMAS), a cooperative institute of the University of Miami and NOAA (agreement NA10OAR4320143).

Data Availability Data are publicly available through the Gulf of Mexico Research Initiative Information and Data Cooperative (GRIIDC) at https://data.gulfresearchinitiative.org.

Open Access This article is licensed under a Creative Commons Attribution 4.0 International License, which permits use, sharing, adaptation, distribution and reproduction in any medium or format, as long as you give appropriate credit to the original author(s) and the source, provide a link to the Creative Commons licence, and indicate if changes were made. The images or other third party material in this article are included in the article's Creative Commons licence, unless indicated otherwise in a credit line to the material. If material is not included in the article's Creative Commons licence and your intended use is not permitted by statutory regulation or exceeds the permitted use, you will need to obtain permission directly from the copyright holder. To view a copy of this licence, visit http://creativecommons.org/licenses/by/4.0/.

\section{References}

Abascal, A.J., S. Castanedo, F.J. Mendez, R. Medina, and I.J. Losada. 2009. Calibration of a Lagrangian transport model using drifting buoys deployed during the Prestige Oil Spill. Journal of Coastal Research 25: 80-90. https://doi.org/10.2112/07-0849.1.

Abascal, A.J., S. Castanedo, R. Minguez, R. Medina, Y. Liu, and R.H. Weisberg. 2015. Stochastic Lagrangian trajectory modeling of surface drifters deployed during the Deepwater Horizon oil spill, in Proc. 38th AMOP Tech. Seminar Env. Contamination \& Response, Env. \& Climate Change Canada, Ottawa, ON, PP. 71-99.

Able, K.W., P.C. López-Duarte, F.J. Fodrie, O.P. Jensen, C.W. Martin, B.J. Roberts, et al. 2015. Fish assemblages in Louisiana salt marshes: Effects of the Macondo Oil Spill. Estuaries and Coasts 38 (5): 1385-1398. https://doi.org/10.1007/ s12237-014-9890-6.

Adcroft, A., R. Hallberg, J.P. Dunne, B.L. Samuels, J.A. Galt, C.H. Barker, et al. 2010. Simulations of underwater plumes of dissolved oil in the Gulf of Mexico. Geophysical Research Letters 37 (18). https://doi.org/10.1029/2010gl044689.

Ainsworth, C.H., C.B. Paris, N. Perlin, L.N. Dornberger, W.F. Patterson 3rd., E. Chancellor, et al. 2018. Impacts of the Deepwater Horizon oil spill evaluated using an end-to-end ecosystem model. PLOS ONE 13 (1): e0190840. https://doi. org/10.1371/journal.pone.0190840.

Ainsworth, C.H., E.P. Chassignet, D. French-McCay, C.J. Beegle-Krause, I. Berenshtein, J. Englehardt, et al. 2021. Ten years of modeling the Deepwater Horizon oil spill. Environmental Modeling and Software 142: 105070. https://doi.org/10.1016/j.envsoft.2021.105070.

Allison, M.A., C.R. Demas, B.A. Ebersole, B.A. Kleiss, C.D. Little, E.A. Meselhe, et al. 2012. A water and sediment budget for the lower Mississippi-Atchafalaya River in flood years 2008-2010: Implications for sediment discharge to the oceans and coastal restoration in Louisiana. Journal of Hydrology 432-433: 84-97. https://doi.org/10.1016/j.jhydrol.2012.02.020.

Anderson, J.B., D.J. Wallace, A.R. Simms, A.B. Rodriguez, and K.T. Milliken. 2014. Variable response of coastal environments of the northwestern Gulf of Mexico to sea-level rise and climate change: Implications for future change. Marine Geology 352: 348-366. https://doi.org/10.1016/j.margeo.2013.12.008.
Androulidakis, Y.S., and V.H. Kourafalou. 2013. On the processes that influence the transport and fate of Mississippi waters under flooding outflow conditions. Ocean Dynamics 63 (2-3): 143-164. https://doi.org/10.1007/s10236-012-0587-8.

Androulidakis, Y.S., V.H. Kourafalou, and M. Le Hénaff. 2014. Influence of frontal cyclone evolution on the 2009 (Ekman) and 2010 (Franklin) Loop Current eddy detachment events. Ocean Science 10 (6): 947-965. https://doi.org/10.5194/os-10-947-2014.

Androulidakis, Y.S., V.H. Kourafalou, and R.V. Schiller. 2015. Process studies on the evolution of the Mississippi River plume: Impact of topography, wind and discharge conditions. Continental Shelf Research 107: 33-49. https://doi.org/10.1016/j.csr.2015.07.014.

Androulidakis, Y., V.H. Kourafalou, T. Özgökmen, O. Garcia-Pineda, B. Lund, M. Le Hénaff, et al. 2018. Influence of river-induced fronts on hydrocarbon transport: A multiplatform observational study. Journal of Geophysical Research: Oceans 123 (5): 3259 3285. https://doi.org/10.1029/2017jc013514.

Androulidakis, Y., V.H. Kourafalou, M. Le Hénaff, H. Kang, T. Sutton, S. Chen, et al. 2019. Offshore spreading of Mississippi waters: Pathways and vertical structure under eddy influence. Journal of Geophysical Research: Oceans 124 (8): 5952-5978. https://doi. org/10.1029/2018JC014661.

Androulidakis, Y., V.H. Kourafalou, M. Le Hénaff, H. Kang, N. Ntaganou, and C. Hu. 2020a. Gulf Stream evolution through the Straits of Florida: The role of eddies and upwelling near Cuba. Ocean Dynamics 70: 1005-1032. https://doi.org/10.1007/s10236-020-01381-5.

Androulidakis, Y.S., V.H. Kourafalou, L. Hole, M. Le Hénaff, and H. Kang. 2020b. Pathways of oil spills from potential Cuban offshore exploration: Influence of ocean circulation. Journal of Marine Science and Engineering 8: 535. https://doi.org/10.3390/ jmse8070535.

Bam, W., L.M. Hooper-Bui, R.M. Strecker, P.L. Adhikari, and E.B. Overton. 2018. Coupled effects of oil spill and hurricane on saltmarsh terrestrial arthropods. PLOS ONE 13 (4): e0194941. https://doi.org/10.1371/journal.pone.0194941.

Bargu, S., D. Justić, J.R. White, R. Lane, J. Day, H. Paerl, et al. 2019. Mississippi River diversions and phytoplankton dynamics in deltaic Gulf of Mexico estuaries: A review. Estuarine, Coastal and Shelf Science 221: 39-52. https://doi.org/10.1016/j.ecss.2019. 02.020 .

Barkan, R., J.C. McWilliams, A.F. Shchepetkin, M.J. Molemaker, L. Renault, A. Bracco, et al. 2017a. Submesoscale dynamics in the northern Gulf of Mexico. Part I: Regional and seasonal characterization and the role of river outflow. Journal of Physical Oceanography 47 (9): 2325-2346. https://doi.org/10.1175/ jpo-d-17-0035.1.

Barkan, R., J.C. McWilliams, M.J. Molemaker, J. Choi, K. Srinivasan, A.F. Shchepetkin, et al. 2017b. Submesoscale dynamics in the northern Gulf of Mexico. Part II: Temperature-salinity relations and cross-shelf transport processes. Journal of Physical Oceanography 47 (9): 2347-2360. https://doi.org/10.1175/jpo-d-17-0040.1.

Barkan, R., M.J. Molemaker, K. Srinivasan, J.C. McWilliams, and E.A. D'Asaro. 2019. The role of horizontal divergence in submesoscale frontogenesis. Journal of Physical Oceanography 49 (6): 1593-1618. https://doi.org/10.1175/jpo-d-18-0162.1.

Barker, C.H. (2011) A statistical outlook for the Deepwater Horizon oil spill. Geophysical monograph 195: 237-244. https://doi.org/ 10.1029/2011GM001129.

Barth, A., A. Alvera-Azcárate, and R.H. Weisberg. 2008. Assimilation of high-frequency radar currents in a nested model of the West Florida Shelf. Journal of Geophysical Research 113 (C8). https:// doi.org/10.1029/2007jc004585.

Beland, M., T.W. Biggs, D.A. Roberts, S.H. Peterson, R.F. Kokaly, and S. Piazza. 2017. Oiling accelerates loss of salt marshes, southeastern Louisiana. PLOS ONE 12 (8): e0181197. https://doi.org/ 10.1371/journal.pone.0181197. 
Berenshtein, I., C.B. Paris, N. Perlin, M.M. Alloy, S.B. Joye, and S. Murawski. 2020. Invisible oil beyond the Deepwater Horizon satellite footprint. Science Advances 6 (7): EAAW 8863. https:// doi.org/10.1126/sciadv.aaw8863.

Blum, M.D., and H.H. Roberts. 2009. Drowning of the Mississippi Delta due to insufficient sediment supply and global sea-level rise. Nature Geoscience 2 (7): 488-491. https://doi.org/10.1038/ ngeo553.

Boffetta, P., H.-O. Adami, C. Berry, and J.S. Mandel. 2013. Atrazine and cancer: a review of the epidemiologic evidence. European Journal of Cancer Prevention 22 (2).

Botsford, L.W., J.W. White, M.A. Coffroth, C.B. Paris, S. Planes, T.L. Shearer, et al. 2009. Connectivity and resilience of coral reef metapopulations in marine protected areas: Matching empirical efforts to predictive needs. Coral Reefs 28 (2): 327-337. https:// doi.org/10.1007/s00338-009-0466-z.

Bracco, A., G. Liu, and D. Sun. 2019a. Mesoscale-submesoscale interactions in the Gulf of Mexico: From oil dispersion to climate. Chaos, Solitons \& Fractals 119: 63-72. https://doi.org/10.1016/j. chaos.2018.12.012

Bracco, A., G. Liu, M.P. Galaska, A.M. Quattrini, and S. Herrera. 2019b. Integrating physical circulation models and genetic approaches to investigate population connectivity in deep-sea corals. Journal of Marine Systems 198: 103189. https://doi.org/ 10.1016/j.jmarsys.2019.103189.

Bracco, A., C.B. Paris, A.J. Esbaugh, K. Frasier, S.B. Joye, G. Liu, et al. 2020. Transport, fate and impacts of the deep plume of petroleum hydrocarbons formed during the Macondo Blowout. Frontiers in Marine Science 7: 542147. https://doi.org/10.3389/ fmars.2020.542147.

Brokaw, R.J., B. Subrahmanyam, and S.L. Morey. 2019. Loop Current and eddy-driven salinity variability in the Gulf of Mexico. Geophysical Research Letters 46 (11): 5978-5986. https://doi. org/10.1029/2019GL082931.

Broström, G., K.H. Christensen, M. Drivdal, and J.E.H. Weber. 2014. Note on Coriolis-Stokes force and energy. Ocean Dynamics 64 (7): 1039-1045. https://doi.org/10.1007/s10236-014-0723-8.

Byrne, D., M. Munnich, I. Frenger, and N. Gruber. 2016. Mesoscale atmosphere ocean coupling enhances the transfer of wind energy into the ocean. Nature Communications 7: ncomms11867. https://doi.org/10.1038/ncomms11867.

Cai, W.-J., X. Hu, W.-J. Huang, M.C. Murrell, J.C. Lehrter, S.E. Lohrenz, et al. 2011. Acidification of subsurface coastal waters enhanced by eutrophication. Nature Geoscience 4 (11): 766770. https://doi.org/10.1038/ngeo1297.

Camilli, R., C.M. Reddy, D.R. Yoerger, B.A.S. Van Mooy, M.V. Jakuba, J.C. Kinsey, C.P. McIntyre, S.P. Sylva, and J.V. Maloney. 2010. Tracking hydrocarbon plume transport and biodegradation at deepwater horizon. Science 330: 201-204. https://doi.org/10.1126/science.1195223.

Cardona, Y., and A. Bracco. 2016. Predictability of mesoscale circulation throughout the water column in the Gulf of Mexico. Deep Sea Research Part II: Topical Studies in Oceanography 129: 332-349. https://doi.org/10.1016/j.dsr2.2014.01.008.

Cardona, Y., D.V. Ruiz-Ramos, I.B. Baums, and A. Bracco. 2016. Potential connectivity of coldwater black coral communities in the northern Gulf of Mexico. PLoS ONE 11 (5): e0156257. https://doi.org/10.1371/journal.pone.0156257.

Carrier, M.J., H. Ngodock, S. Smith, G. Jacobs, P. Muscarella, T. Ozgokmen, et al. 2014. Impact of assimilating ocean velocity observations inferred from Lagrangian drifter data using the NCOM-4DVAR. Monthly Weather Review 142 (4): 1509-1524. https://doi.org/10.1175/mwr-d-13-00236.1.

Chassignet, E., H. Hurlburt, E.J. Metzger, O. Smedstad, J. Cummings, G. Halliwell, et al. 2009. US GODAE: Global ocean prediction with the HYbrid Coordinate Ocean Model (HYCOM).
Oceanography 22 (2): 64-75. https://doi.org/10.5670/ oceanog.2009.39.

Chatry, M., J. Dugas, and K.A. Easley. 1983. Optimum salinity regime for oyster production on Louisiana's state seed grounds. Contributions in Marine Science 26: 81-94.

Chen, C.S., H. Liu, and R.C. Breadsley. 2003. An unstructured, finitevolume, three-dimensional, primitive equation ocean model: Application to coastal ocean and estuaries. Journal of Atmospheric and Oceanic Technology 20: 159-186. https://doi.org/ 10.1175/1520-0426(2003)020\%3c0159:AUGFVT\%3e2.0.CO;2.

Chen, S., and C. Hu. 2017. Estimating sea surface salinity in the northern Gulf of Mexico from satellite ocean color measurements. Remote Sensing of Environment 201: 115-132. https://doi.org/ 10.1016/j.rse.2017.09.004.

Chen, Y. 2017. Fish resources of the Gulf of Mexico. In Habitats and Biota of the Gulf of Mexico: Before the Deepwater Horizon Oil Spill, ed. C.H. Ward, 869-1038. New York: Springer.

Chen, J., R. Weisberg, Y. Liu, and L. Zheng. 2018. The Tampa Bay coastal ocean model performance for Hurricane Irma. Marine Technology Society Journal 52. https://doi.org/10.4031/MTSJ. 52.3.6.

Choi, J., A. Bracco, R. Barkan, A.F. Shchepetkin, J.C. McWilliams, and J.M. Molemaker. 2017. Submesoscale dynamics in the northern Gulf of Mexico. Part III: Lagrangian implications. Journal of Physical Oceanography 47 (9): 2361-2376. https://doi.org/10. 1175/jpo-d-17-0036.1.

Chuang, W.-S., and W.J. Wiseman Jr. 1983. Coastal sea level response to frontal passages on the Louisiana-Texas shelf. Journal of Geophysical Research: Oceans 88 (C4): 2615-2620. https://doi.org/ 10.1029/JC088iC04p02615.

Clark, G.M., D.A. Goolsby, and W.A. Battaglin. 1999. Seasonal and annual load of herbicides from the Mississippi River Basin to the Gulf of Mexico. Environmental Science \& Technology 33 (7): 981-986. https://doi.org/10.1021/es980962u.

Coelho, E.F., P. Hogan, G. Jacobs, P. Thoppil, H.S. Huntley, B.K. Haus, et al. 2015. Ocean current estimation using a Multi-Model Ensemble Kalman Filter during the Grand Lagrangian Deployment experiment (GLAD). Ocean Modelling 87: 86-106. https:// doi.org/10.1016/j.ocemod.2014.11.001.

Coogan, J., B. Dzwonkowski, and J. Lehrter. 2019. Effects of coastal upwelling and downwelling on hydrographic variability and dissolved oxygen in Mobile Bay. Journal of Geophysical Research: Oceans 124 (2): 791-806. https://doi.org/10.1029/2018JC014592.

Cowen, R.K., and S. Sponaugle. 2009. Larval dispersal and marine population connectivity. Annual Review of Marine Science 1: 443-466. https://doi.org/10.1146/annurev.marine.010908. 163757.

CPRA (Coastal Protection and Restoration Authority). 2012. Louisiana's comprehensive master plan for a sustainable coast. http://coastal. la.gov/our-plan/2012-coastal-masterplan/. Accessed 30 June 2021.

CPRA (Coastal Protection and Restoration Authority). 2017. Louisiana's comprehensive master plan for a sustainable coast. http://coastal.la. gov/our-plan/2017-coastal-master-plan/. Accessed 30 June 2021.

Crowder, L., and E. Norse. 2008. Essential ecological insights for marine ecosystem-based management and marine spatial planning. Marine Policy 32 (5): 772-778. https://doi.org/10.1016/j. marpol.2008.03.012.

Cui, L. 2018. Tidal-, wind-, and buoyancy-driven dynamics in the Barataria Estuary and its impact on estuarine-shelf exchange processes. Ph.D. Dissertation, Louisiana State University, 165pp.

Cui, L., H. Huang, C. Li, and D. Justić. 2018. Lateral circulation in a partially stratified tidal inlet. Journal of Marine Science and Engineering 6 (4): 159. https://doi.org/10.3390/jmse6040159.

Curcic, M., S.S. Chen, and T.M. Özgökmen. 2016. Hurricane-induced ocean waves and stokes drift and their impacts on surface 
transport and dispersion in the Gulf of Mexico. Geophysical Research Letters 43 (6): 2773-2781. https://doi.org/10.1002/ $2015 \mathrm{~g} 1067619$.

Dagestad, K.-F., J. Röhrs, Ø. Breivik, and B. Ådlandsvik. 2018. OpenDrift v1.0: a generic framework for trajectory modelling. Geoscientific Model Development 11 (4): 1405-1420.

D'Asaro, E.A., A.Y. Shcherbina, J.M. Klymak, J. Molemaker, G. Novelli, C.M. Guigand, et al. 2018. Ocean convergence and the dispersion of flotsam. Proceedings of the National Academy of Sciences of the United States of America 115 (6): 1162-1167. https://doi.org/10.1073/pnas.1718453115.

D’Asaro, E., D.F. Carlson, M. Chamecki, R.R. Hacourt, B.K. Haus, B. Fox-Kemper, et al. 2020. Advances in observing and understanding small-scale open ocean circulation during the Gulf of Mexico Research Initiative Era. Frontiers. https://doi.org/10.3389/fmars. 2020.00349.

Danovaro, R., L. Carugati, M. Berzano, A.E. Cahill, S. Carvalho, A. Chenuil, et al. 2016. Implementing and innovating marine monitoring approaches for assessing marine environmental status. Frontiers in Marine Science 3. https://doi.org/10.3389/fmars. 2016.00213.

Das, A., D. Justić, and E. Swenson. 2010. Modeling estuarine-shelf exchanges in a deltaic estuary: Implications for coastal carbon budgets and hypoxia. Ecological Modelling 221 (7): 978-985. https://doi.org/10.1016/j.ecolmodel.2009.01.023.

Das, A., D. Justić, E. Swenson, R. E. Turner, M. Inoue, and D. Park. 2011. Coastal land loss and hypoxia: the 'outwelling' hypothesis revisited. Environmental Research Letters 6 (2). https://doi.org/ 10.1088/1748-9326/6/2/025001.

Das, A., D. Justić, M. Inoue, A. Hoda, H. Huang, and D. Park. 2012. Impacts of Mississippi River diversions on salinity gradients in a deltaic Louisiana estuary: Ecological and management implications. Estuarine, Coastal and Shelf Science 111: 17-26. https:// doi.org/10.1016/j.ecss.2012.06.005.

Day, J.W., Jr., and P.H. Templet. 1989. Consequences of sea level rise: Implications from the Mississippi Delta. Coastal Management 17: 241-257. https://doi.org/10.1080/08920758909362088.

Day, J.W., Jr., J.F. Martin, L. Cardoch, and P.H. Templet. 1997. System functioning as a basis for sustainable management of deltaic ecosystems. Coastal Management 25 (2): 115-153. https://doi. org/10.1080/08920759709362315.

Deegan, L.A., D.S. Johnson, R.S. Warren, B.J. Peterson, J.W. Fleeger, S. Fagherazzi, et al. 2012. Coastal eutrophication as a driver of salt marsh loss. Nature 490 (7420): 388-392. https://doi.org/10. 1038/nature11533.

Defne, Z., N.K. Ganju, and J.M. Moriarty. 2019. Hydrodynamic and morphologic response of a back-barrier estuary to an extratropical storm. Journal of Geophysical Research: Oceans 124 (11): 7700-7717. https://doi.org/10.1029/2019JC015238.

DeLuca, B. G. 2014. USACE perspective on Mississippi River sediment diversions. Presentation to the Water Institute of the Gulf on behalf of the USACE Mississippi Valley Division, Mississippi River Commission on January 2014. http://thewaterinstitute.cdn. zcomm.com/userfiles/file/DeLuca_USACE.pdf. Accessed 30 June 2021.

Devi, G.K., B.P. Ganasri, and G.S. Dwarakish. 2015. Applications of remote sensing in satellite oceanography: A review. Aquatic Procedia 4: 579-584. https://doi.org/10.1016/j.aqpro.2015.02.075.

Dietrich, J.C., C.J. Trahan, M.T. Howard, J.G. Fleming, R.J. Weaver, S. Tanaka, et al. 2012. Surface trajectories of oil transport along the Northern Coastline of the Gulf of Mexico. Continental Shelf Research 41: 17-47. https://doi.org/10.1016/j.csr.2012.03.015.

Dixon, T.H., F. Amelung, A. Ferretti, F. Novali, F. Rocca, R. Dokka, et al. 2006. Space geodesy: Subsidence and flooding in New Orleans. Nature 441 (7093): 587-588. https://doi.org/10.1038/ 441587a.
Drouin, K.L., A.J. Mariano, E.H. Ryan, and L.C. Laurindo. 2019. Lagrangian simulation of oil trajectories in the Florida Straits. Marine Pollution Bulletin 140: 204-218. https://doi.org/10. 1016/j.marpolbul.2019.01.031.

Dukhovskoy, D.S., R.R. Leben, E.P. Chassignet, C.A. Hall, S.L. Morey, and R. Nedbor-Gross. 2015. Characterization of the uncertainty of loop current metrics using a multidecadal numerical simulation and altimeter observation. Deep-Sea Research I 100: 140158. https://doi.org/10.1016/j.dsr.2015.01.005.

Dukhovskoy, D.S., S.L. Morey, E.P. Chassignet, X. Chen, V.J. Coles, L. Cui, et al. 2021. Development of the CSOMIO Coupled OceanOil-Sediment- Biology Model. Frontiers in Marine Science 8: 194. https://doi.org/10.3389/fmars.2021.629299.

Dzwonkowski, B., K. Park, and R. Collini. 2015. The coupled estuarineshelf response of a river-dominated system during the transition from low to high discharge. Journal of Geophysical Research: Oceans 120: 6145-6163. https://doi.org/10.1002/2015JC010714.

Eisemann, E.R., D.J. Wallace, M.C. Buijsman, and T. Pierce. 2018. Response of a vulnerable barrier island to multi-year storm impacts: LiDAR-data-inferred morphodynamic changes on Ship Island, Mississippi, USA. Geomorphology (amst) 313: 58-71. https://doi.org/10.1016/j.geomorph.2018.04.001.

Epifanio, C.E., and R.W. Garvine. 2001. Larval transport on the Atlantic continental shelf of North America: A review. Estuarine, Coastal and Shelf Science 52: 51-77. https://doi.org/10.1006/ ecss.2000.0727.

Faillettaz, R., C.B. Paris, and J.-O. Irisson. 2018. Larval fish swimming behavior alters dispersal patterns from marine protected areas in the north-western Mediterranean Sea. Frontiers in Marine Science 5. https://doi.org/10.3389/fmars.2018.00097.

Feng, Z., and C. Li. 2010. Cold-front-induced flushing of the Louisiana Bays. Journal of Marine Systems 82 (4): 252-264. https://doi. org/10.1016/j.jmarsys.2010.05.015.

Fitzhugh, G., C. Koenig, F. Coleman, C. Grimes, and W. Sturges. 2005. Spatial and temporal patterns in fertilization and settlement of young gag (Mycteroperca microlepis) along the West Florida Shelf. Bulletin of Marine Science 77: 377-396.

Fodrie, F.J., and K.L. Heck Jr. 2011. Response of coastal fishes to the Gulf of Mexico oil disaster. PLoS ONE 6 (7): e21609. https://doi. org/10.1371/journal.pone.0021609.

Fogarty, M.J., and L.W. Botsford. 2007. Population connectivity and spatial management of marine fisheries. Oceanography 20: $112-123$.

Fogarty, M.J., and L. O'Brien. 2016. Recruitment in marine fish populations. In Fish Reproductive Biology: Implications for Assessment and Management, 2nd ed., ed. T. Jakobsen, M.J. Fogarty, B.A. Megrey, and E. Moksness, 9-49. Chichester: Wiley-Blackwell.

Foy, G. 1990. Oil and gas activity and Louisiana wetland loss. Journal of Environmental Management 31 (3): 289-297. https://doi.org/ 10.1016/S0301-4797(05)80042-8.

Fraser, K.C., K.T.A. Davies, C.M. Davy, A.T. Ford, D.T.T. Flockhart, and E.G. Martins. 2018. Tracking the conservation promise of movement ecology. Frontiers in Ecology and Evolution 6. https:// doi.org/10.3389/fevo.2018.00150.

Gabric, A.J., and J. Parslow. 1994. Factors affecting larval dispersion in the central Great Barrier Reef. In The Bio-Physics of Marine Larval Dispersal, ed. Sammarco, P.W., and M.L. Heron, 149-156. Washington, DC.: American Geophysical Union.

Gagliano, S.M., P. Light, and R.E., Becker. 1971. Controlled diversions in the Mississippi Delta System: an approach to environmental management. Coastal Resources Unit, Center for Wetland Resources, Louisiana State University, Baton Rouge, LA. Hydrologic and Geologic Studies of Coastal Louisiana Report No. 8.

Gallego, A., E.W. North, and P. Petitgas. 2007. Introduction: Status and future of modelling physical-biological interactions during 
the early life of fishes. Marine Ecology Progress Series 347: 121-126. https://doi.org/10.3354/meps06972.

Garcia-Pineda, O., Y. Androulidakis, M. Le Hénaff, V. Kourafalou, L.R. Hole, H. Kang, et al. 2020. Measuring oil residence time with GPS-drifters, satellites, and Unmanned Aerial Systems (UAS). Marine Pollution Bulletin 150: 110644.

Goolsby, D.A., W.A. Battaglin, G.B. Lawrence, R.S. Artz, B.T. Aulenbach, R.P. Hooper, et al. 1999. Flux and sources of nutrients in the Mississippi-Atchafalaya River Basin, Topic 3 Report for the integrated assessment on hypoxia in the Gulf of Mexico. NOAA Coastal Ocean Program Decision Analysis Series No. 17.

Gough, M.K., F.J. Beron-Vera, M.J. Olascoaga, J. Sheinbaum, J. Jouanno, and R. Duran. 2019. Persistent Lagrangian transport patterns in the northwestern Gulf of Mexico. Journal of Physical Oceanography 49 (2): 353-367. https://doi.org/10.1175/ jpo-d-17-0207.1.

Griffa, A., 1996. Applications of stochastic particle models to oceanographic problems. In Stochastic Modelling in Physical Oceanography. Progress in Probability, vol. 39, ed Adler, R.J., P. Müller, and B. L. Rozovskii, 113-140. Boston: Birkhäuser.

Hamilton, P., and T.N. Lee. 2005. Eddies and jets over the slope of the northeast Gulf of Mexico. Circulation in the Gulf of Mexico: Observations and Models 161: 123-142. https://doi.org/10.1029/ $161 \mathrm{GM} 010$

Hawkins, S.J., A.L. Allcock, A.E. Bates, L.B. Firth, I.P. Smith, S.E. Swearer, and P.A. Todd. 2019. A review of biophysical models of marine larval dispersal. Annual Reviews of Oceanography and Marine Biology 57: 325-356.

Hays, G.C., L.C. Ferreira, A.M.M. Sequeira, M.G. Meekan, C.M. Duarte, H. Bailey, et al. 2016. Key questions in marine megafauna movement ecology. Trends in Ecology \& Evolution 31 (6): 463-475. https://doi.org/10.1016/j.tree.2016.02.015.

Haza, A.C., T.M. Özgökmen, and P. Hogan. 2016. Impact of submesoscales on surface material distribution in a gulf of Mexico mesoscale eddy. Ocean Modelling 107: 28-47. https://doi.org/ 10.1016/j.ocemod.2016.10.002.

He, R., and R.B. Weisberg. 2003. A Loop Current intrusion case study on the West Florida Shelf. Journal of Physical Oceanography 33 (2): 465-477. https://doi.org/10.1175/1520-0485(2003)033\% 3C0465:ALCICS\%3E2.0.CO;2.

He, R., Y. Liu, and R.H. Weisberg. 2004. Coastal ocean wind fields gauged against the performance of an ocean circulation model. Geophysical Research Letters 31 (14). https://doi.org/10.1029/ $2003 \mathrm{~g} 1019261$.

He, S., and Y.J. Xu. 2017. Assessing dissolved carbon transport and transformation along an estuarine river with stable isotope analyses. Estuarine, Coastal and Shelf Science 197: 93-106. https:// doi.org/10.1016/j.ecss.2017.08.024.

Hiatt, M., G. Snedden, J.W. Day, R.V. Rohli, J.A. Nyman, R. Lane, et al. 2019. Drivers and impacts of water level fluctuations in the Mississippi River delta: Implications for delta restoration. Estuarine, Coastal and Shelf Science 224: 117-137. https://doi.org/10.1016/j. ecss.2019.04.020.

Hole, L.R., K.-F. Dagestad, J. Röhrs, C. Wettre, V.H. Kourafalou, Y. Androulidakis, et al. 2019. The DeepWater Horizon Oil Slick: simulations of river front effects and oil droplet size distribution. Journal of Marine Science and Engineering 7 (10). https://doi. org/10.3390/jmse7100329.

Hole, L., V. Aguiar, K.-F. Dagestad, V.H. Kourafalou, Y. Androulidakis, H. Kang, et al. 2021. Long term oil drift simulations from potential oil spills around Cuba. Marine Pollution Bulletin 167: 112285. https://doi.org/10.1016/j.marpolbul.2021.112285.

Holm, G.O., Jr., T.J. Hess Jr., D. Justić, L. McNease, R.G. Linscombe, and S.A. Nesbitt. 2003. Population recovery of the eastern brown pelican following its extirpation in Louisiana. The Wilson Bulletin 115 (4): 431-437. https://doi.org/10.1676/03-019.

Holstein, D.M., C.B. Paris, A.C. Vaz, and T.B. Smith. 2016a. Modeling vertical coral connectivity and mesophotic refugia. Coral Reefs 35 (1): 23-37. https://doi.org/10.1007/s00338-015-1339-2.

Holstein, D.M., T.B. Smith, and C.B. Paris. 2016b. Depth-independent reproduction in the reef coral porites astreoides from shallow to mesophotic Zones. PLoS ONE 11 (1): e0146068. https://doi.org/ 10.1371/journal.pone.0146068.

Hu, C. 2011. An empirical approach to derive MODIS ocean color patterns under severe sun glint. Geophysical Research Letters 38(1): n/a-n/a. https://doi.org/10.1029/2010g1045422.

Hu, C., J.R. Nelson, E. Johns, Z. Chen, R.H. Weisberg, and F.E. MüllerKarger. 2005. Mississippi River water in the Florida Straits and in the Gulf Stream off Georgia in summer 2004. Geophysical Research Letters 32 (14). https://doi.org/10.1029/2005gl022942.

Huang, H., D. Justić, R.R. Lane, J.W. Day, and J.E. Cable. 2011. Hydrodynamic response of the Breton Sound estuary to pulsed Mississippi River inputs. Estuarine, Coastal and Shelf Science 95 (1): 216-231. https://doi.org/10.1016/j.ecss.2011.08.034.

Huang, W., C. Li, J.R. White, S. Bargu, B. Milan, and S. Bentley. 2020. Numerical experiments on variation of freshwater plume and leakage effect From Mississippi River Diversion in the Lake Pontchartrain Estuary. Journal of Geophysical Research: Oceans 125 (2): e2019JC015282. https://doi.org/10.1029/2019JC015282.

Huang, H., L. Cui, D. Justić, K.A. Rose, and D. Liping. Residual circulation dynamics in the Breton Sound Estuary and BretonChandeleur Sound: With implication to the effect of river diversion on oil slick movement. Journal of Geophysical Research: Oceans (in review).

Huguenard, K.D., A. Valle-Levinson, M. Li, R.J. Chant, and A.J. Souza. 2015. Linkage between lateral circulation and nearsurface vertical mixing in a coastal plain estuary. Journal of Geophysical Research: Oceans 120 (6): 4048-4067. https://doi. org/10.1002/2014jc010679.

Huguenard, K.D., D.J. Bogucki, D.G. Ortiz-Suslow, N.J.M. Laxague, J.H. MacMahan, T.M. Özgökmen, et al. 2016. On the nature of the frontal zone of the Choctawhatchee Bay plume in the Gulf of Mexico. Journal of Geophysical Research: Oceans 121 (2): 1322-1345. https://doi.org/10.1002/2015jc010988.

Huntley, H.S., B.L. Lipphardt, G. Jacobs, and A.D. Kirwan. 2015. Clusters, deformation, and dilation: Diagnostics for material accumulation regions. Journal of Geophysical Research: Oceans 120 (10): 6622-6636. https://doi.org/10.1002/2015jc011036.

Hussey, N.E., S.T. Kessel, K. Aarestrup, S.J. Cooke, P.D. Cowley, A.T. Fisk, et al. 2015. Aquatic animal telemetry: A panoramic window into the underwater world. Science 348 (6240): 1255642. https:// doi.org/10.1126/science.1255642.

Inoue, M., D. Park, D. Justić, and W. Wiseman Jr. 2008. A highresolution integrated hydrology-hydrodynamic model of the Barataria Basin system. Environmental Modelling \& Software 23 (9): 1122-1132. https://doi.org/10.1016/j.envsoft.2008.02. 011.

Iskandarani, M., M. Le Hénaff, W.C. Thacker, A. Srinivasan, and O.M. Knio. 2016. Quantifying uncertainty in Gulf of Mexico forecasts stemming from uncertain initial conditions. Journal of Geophysical Research: Oceans 121 (7): 4819-4832. https://doi.org/10. 1002/2015jc011573.

Ivins, E.R., R.K. Dokka, and R.G. Blom. 2007. Post-glacial sediment load and subsidence in coastal Louisiana. Geophysical Research Letters 34 (16). https://doi.org/10.1029/2007gl030003.

Jacobs, G.A., B.P. Bartels, D.J. Bogucki, F.J. Beron-Vera, S.S. Chen, E.F. Coelho, et al. 2014. Data assimilation considerations for improved ocean predictability during the Gulf of Mexico Grand Lagrangian Deployment (GLAD). Ocean Modelling 83: 98-117. https://doi.org/10.1016/j.ocemod.2014.09.003. 
Johansen, Ø., M. Reed, and N.R. Bodsberg. 2015. Natural dispersion revisited. Marine Pollution Bulletin 93 (1): 20-26. https://doi. org/10.1016/j.marpolbul.2015.02.026.

Johnson, D.R., H.M. Perry, J. Lyczkowski-Shultz, and D. Hanisko. 2009. Red snapper larval transport in the northern Gulf of Mexico. Transactions of the American Fisheries Society 138 (3): 458-470. https://doi.org/10.1577/T08-008.1.

Jolliff, J.K., T.A. Smith, S. Ladner, and R.A. Arnone. 2014. Simulating surface oil transport during the Deepwater Horizon oil spill: Experiments with the BioCast system. Ocean Modelling 75: 84-99. https://doi.org/10.1016/j.ocemod.2014.01.004.

Jones, B.T., J. Gyory, E.K. Grey, M. Bartlein, D.S. Ko, R.W. Nero, et al. 2015. Transport of blue crab larvae in the northern Gulf of Mexico during the Deepwater Horizon oil spill. Marine Ecology Progress Series 527: 143-156. https://doi.org/10.3354/meps11238.

Juarez, B., A. Valle-Levinson, and C. Li. 2020. Estuarine salt-plug induced by freshwater pulses from the inner shelf. Estuarine, Coastal and Shelf Science 232. https://doi.org/10.1016/j.ecss. 2019.106491.

Justić, D., V.J. Bierman, D. Scavia, and R.D. Hetland. 2007. Forecasting Gulf's hypoxia: The next 50 years? Estuaries and Coasts 30 (5): 791-801. https://doi.org/10.1007/BF02841334.

Justić, D., and L. Wang. 2014. Assessing temporal and spatial variability of hypoxia over the inner Louisiana-upper Texas shelf: Application of an unstructured-grid three-dimensional coupled hydrodynamic-water quality model. Continental Shelf Research 72: 163-179. https://doi.org/10.1016/j.csr.2013.08.006.

Justić, D., K.A. Rose, R. Hetland, and K. Fennel. 2017. Modeling coastal hypoxia: Numerical simulations of patterns, controls and effects of dissolved oxygen dynamics. New York: Springer.

Katsanevakis, S., V. Stelzenmüller, A. South, T.K. Sørensen, P.J.S. Jones, S. Kerr, et al. 2011. Ecosystem-based marine spatial management: Review of concepts, policies, tools, and critical issues. Ocean \& Coastal Management 54 (11): 807-820. https://doi.org/10.1016/j. ocecoaman.2011.09.002

Kemp, G., J. Day, A. Yáñez-Arancibia, and N. Peyronnin. 2016. Can continental shelf river plumes in the northern and southern Gulf of Mexico promote ecological resilience in a time of climate change? Water 8(3). https://doi.org/10.3390/w8030083.

Khade, V., J. Kurian, P. Chang, I. Szunyogh, K. Thyng, and R. Montuoro. 2017. Oceanic ensemble forecasting in the Gulf of Mexico: An application to the case of the Deep Water Horizon oil spill. Ocean Modelling 113: 171-184. https://doi.org/10.1016/j.ocemod.2017. 04.004.

Kourafalou, V. H., L.-Y. Oey, J. D. Wang and T. N. Lee. 1996. The fate of river discharge on the continental shelf. Part I: modeling the river plume and the inner-shelf coastal current. Journal of Geophysical Research 101 (C2): 3415-3434. https://doi.org/10. 1029/95JC03024.

Kourafalou, V.H., G. Peng, H. Kang, P.J. Hogan, O.-M. Smedstad, and R.H. Weisberg. 2009. Evaluation of global ocean data assimilation experiment products on south Florida nested simulations with the Hybrid Coordinate Ocean Model. Ocean Dynamics 59 (1): 47-66. https://doi.org/10.1007/s10236-008-0160-7.

Kourafalou, V.H., and H. Kang. 2012. Florida Current meandering and evolution of cyclonic eddies along the Florida Keys Reef Tract: are they interconnected? Journal of Geophysical Research: Oceans 117 (C5). https://doi.org/10.1029/2011jc007383.

Kourafalou, V.H., and Y.S. Androulidakis. 2013. Influence of Mississippi River induced circulation on the Deepwater Horizon oil spill transport. Journal of Geophysical Research: Oceans 118 (8): 3823-3842. https://doi.org/10.1002/jgrc.20272.

Kourafalou, V.H., P. De Mey, M. Le Hénaff, G. Charria, C.A. Edwards, R. He, et al. 2015. Coastal Ocean Forecasting: System integration and evaluation. Journal of Operational Oceanography 8 (sup1): s127-s146. https://doi.org/10.1080/1755876x.2015.1022336.
Kourafalou, V.H., Y.S. Androulidakis, H. Kang, R.H. Smith, and A. Valle-Levinson. 2018. Physical connectivity between Pulley Ridge and Dry Tortugas coral reefs under the influence of the Loop Current/Florida Current system. Progress in Oceanography 165: 75-99. https://doi.org/10.1016/j.pocean.2018.05.004.

Kuitenbrouwer, D., A. Reniers, J. MacMahan, and M.K. Roth. 2018. Coastal protection by a small scale river plume against oil spills in the Northern Gulf of Mexico. Continental Shelf Research 163: 1-11. https://doi.org/10.1016/j.csr.2018.05.002.

Kumar, N., G. Voulgaris, J.C. Warner, and M. Olabarrieta. 2012. Implementation of the vortex force formalism in the coupled ocean-atmosphere-wave-sediment transport (COAWST) modeling system for inner shelf and surf zone applications. Ocean Modelling 47: 65-95. https://doi.org/10.1016/j.ocemod.2012. 01.003 .

Lane, R.R., and J.W. Day. 1999. Water quality analysis of a freshwater diversion at Caernarvon, Louisiana. Estuaries 22: 327-336. https://doi.org/10.2307/1352988.

Lane, R.R., J.W. Day, B.D. Marx, E. Reyes, E. Hyfield, and J.N. Day. 2007. The effects of riverine discharge on temperature, salinity, suspended sediment and chlorophyll a in a Mississippi delta estuary measured using a flow-through system. Estuarine, Coastal and Shelf Science 74 (1-2): 145-154. https://doi.org/10.1016/j. ecss.2007.04.008.

Langan, M.M., and K.D. Hoagland. 1996. Growth responses of Typha latifolia and Scirpus acutus to atrazine contamination. Bulletin of Environmental Contamination and Toxicology 57 (2): 307-314. https://doi.org/10.1007/s001289900191.

Larson, R.A., G.R. Brooks, P.T. Schwing, A.R. Diercks, C.W. Holmes, J.P. Chanton, et al. 2020. Characterization of the sedimentation associated with the Deepwater Horizon blowout: Depositional pulse, initial response, and stabilization. In Deep Oil Spills, ed. S. Murawski, et al., 235-252. Cham: Springer International Publishing.

Laurent, A., K. Fennel, W.-J. Cai, W.-J. Huang, L. Barbero, and R. Wanninkhof. 2017. Eutrophication-induced acidification of coastal waters in the northern Gulf of Mexico: Insights into origin and processes from a coupled physical-biogeochemical model. Geophysical Research Letters 44 (2): 946-956. https:// doi.org/10.1002/2016gl071881.

Laxague, N.J.M., T.M. Özgökmen, B.K. Haus, G. Novelli, A. Shcherbina, P. Sutherland, et al. 2018. Observations of near-surface current shear help describe oceanic oil and plastic transport. Geophysical Research Letters 45 (1): 245-249. https://doi.org/10.1002/2017gl075891.

Ledwell, J.R., R. He, Z. Xue, S.F. DiMarco, L.J. Spencer, and P. Chapman. 2016. Dispersion of a tracer in the deep Gulf of Mexico. Journal of Geophysical Research: Oceans 121 (2): 1110-1132. https://doi.org/ 10.1002/2015JC011405.

Le Hénaff, M., V.H. Kourafalou, Y. Morel, and A. Srinivasan. 2012a. Simulating the dynamics and intensification of cyclonic Loop Current Frontal Eddies in the Gulf of Mexico. Journal of Geophysical Research: Oceans 117 (C2). https://doi.org/10.1029/ $2011 \mathrm{jc} 007279$.

Le Hénaff, M., V.H. Kourafalou, C.B. Paris, J. Helgers, Z.M. Aman, P.J. Hogan, et al. 2012b. Surface evolution of the deepwater horizon oil spill patch: Combined effects of circulation and windinduced drift. Environmental Science \& Technology 46 (13): 7267-7273. https://doi.org/10.1021/es301570w.

Le Hénaff, M., V.H. Kourafalou, R. Dussurget, and R. Lumpkin. 2014. Cyclonic activity in the eastern Gulf of Mexico: Characterization from along-track altimetry and in situ drifter trajectories. Progress in Oceanography 120: 120-138. https://doi.org/10.1016/j. pocean.2013.08.002.

Le Hénaff, M., and V.H. Kourafalou. 2016. Mississippi waters reaching South Florida reefs under no flood conditions: Synthesis of 
observing and modeling system findings. Ocean Dynamics 66 (3): 435-459. https://doi.org/10.1007/s10236-016-0932-4.

Le Hénaff, M., F. Muller-Karger, V. Kourafalou, D. Otis, K. Johnson, L. McEachron, et al. 2019. Coral mortality event in the Flower Garden Banks of the Gulf of Mexico in July 2016: Local hypoxia due to cross-shelf transport of coastal flood waters? Continental Shelf Research 190: 103988. https://doi.org/10.1016/j.csr.2019. 103988.

Lehrter, J.C., D.S. Ko, M.C. Murrell, J.D. Hagy, B.A. Schaeffer, R.M. Greene, et al. 2013. Nutrient distributions, transports, and budgets on the inner margin of a river-dominated continental shelf. Journal of Geophysical Research: Oceans 118 (10): 4822-4838. https://doi.org/10.1002/jgrc. 20362.

Lett, C., K.A. Rose, and B.A. Megrey. 2009. Biophysical models of small pelagic fish. In Climate Change and Small Pelagic Fish, ed. D. Checkley, J. Alheit, Y. Oozeki, and C. Roy, 88-111. Cambridge: Cambridge University Press.

Li, C., J.R. White, C. Chen, H. Lin, E. Weeks, K. Galvan, et al. 2011. Summertime tidal flushing of Barataria Bay: transports of water and suspended sediments. Journal of Geophysical Research 116 (C4). https://doi.org/10.1029/2010jc006566.

Limouzy-Paris, C.B., H.C. Graber, D.L. Jones, A.W. Röpke, and W.J. Richards. 1997. Translocation of larval coral reef fishes via submesoscale spin-off eddies from the Florida Current. Bulletin of Marine Science 60 (3): 966-983.

Liu, Y., and R.H. Weisberg. 2011. Evaluation of trajectory modeling in different dynamic regions using normalized cumulative Lagrangian separation. Journal of Geophysical Research 116 (C9). https://doi.org/10.1029/2010jc006837.

Liu, Y., A. MacFadyen, Z.-G. Ji, and R.H. Weisberg. 2011a. Monitoring and modeling the Deepwater Horizon Oil Spill: A recordbreaking enterprise. Washington, D.C.: AGU/geopress.

Liu, Y., R.H. Weisberg, C. Hu, and L. Zheng. 2011b. Trajectory forecast as a rapid response to the Deepwater Horizon oil spill. Monitoring and Modeling the Deepwater Horizon Oil Spill: A Record-Breaking Enterprise 153-165. https://doi.org/10.1029/ 2011GM001121.

Liu, Y., R.H. Weisberg, C. Hu, and L. Zheng. 2011c. Tracking the Deepwater Horizon oil spill: A modeling perspective. Eos 92: 45-52. https://doi.org/10.1029/2011EO060001.

Liu, Y., R.H. Weisberg, C. Hu, C. Kovach, and R. RiethmüLler. 2011d. Evolution of the Loop Current system during the Deepwater Horizon oil spill event as observed with drifters and satellites. Monitoring and Modeling the Deepwater Horizon Oil Spill: A Record-Breaking Enterprise 91-101. https://doi.org/10.1029/ $2011 \mathrm{GM} 001127$.

Liu, Y., H. Kerkering, and R.H. Weisberg. 2015. Coastal ocean observing systems. New York: Academic Press.

Liu, Y., R.H. Weisberg, and L. Zheng. 2019. Impacts of hurricane Irma on the circulation and transport in Florida Bay and the Charlotte Harbor estuary. Estuaries and Coasts 42. https://doi.org/10.1007/ s12237-019-00647-6.

Lorenzen, K., and E.V. Camp. 2019. Density-dependence in the life history of fishes: When is a fish recruited? Fisheries Research 217: 5-10.

Lund, B., B.K. Haus, J. Horstmann, H.C. Graber, R. Carrasco, N.J. Laxague, et al. 2018. Near-surface current mapping by shipboard marine X-band radar: A validation. Journal of Atmospheric and Oceanic Technology 35 (5): 1077-1090. https://doi.org/10.1175/ JTECH-D-17-0154.1.

Lundberg, C.J., R.R. Lane, and J.W. Day Jr. 2014. Spatial and temporal variations in nutrients and water-quality parameters in the Mississippi River-influenced Breton Sound Estuary. Journal of Coastal Research 30 (2): 328-336. https://doi.org/10.2112/ JCOASTRES-D-12-00015.1.
Luo, H., A. Bracco, Y. Cardona, and J.C. McWilliams. 2016. Submesoscale circulation in the northern Gulf of Mexico: Surface processes and the impact of the freshwater river input. Ocean Modelling 101: 68-82. https://doi.org/10.1016/j.ocemod.2016. 03.003.

Lynch, S.M., J.A. Rusiecki, A. Blair, M. Dosemeci, J. Lubin, D. Sandler, et al. 2006. Cancer incidence among pesticide applicators exposed to cyanazine in the agricultural health study. Environmental Health Perspectives 114 (8): 1248-1252. https://doi. org/10.1289/ehp.8997.

Mariano, A.J., V.H. Kourafalou, A. Srinivasan, H. Kang, G.R. Halliwell, E.H. Ryan, et al. 2011. On the modeling of the 2010 Gulf of Mexico Oil Spill. Dynamics of Atmospheres and Oceans 52 (1-2): 322-340. https://doi.org/10.1016/j. dynatmoce.2011.06.001.

Mariotti, G. 2016. Revisiting salt marsh resilience to sea level rise: Are ponds responsible for permanent land loss? Journal of Geophysical Research: Earth Surface 121 (7): 1391-1407. https://doi.org/ 10.1002/2016jf003900.

Mariotti, G., H. Huang, Z. Xue, B. Li, D. Justić, and Z. Zang. 2018. Biased wind measurements in estuarine waters. Journal of Geophysical Research: Oceans 123 (5): 3577-3587. https://doi.org/ 10.1029/2017jc013748.

Mariotti, G., G. Ceccherini, M. McDonell, and D. Justić. 2021. A comprehensive assessment of sediment dynamics in the Barataria Basin (LA, USA) distinguishes riverine advection from wave resuspension and identifies the Gulf Intracoastal Waterway as a major sediment source. Estuaries and Coasts. https://doi.org/10. 1007/s12237-021-00957-8.

Marmer, H.A. 1948. The currents in Barataria Bay, report. Tex. A\&M Res. Found., College Station, Tex., 30 pp.

Marmer, H.A. 1954. Tides and sea level in the Gulf of Mexico. In Gulf of Mexico, Its Origin, Waters and Marine Life, 101-118. U.S. Fish and Wildlife Service Bulletin 55.

Marton, J.M., and B.J. Roberts. 2014. Spatial variability of phosphorus sorption dynamics in Louisiana salt marshes. Journal of Geophysical Research: Biogeosciences 119 (3): 451-465. https://doi.org/10.1002/2013jg002486.

Martin, C.W., K.A. Lewis, A.M. McDonald, T.P. Spearman, S.B. Alford, R.C. Christian, et al. 2020. Disturbance-driven changes to northern Gulf of Mexico nekton communities following the Deepwater Horizon oil spill. Mar Pollut Bull 155: 111098. https://doi.org/10.1016/j.marpolbul.2020.111098.

Mayer, D.A., R.H. Weisberg, L. Zheng, and Y. Liu. 2017. Winds on the West Florida Shelf: Regional comparisons between observations and model estimates. Journal of Geophysical Research: Oceans 122 (2): 834-846. https://doi.org/10.1002/ 2016jc012112.

McKee, K., K. Rogers, and N. Saintilan. 2012. Response of salt marsh and mangrove wetlands to changes in atmospheric $\mathrm{CO}_{2}$, climate, and sea level. In Global change and the function and distribution of wetlands, 63-96. Dordrecht: Springer.

McMillin, D.J., and J.C. Means. 1996. Spatial and temporal trends of pesticide residues in water and particulates in the Mississippi River plume and the northwestern Gulf of Mexico. Journal of Chromatography A 754 (1): 169-185. https://doi.org/10.1016/ S0021-9673(96)00325-1.

McWilliams, J.C. 2016. Submesoscale currents in the ocean. Proceedings: Mathematical, Physical and Engineering Sciences 472(2189): 20160117. https://doi.org/10.1098/rspa.2016.0117.

Meade, R.H. 1995. Contaminants in the Mississippi River, 1987-92. https://pubs.usgs.gov/circ/circ1133/index.html. Accessed 30 June 2021.

Meade, R.H. 1996. River-sediment inputs to major deltas. In Sea-Level Rise and Coastal Subsidence, ed. J. Milliman and B. Haq, 63-85. London: Kluwer. 
Mendelssohn, I.A., G.L. Andersen, D.M. Baltz, R.H. Caffey, K.R. Carman, J.W. Fleeger, et al. 2012. Oil impacts on coastal wetlands: Implications for the Mississippi River Delta ecosystem after the Deepwater Horizon oil spill. BioScience 62 (6): 562-574. https://doi.org/10. 1525/bio.2012.62.6.7.

Metaxas, A., and M. Saunders. 2009. Quantifying the "bio-" components in biophysical models of larval transport in marine benthic invertebrates: Advances and pitfalls. The Biological Bulletin 216: 257-272. https://doi.org/10.1086/BBLv216n3p257.

Michel, J., E.H. Owens, S. Zengel, A. Graham, Z. Nixon, T. Allard, et al. 2013. Extent and degree of shoreline oiling: Deepwater Horizon oil spill, Gulf of Mexico, USA. PLoS ONE 8 (6): e65087. https://doi.org/10.1371/journal.pone.0065087.

Milliman, J.D., and R.H. Meade. 1983. World-wide delivery of river sediment to the oceans. The Journal of Geology 91 (1): 1-21.

Milliman, J.D., and K. Farnsworth. 2011. River discharge to the coastal ocean - a global synthesis. Cambridge University Press. https://doi.org/10.1017/CBO9780511781247.

Miron, P., F.J. Beron-Vera, M.J. Olascoaga, J. Sheinbaum, P. PerezBrunius, and G. Froyland. 2017. Lagrangian dynamical geography of the Gulf of Mexico. Scientific Reports 7 (1): 7021. https:// doi.org/10.1038/s41598-017-07177-w.

Mitsch, W.J., J.W. Day Jr., P.M. Gilliam, D.L. Groffman, G.W. Hey, and N. Wang. 2001. Reducing nitrogen loading to the Gulf of Mexico from the Mississippi River basin: Strategies to counter a persistent ecological problem: Ecotechnology-the use of natural ecosystems to solve environmental problems-should be a part of efforts to shrink the zone of hypoxia in the Gulf of Mexico. BioScience 51: 373-388. https://doi.org/10.1641/00063568(2001)051[0373:RNLTTG]2.0.CO;2.

Mize, S.V., J.C. Murphy, T.H. Diehl, and D.K. Demcheck. 2018. Suspended-sediment concentrations and loads in the lower Mississippi and Atchafalaya rivers decreased by half between 1980 and 2015. Journal of Hydrology 564: 1-11. https://doi.org/10. 1016/j.jhydrol.2018.05.068.

Moody, R.M., J. Cebrian, and K.L. Heck Jr. 2013. Interannual recruitment dynamics for resident and transient marsh species: Evidence for a lack of impact by the Macondo oil spill. PLOS ONE 8 (3): e58376. https://doi.org/10.1371/journal.pone.0058376.

Morey, S., N. Wienders, D. Dukhovskoy, and M. Bourassa. 2018. Measurement characteristics of near-surface currents from ultrathin drifters, drogued drifters, and HF radar. Remote Sensing 10 (10). https://doi.org/10.3390/rs10101633.

Morton, R.A., T.L. Miller, and L.J. Moore. 2004, National assessment of shoreline change: Part 1: Historical shoreline changes and associated coastal land loss along the U.S. Gulf of Mexico: U.S. Geological Survey Open-file Report 2004-1043, 45p. https:// pubs.usgs.gov/of/2004/1043/ofr-2004-1043.pdf. Accessed 30 June 2021.

Morton, R.A. 2008. Historical changes in the Mississippi-Alabama barrier-island chain and the roles of extreme storms, sea level, and human activities. Journal of Coastal Research 246: 15871600. https://doi.org/10.2112/07-0953.1.

Murawski, S.A., W.T. Hogarth, E.B. Peebles, and L. Barbeiri. 2014. Prevalence of external skin lesions and polycyclic aromatic hydrocarbon concentrations in Gulf of Mexico fishes, post-Deepwater Horizon. Transactions of the American Fisheries Society 143 (4): 1084-1097. https://doi.org/10.1080/00028487.2014.911205.

Murawski, S.A., J.W. Fleeger, W.F. Patterson, C. Hu, K. Daly, I. Romero, and G.A. Toro-Farmer. 2016. How did the oil spill affect coastal and continental Deepwater Horizon shelf ecosystems of the Gulf of Mexico? Oceanography 29: 160-173. https:// doi.org/10.5670/oceanog.2016.80.

Murawski, S.A., E.B. Peebles, A. Gracia, J.W. Tunnell, and M. Armenteros. 2018. Comparative abundance, species composition, and demographics of continental shelf fish assemblages throughout the Gulf of Mexico. Marine and Coastal Fisheries 10 (3): 325-346. https://doi.org/10.1002/mcf2.10033.

Murawski, S.A., J.P. Kilborn, D. Chagaris, D. Donaldson, F. Hernandez, T. MacDonald, et al. 2020. A synthesis of Deepwater Horizon impacts on coastal and nearshore living marine resources. Frontiers in Marine Science 7: 1212. https://doi.org/10.3389/fmars. 2020.594862.

Murphy, P.L., and A. Valle-Levinson. 2008. Tidal and residual circulation in the St. Andrew Bay system, Florida. Continental Shelf Research 28(19): 2678-2688. https://doi.org/10.1016/j.csr.2008. 09.003.

Murphy, P.L., A.F. Waterhouse, T.J. Hesser, A.M. Penko, and A. ValleLevinson. 2009. Subtidal flow and its variability at the entrance to a subtropical lagoon. Continental Shelf Research 29 (20): 2318-2332. https://doi.org/10.1016/j.csr.2009.09.011.

Nathan, R., W.M. Getz, E. Revilla, M. Holyoak, R. Kadmon, D. Saltz, and P.E. Smouse. 2008. A movement ecology paradigm for unifying organismal movement research. Proceedings of the National Academy of Sciences of the United States of America 105: 19052-19059. https://doi.org/10.1073/pnas.0800375105.

Nixon, S.W. 1980. Between coastal marshes and coastal waters-a review of twenty years of speculation and research on the role of salt marshes in estuarine productivity and water chemistry. In Estuarine and Wetlands Processes with Emphasis on Modeling, ed. P. Hamilton and K.B. Macdonald, 437-525. New York: Plenum Press.

Nixon, Z., S. Zengel, M. Baker, M. Steinhoff, G. Fricano, S. Rouhani, et al. 2016. Shoreline oiling from the Deepwater Horizon oil spill. Marine Pollution Bulletin 107 (1): 170-178. https://doi. org/10.1016/j.marpolbul.2016.04.003.

North, E.W., E.E. Adams, A.E. Thessen, Z. Schlag, R. He, S.A. Socolofsky, et al. 2015. The influence of droplet size and biodegradation on the transport of subsurface oil droplets during the Deepwater Horizon spill: a model sensitivity study. Environmental Research Letters 10 (2). https://doi.org/10.1088/1748-9326/ 10/2/024016.

Novelli, G., C.M. Guigand, C. Cousin, E.H. Ryan, N.J. Laxague, H. Dai, et al. 2017. A biodegradable surface drifter for ocean sampling on a massive scale. Journal of Atmospheric and Oceanic Technology 34 (11): 2509-2532. https://doi.org/10.1175/ JTECH-D-17-0055.1.

Odum, W.E., J.S. Fisher, and J.C. Pickral. 1979. Factors controlling the flux of particulate organic carbon from estuarine wetlands. In Ecological processes in coastal and marine systems, ed. R.J. Livingston, 69-80. New York: Plenum Press.

Olabarrieta, M., A. Valle-Levinson, C.J. Martinez, C. Pattiaratchi, and L. Shi. 2017. Meteotsunamis in the northeastern Gulf of Mexico and their possible link to El Niño Southern Oscillation. Natural Hazards 88 (3): 1325-1346. https://doi.org/10.1007/ s11069-017-2922-3.

Olson, D.B., and C.B. Paris. 2019. Lagrangian biological models. In Encyclopedia of Ocean Sciences, 2nd ed., ed. J.H. Steele, K.K. Turekian, and S.A. Thorpe, 513-519. Cambridge: Academic Press.

Ortner, P.B., T.N. Lee, P.J. Milne, R.G. Zika, M.E. Clarke, G.P. Podesta, et al. 1995. Mississippi River flood waters that reached the Gulf Stream. Journal of Geophysical Research: Oceans 100 (C7): 13595-13601. https://doi.org/10.1029/95JC01039.

Pan, C., L. Zheng, R. Weisberg, Y. Liu, and C. Lembke. 2014. Comparisons of different ensemble schemes for glider data assimilation on West Florida Shelf. Ocean Modelling 81. https://doi.org/ 10.1016/j.ocemod.2014.06.005.

Paris, C.B., and R.K. Cowen. 2004. Direct evidence of a biophysical retention mechanism for coral reef fish larvae. Limnology and 
Oceanography 49: 1964-1979. https://doi.org/10.4319/lo.2004. 49.6.1964.

Paris, C.B., M. Le Hénaff, Z.M. Aman, A. Subramaniam, J. Helgers, D.-P. Wang, et al. 2012. Evolution of the Macondo Well Blowout: Simulating the effects of the circulation and synthetic dispersants on the subsea oil transport. Environmental Science \& Technology 46 (24): 13293-13302. https://doi.org/10.1021/es303197h.

Paris, C.B., J. Helgers, E. van Sebille, and A. Srinivasan. 2013. Connectivity modeling system: A probabilistic modeling tool for the multi-scale tracking of biotic and abiotic variability in the ocean. Environmental Modelling \& Software 42: 47-54. https://doi.org/ 10.1016/j.envsoft.2012.12.006.

Paris, C.B., S.A. Murawski, M.J. Olascoaga, A.C. Vaz, I. Berenshtein, P. Miron, et al. 2020. Connectivity of the Gulf of Mexico continental shelf fish populations and implications of simulated oil spills. In Scenarios and Responses to Future Deep Oil Spills: Fighting the Next War, ed. S.A. Murawski, C.H. Ainsworth, S. Gilbert, D.J. Hollander, C.B. Paris, M. Schlüter, and D.L. Wetzel, 369-389. Cham: Springer International Publishing.

Payandeh, A.R., D. Justić, G. Mariotti, H. Huang, and S. Sorourian. 2019. Subtidal water level and current variability in a bar-built estuary during cold front season: Barataria Bay, Gulf of Mexico. Journal of Geophysical Research: Oceans 124 (10): 7226-7246. https://doi.org/10.1029/2019JC015081.

Payandeh, A. R., D. Justić, G. Mariotti, H. Huang, K. Valentine, and N. D. Walker. 2021. Suspended sediment dynamics in a deltaic estuary controlled by subtidal motion and offshore river plumes. Estuarine, Coastal and Shelf Science 250. https://doi.org/10. 1016/j.ecss.2020.107137.

Pearson, J., B. Fox-Kemper, R. Barkan, J. Choi, A. Bracco, and J.C. McWilliams. 2019. Impacts of convergence on structure functions from surface drifters in the Gulf of Mexico. Journal of Physical Oceanography 49 (3): 675-690. https://doi.org/10. 1175/jpo-d-18-0029.1.

Perez, B.C., J.W. Day, L.J. Rouse, R.F. Shaw, and M. Wang. 2000. Influence of Atchafalaya River discharge and winter frontal passage on suspended sediment concentration and flux in Fourleague Bay, Louisiana. Estuarine, Coastal and Shelf Science 50 (2): 271-290. https://doi.org/10.1006/ecss.1999.0564.

Perez-Umphrey, A.A., C.M. Bergeon Burns, P.C. Stouffer, S. Woltmann, and S.S. Taylor. 2018. Polycyclic aromatic hydrocarbon exposure in seaside sparrows (Ammodramus maritimus) following the 2010 Deepwater Horizon oil spill. Science of the Total Environment 630: 1086-1094. https://doi.org/10.1016/j.scitotenv.2018.02.281.

Perlin, N., C. B. Paris, I. Berenshtein, A. C. Vaz, R. Faillettaz, Z. M. Aman, et al. 2019. Far-field modeling of deep-sea blowout: sensitivity studies of initial conditions, biodegradation, sedimentation and SSDI on surface slicks and oil plume concentrations. In Deep Oil Spills: Facts, Fate and Effects, ed. Murawski, S. A., C. Ainsworth, S. Gilbert, D. Hollander, C. B. Paris, M. Schlüter, and D. Wetzel, 170-192. Cham: Springer International.

Petitgas, P., A.D. Rijnsdorp, M. Dickey-Collas, G.H. Engelhard, M.A. Peck, J.K. Pinnegar, et al. 2013. Impacts of climate change on the complex life cycles of fish. Fisheries Oceanography 22 (2): 121-139. https://doi.org/10.1111/fog.12010.

Peyronnin, N., R. Caffey, J. Cowan, D. Justić, A. Kolker, S. Laska, et al. 2017. Optimizing sediment diversion operations: working group recommendations for integrating complex ecological and social landscape interactions. Water 9(6). https://doi.org/10. 3390/w9060368.

Plagányi, É.E., M.D. Haywood, R.J. Gorton, M.C. Siple, and R.A. Deng. 2019. Management implications of modelling fisheries recruitment. Fisheries Research 217: 169-184. https://doi.org/ 10.1016/j.fishres.2019.03.007.

Poje, A.C., T.M. Ozgokmen, B.L. Lipphardt Jr., B.K. Haus, E.H. Ryan, A.C. Haza, et al. 2014. Submesoscale dispersion in the vicinity of the Deepwater Horizon spill. Proceedings of the National Academy of Sciences of the United States of America 111 (35): 12693-12698. https://doi.org/10.1073/pnas.1402452111.

Putman, N.F., and R. He. 2013a. Tracking the long-distance dispersal of marine organisms: Sensitivity to ocean model resolution. Journal of the Royal Society Interface 10 (81): 20120979. https://doi.org/ 10.1098/rsif.2012.0979.

Putman, N.F., K.L. Mansfield, R. He, D.J. Shaver, and P. Verley. 2013b. Predicting the distribution of oceanic-stage Kemp's ridley sea turtles. Biology Letters 9 (5): 20130345. https://doi.org/10.1098/ rsbl.2013.0345.

Putrasahan, D.A., I. Kamenkovich, M. Le Hénaff, and B.P. Kirtman. 2017. Importance of ocean mesoscale variability for air-sea interactions in the Gulf of Mexico. Geophysical Research Letters 44 (12): 6352-6362. https://doi.org/10.1002/2017gl072884.

Rabalais, N.N., R.E. Turner, B.K. Sen Gupta, D.F. Boesch, P. Chapman, and M.C. Murrell. 2007. Hypoxia in the northern Gulf of Mexico: Does the science support the Action Plan to reduce, mitigate, and control hypoxia? Estuaries and Coasts 30 (5): 753-772. https:// doi.org/10.1007/BF02841332.

Renault, L., J.C. McWilliams, and J. Gula. 2018. Dampening of submesoscale currents by air-sea stress coupling in the Californian upwelling system. Scientific Reports 8 (1): 13388. https://doi.org/ 10.1038/s41598-018-31602-3.

Roberts, B.J., and S.M. Doty. 2015. Spatial and temporal patterns of benthic respiration and net nutrient fluxes in the Atchafalaya River delta estuary. Estuaries and Coasts 38 (6): 1918-1936. https://doi.org/10.1007/s12237-015-9965-z.

Rodríguez, E., A. Wineteer, D. Perkovic-Martin, T. Gál, B. Stiles, N. Niamsuwan, et al. 2018. Estimating ocean vector winds and currents using a Ka-Band Pencil-Beam Doppler Scatterometer. Remote Sensing 10(4). https://doi.org/10.3390/rs10040576.

Rogers, B.D., R.F. Shaw, W.H. Herke, and R.H. Blanchet. 1993. Recruitment of postlarval and juvenile brown shrimp (Penaeus aztecus Ives) from offshore to estuarine waters of the northwestern Gulf of Mexico. Estuarine, Coastal and Shelf Science 36: 377-394. https://doi.org/10.1006/ecss.1993.1023.

Röhrs, J., K.H. Christensen, L.R. Hole, G. Broström, M. Drivdal, and S. Sundby. 2012. Observation-based evaluation of surface wave effects on currents and trajectory forecasts. Ocean Dynamics 62 (10): 1519-1533. https://doi.org/10.1007/s10236-012-0576-y.

Ropert-Coudert, Y., A. Kato, D. Grémillet, and F. Crenner. 2012. Biologging: Recording the ecophysiology and behaviour of animals moving freely in their environment. In Sensors for Ecology: Towards Integrated Knowledge of Ecosystems, ed. J.F. Le Galliard, J.M. Guarini, and F. Gaill, 17-41. Paris: CNRS.

Rose, K.A., J. Fiechter, E.N. Curchitser, K. Hedstrom, M. Bernal, S. Creekmore, et al. 2015. Demonstration of a fully-coupled endto-end model for small pelagic fish using sardine and anchovy in the California Current. Progress in Oceanography 138: 348-380. https://doi.org/10.1016/j.pocean.2015.01.012.

Roth, M.K., J. MacMahan, A. Reniers, T.M. Özgökmen, K. Woodall, and B. Haus. 2017. Observations of inner shelf cross-shore surface material transport adjacent to a coastal inlet in the northern Gulf of Mexico. Continental Shelf Research 137: 142-153. https://doi.org/10.1016/j.csr.2016.12.017.

Rozas, L.P. 1995. Hydroperiod and its influence on nekton use of the salt marsh: A pulsing ecosystem. Estuaries 18 (4): 579-590. https://doi. org/10.2307/1352378.

Samuels, W.B., N.E. Huang, and D.E. Amstutz. 1982. An oilspill trajectory analysis model with a variable wind deflection angle. Ocean Engineering 9 (4): 347-360. https://doi.org/10.1016/ 0029-8018(82)90028-2.

Schiller, R. V., V. H. Kourafalou, P. Hogan, and N. D. Walker. 2011. The dynamics of the Mississippi River plume: impact 
of topography, wind and offshore forcing on the fate of plume waters. Journal of Geophysical Research 116(C6). https://doi. org/10.1029/2010jc006883.

Schiller, R.V., and V.H. Kourafalou. 2014. Loop Current impact on the transport of Mississippi River waters. Journal of Coastal Research 30 (6): 1287-1306. https://doi.org/10.2112/JCOASTRES-D-13-00025.1.

Schroder, W.W., and W.J. Wiseman Jr. 1999. Geology and hydrodynamics of Gulf of Mexico estuaries. In Biogeochemistry of Gulf of Mexico Estuaries, ed. T.S. Bianchi, J.R. Pennock, and R.R. Twilley, 3-28. New York: John Wiley \& Sons Inc.

Schutte, C.A., J.M. Marton, A.E. Bernhard, A.E. Giblin, and B.J. Roberts. 2020. No evidence for long-term impacts of oil spill contamination on salt marsh soil nitrogen cycling processes. Estuaries and Coasts 43 (4): 865-879. https://doi.org/10.1007/ s12237-020-00699-z.

Shaw, R.F., W.J. Wiseman, R.E. Turner, L.J. Rouse, R.E. Condrey, and F.J. Kelly. 1985. Transport of larval gulf menhaden Brevoortia patronus in continental shelf waters of western Louisiana: A hypothesis. Transactions of the American Fisheries Society 114: 452-460. https://doi.org/10.1577/1548-8659(1985)114\%3c452: TOLGMB\%3e2.0.CO;2.

Shepherd, J., D. Benoit, K. Halanych, M. Carron, R. Shaw, and C. Wilson. 2016. Introduction to the special issue: An overview of the Gulf of Mexico Research Initiative. Oceanography 29 (3): 26-32. https://doi.org/10.5670/oceanog.2016.58.

Shi, L., M. Olabarrieta, A. Valle-Levinson, and J.C. Warner. 2019. Relevance of wind stress and wave-dependent ocean surface roughness on the generation of winter meteotsunamis in the Northern Gulf of Mexico. Ocean Modelling 140: 101408. https://doi.org/10. 1016/j.ocemod.2019.101408.

Silliman, B.R., J. van de Koppel, M.W. McCoy, J. Diller, G.N. Kasozi, K. Earl, et al. 2012. Degradation and resilience in Louisiana salt marshes after the BP-Deepwater Horizon oil spill. Proceedings of the National Academy of Sciences of the United States of America 109 (28): 11234-11239. https://doi.org/10.1073/pnas. 1204922109.

Snedden, G.A., J.E. Cable, C. Swarzenski, and E. Swenson. 2007. Sediment discharge into a subsiding Louisiana deltaic estuary through a Mississippi River diversion. Estuarine, Coastal and Shelf Science 71 (1-2): 181-193. https://doi.org/10.1016/j.ecss. 2006.06.035.

Snyder, S.M., E.L. Pulster, D.L. Wetzel, and S.A. Murawski. 2015. PAH exposure in Gulf of Mexico Demersal fishes, post-Deepwater Horizon. Environmental Science \& Technology 49 (14): 8786-8795. https://doi.org/10.1021/acs.est. $5 \mathrm{~b} 01870$.

Solo-Gabriele, H., T. Fiddaman, C. Mauritzen, C. Ainsworth, D. Abramson, I. Berenshtein, et al. 2021. Towards integrated modeling of the long-term impacts of oil spills. Marine Policy 131: 104554. https://doi.org/10.1016/j.marpol.2021.104554.

Sorourian, S. 2019. Numerical modeling of wave dynamics and sediment transport near the Mississippi Birdfoot Delta and Barataria Estuary. Ph.D. Dissertation, Louisiana State University, 216pp.

Spaulding, M.L. 1988. A state-of-the-art review of oil spill trajectory and fate modeling. Oil and Chemical Pollution 4 (1): 39-55. https://doi.org/10.1016/S0269-8579(88)80009-1.

Srinivasan A, Helgers J, Paris CB, Le Hénaff M, Kang H, Kourafalou VH, Iskandarani M, Thacker WC, Zysman JP, Tsinoremas NF, Knio OM (2010) Many task computing for modeling the fate of oil discharged from the deep water horizon well blowout, 2010 3rd Workshop on Many-Task Computing on Grids and Supercomputers, art. no.5699424, MTAGS10, ISBN:978-142449704

Staaterman, E., C.B. Paris, and J. Helgers. 2012. Orientation behavior in fish larvae: A missing piece to Hjort's critical period hypothesis. Journal of Theoretical Biology 304: 188-196. https://doi.org/10. 1016/j.jtbi.2012.03.016.
Sturges, W., and R. Leben. 2000. Frequency of ring separation from the Loop Current in the Gulf of Mexico: A revised estimate. Journal of Physical Oceanography 30: 1814-1819. https://doi.org/ 10.1175/1520-0485(2000)030\%3c1814:FORSFT\%3e2.0.CO;2.

Sun, S., C. Hu, O. Garcia-Pineda, V. Kourafalou, M.L. Henaff, and Y. Androulidakis. 2018. Remote sensing assessment of oil spills near a damaged platform in the Gulf of Mexico. Marine Pollution Bulletin. 136: 141-151. https://doi.org/10.1016/j.marpo lbul.2018.09.004.

Sun, D., A. Bracco, R. Barkan, M. Berta, D. Dauhajre, M.J. Molemaker, et al. 2020. Diurnal cycling of submesoscale dynamics: Lagrangian implications in drifter observations and model simulations of the Northern Gulf of Mexico. Journal of Physical Oceanography. https://doi.org/10.1175/JPO-D-19-0241.1.

Swarzenski, C.M., T.W. Doyle, B. Fry, and T.G. Hargis. 2008. Biogeochemical response of organic-rich freshwater marshes in the Louisiana delta plain to chronic river water influx. Biogeochemistry 90 (1): 49-63. https://doi.org/10.1007/s10533-008-9230-7.

Swarzenski, C.M., and S.M. Perrien. 2015. Discharge, suspended sediment, and salinity in the Gulf Intracoastal Waterway and adjacent surface waters in South-Central Louisiana, 1997-2008. USGS Numbered Series 2015-5132. Scientific Investigations Report. Reston, VA: U.S. Geological Survey.

Teodósio, M.A., C.B. Paris, E. Wolanski, and P. Morais. 2016. Biophysical processes leading to the ingress of temperate fish larvae into estuarine nursery areas: A review. Estuarine, Coastal and Shelf Science 183: 187-202. https://doi.org/10.1016/j.ecss.2016. 10.022 .

Tester, P.A., and K.A. Steidinger. 1997. Gymnodinium breve red tide blooms: initiation, transport, and consequences of surface circulation. Limnology and Oceanography 42(5part2): 1039-1051. https://doi.org/10.4319/lo.1997.42.5_part_2.1039.

Todd, A.C., S.L. Morey, and E.P. Chassignet. 2014. Circulation and cross-shelf transport in the Florida Big Bend. Journal of Marine Research 72 (6): 445-475. https://doi.org/10.1357/ 002224014815540660.

Turner, R.E. 1997. Wetland loss in the Northern Gulf of Mexico: Multiple working hypotheses. Estuaries 20 (1): 1-13. https://doi.org/ $10.2307 / 1352716$.

Turner, R.E., E.B. Overton, B.M. Meyer, M.S. Miles, and L. HooperBui. 2014a. Changes in the concentration and relative abundance of alkanes and PAHs from the Deepwater Horizon oiling of coastal marshes. Marine Pollution Bulletin 86 (1): 291-297. https://doi.org/10.1016/j.marpolbul.2014.07.003.

Turner, R.E., E.B. Overton, B.M. Meyer, M.S. Miles, G. McClenachan, L. Hooper-Bui, et al. 2014b. Distribution and recovery trajectory of Macondo (Mississippi Canyon 252) oil in Louisiana coastal wetlands. Marine Pollution Bulletin 87 (1-2): 57-67. https://doi. org/10.1016/j.marpolbul.2014.08.011.

Turner, R.E., and G. McClenachan. 2018. Reversing wetland death from 35,000 cuts: Opportunities to restore Louisiana's dredged canals. PLoS ONE 13 (12): e0207717. https://doi.org/10.1371/ journal.pone.0207717.

Turner, R.E., E.M. Swenson, C.S. Milan, and J.M. Lee. 2019. Spatial variations in Chlorophyll a, C, N, and P in a Louisiana estuary from 1994 to 2016. Hydrobiologia. https://doi.org/10.1007/ s10750-019-3918-7.

Valentine, K., and G. Mariotti. 2019. Wind-driven water level fluctuations drive marsh edge erosion variability in microtidal coastal bays. Continental Shelf Research 176: 76-89. https://doi.org/10. 1016/j.csr.2019.03.002.

Valle-Levinson, A. 2011. Classification of estuarine circulation. In Classification of estuarine and nearshore coastal ecosystems, ed. Wolanski, E. and D. McLusky, Vol. 1, Treatise on Estuarine and Coastal Science, 75-86. Amsterdam: Elsevier. https://doi.org/10. 1016/B978-0-12-374711-2.00106-6. 
Valle-Levinson, A., K. Huguenard, L. Ross, J. Branyon, J. MacMahan, and A. Reniers. 2015. Tidal and nontidal exchange at a subtropical inlet: Destin Inlet, Northwest Florida. Estuarine, Coastal and Shelf Science 155: 137-147. https://doi.org/10.1016/j.ecss.2015.01.020.

Vaz, A.C., C.B. Paris, M.J. Olascoaga, V.H. Kourafalou, H. Kang, and J.K. Reed. 2016. The perfect storm: Match-mismatch of biophysical events drives larval reef fish connectivity between Pulley Ridge mesophotic reef and the Florida Keys. Continental Shelf Research 125: 136-146. https://doi.org/10.1016/j.csr.2016. 06.012.

Verri, G., N. Pinardi, F. Bryan, Y.-h. Tseng, G. Coppini, and E. Clementi. 2020. A box model to represent estuarine dynamics in mesoscale resolution ocean models. Ocean Modelling 148. https://doi.org/ 10.1016/j.ocemod.2020.101587.

Vukovich, F.M. 2007. Climatology of ocean features in the Gulf of Mexico using satellite remote sensing data. Journal of Physical Oceanography 37 (3): 689-707. https://doi.org/10.1175/ jpo2989.1.

Walker, N.D. 1996. Satellite assessment of Mississippi River plume variability: Causes and predictability. Remote Sensing of Environment 58 (1): 21-35. https://doi.org/10.1016/0034-4257(95) 00259-6.

Walker, N.D., W.J. Wiseman, Jr., L.J. Rouse, Jr., and A. Babin. 2005. Effects of river discharge, wind stress, and slope eddies on circulation and the satellite-observed structure of the Mississippi River plume. Journal of Coastal Research 21 (6 (216)): 1228-1244. https://doi.org/10.2112/04-0347.1.

Walker, N.D., C.T. Pilley, V.V. Raghunathan, E.J. D’Sa, R.R. Leben, N.C. Hoffmann, et al. 2011. Impacts of Loop Current frontal cyclonic eddies and wind forcing on the 2010 Gulf of Mexico Oil Spill., in Monitoring and Modeling the Deepwater Horizon Oil Spill: A Record-Breaking Enterprise. Geophysical Monograph Series 195: 103-116. https://doi.org/10.1029/2011GM001120.

Wallace, A.A., D.J. Hollander, and E.B. Peebles. 2014. Stable isotopes in fish eye lenses as potential recorders of trophic and geographic history. PLOS ONE 9 (10): e108935. https://doi.org/10.1371/ journal.pone.0108935.

Walsh, J.J. 2003. Phytoplankton response to intrusions of slope water on the West Florida Shelf: Models and observations. Journal of Geophysical Research 108 (C6). https://doi.org/10.1029/ $2002 \mathrm{jc} 001406$

Ward, E.J., K.L. Oken, K.A. Rose, S. Sable, K. Watkins, E.E. Holmes, and M.D. Scheuerell. 2018. Applying spatiotemporal models to monitoring data to quantify fish population responses to the Deepwater Horizon oil spill in the Gulf of Mexico. Environmental Monitoring and Assessment 190: 1-16. https://doi.org/ 10.1007/s10661-018-6912-z.

Warner, J.C., B. Armstrong, R. He, and J.B. Zambon. 2010. Development of a coupled ocean-atmosphere-wave-sediment transport (COAWST) modeling system. Ocean Modelling 35 (3): 230-244. https://doi.org/10.1016/j.ocemod.2010.07.010.

Warner, J.C., W.C. Schwab, J.H. List, I. Safak, M. Liste, and W.E. Baldwin. 2017. Inner-shelf ocean dynamics and seafloor morphologic changes during Hurricane Sandy. Continental Shelf Research 138: 1-18. https://doi.org/10.1016/j.csr.2017.02.003.

Watkins, K.S., and K.A. Rose. 2013. Evaluating the performance of individual-based animal movement models in novel environments. Ecological Modelling 250: 214-234. https://doi.org/10. 1016/j.ecolmodel.2012.11.011.

Wei, E., A. Zhang, Z. Yang, Y. Chen, J. Kelley, F. Aikman, et al. 2014. NOAA's nested northern Gulf of Mexico operational forecast systems development. Journal of Marine Science and Engineering 2 (1): 1-17. https://doi.org/10.3390/jmse2010001.

Weisberg, R.H. 2003. Local and deep-ocean forcing contributions to anomalous water properties on the West Florida Shelf. Journal of Geophysical Research 108 (C6). https://doi.org/10.1029/ $2002 \mathrm{jc} 001407$.

Weisberg, R.H., R. He, G. Kirkpatrick, F. Muller-Karger, and J.J. Walsh. 2004. Coastal ocean circulation influences on remotely sensed optical properties: A west Florida shelf case study. Oceanography 17: 68-75. https://doi.org/10.5670/oceanog.2004.49.

Weisberg, R. H., R. He, Y. Liu, and J. I. Virmani. 2005. West Florida Shelf circulation on synoptic, seasonal and interannual time scales. In Circulation in the Gulf of Mexico: Observations and Models, ed. W. B. Sturges, and A. Lugo. Washington, D. C.: AGU. https://doi.org/10.1029/161GM23.

Weisberg, R.H., and L. Zheng. 2006. Hurricane storm surge simulations for Tampa Bay. Estuaries and Coasts 29 (6): 899-913. https://doi.org/10.1007/BF02798649.

Weisberg, R.H., A. Barth, A. Alvera-Azcárate, and L. Zheng. 2009. A coordinated coastal ocean observing and modeling system for the West Florida Continental Shelf. Harmful Algae 8 (4): 585-597. https://doi.org/10.1016/j.hal.2008.11.003.

Weisberg, R.H., L. Zheng, and Y. Liu. 2011. Tracking subsurface oil in the aftermath of the Deepwater Horizon Well Blowout. Monitoring and Modeling the Deepwater Horizon Oil Spill: A Record-Breaking Enterprise 205-215. https://doi.org/10.1029/ $2011 \mathrm{GM} 001131$.

Weisberg, R.H., L. Zheng, and E. Peebles. 2014. Gag grouper larvae pathways on the West Florida Shelf. Continental Shelf Research 88: 11-23. https://doi.org/10.1016/j.csr.2014.06.003.

Weisberg, R.H., L. Zheng, and Y. Liu. 2015. Chapter 4 - Basic tenets for coastal ocean ecosystems monitoring. In Coastal Ocean Observing Systems, ed. Y. Liu, H. Kerkering, and R.H. Weisberg, 40-57. Boston: Academic Press.

Weisberg, R.H., L. Zheng, Y. Liu, A.A. Corcoran, C. Lembke, C. Hu, et al. 2016a. Karenia brevis blooms on the West Florida Shelf: A comparative study of the robust 2012 bloom and the nearly null 2013 event. Continental Shelf Research 120: 106-121. https://doi. org/10.1016/j.csr.2016.03.011.

Weisberg, R.H., L. Zheng, Y. Liu, S. Murawski, C. Hu, and J. Paul. 2016b. Did Deepwater Horizon hydrocarbons transit to the west Florida continental shelf? Deep Sea Research Part II: Topical Studies in Oceanography 129: 259-272. https://doi.org/10. 1016/j.dsr2.2014.02.002.

Weisberg, R.H., Z. Lianyuan, and Y. Liu. 2017. On the movement of Deepwater Horizon Oil to northern Gulf beaches. Ocean Modelling 111: 81-97. https://doi.org/10.1016/j.ocemod.2017.02.002.

Weisberg, R.H., Y. Liu, C. Lembke, C. Hu, K. Hubbard, and M. Garrett. 2019. The coastal ocean circulation influence on the 2018 West Florida Shelf K. brevis red tide bloom. Journal of Geophysical Research: Oceans 124 (4): 2501-2512. https://doi. org/10.1029/2018JC014887.

Wenegrat, J.O., M.J. McPhaden, and R.-C. Lien. 2014. Wind stress and near-surface shear in the equatorial Atlantic Ocean. Geophysical Research Letters 41 (4): 1226-1231. https://doi.org/10.1002/ $2013 \mathrm{~g} 1059149$

White, E., F. Messina, L. Moss, and E. Meselhe. 2018. Salinity and marine mammal dynamics in Barataria Basin: Historic patterns and modeled diversion scenarios. Water 10 (8): 1015. https://doi. org/10.3390/w10081015.

Wilbur, H.M. 1980. Complex life cycles. Annual Review of Ecology and Systematics 11 (1): 67-93. https://doi.org/10.1146/annurev. es.11.110180.000435.

Wissel, B., A. Gace, and B. Fry. 2005. Tracing river influences on phytoplankton dynamics in two Louisiana estuaries. Ecology 86 (10): 2751-2762. https://doi.org/10.1890/04-1714.

Yapa, P.D. 1996. State-of-the-art review of modeling transport and fate of oil spills. Journal of Hydraulic Engineering 122 (11): 
594-609. https://doi.org/10.1061/(ASCE)0733-9429(1996)122: 11(594)

Ye, L., A.J. Manning, J. Holyoke, J.A. Penaloza-Giraldo, and T.-J. Hsu. 2021. The role of biophysical stickiness on oil-mineral flocculation and settling in seawater. Frontiers in Marine Science 8. https://doi.org/10.3389/fmars.2021.628827.

Ye, L., A.J. Manning, and T.J. Hsu. 2020. Oil-mineral flocculation and settling velocity in saline water. Water Research 173: 115569. https://doi.org/10.1016/j.watres.2020.115569.

Zambon, J.B., R. He, and J.C. Warner. 2014. Investigation of hurricane Ivan using the coupled ocean-atmosphere-wave-sediment transport (COAWST) model. Ocean Dynamics 64 (11): 1535-1554. https://doi.org/10.1007/s10236-014-0777-7.

Zeng, X. 2019. Potential connectivity among spatially distinct management zones for Bonefish (Albula vulpes) via larval dispersal. Environmental biology of fishes v. 102(no. 2): pp. 233-252-2019 v.2102 no.2012. https://doi.org/10.1007/s10641-018-0826-Z.

Zengel, S., B.M. Bernik, N. Rutherford, Z. Nixon, and J. Michel. 2015. Heavily oiled salt marsh following the Deepwater Horizon oil spill, ecological comparisons of shoreline cleanup treatments and recovery. PLoS ONE 10 (7): e0132324. https://doi.org/10.1371/ journal.pone.0132324.

Zheng, L., and R.H. Weisberg. 2010. Rookery Bay and Naples Bay circulation simulations: Applications to tides and fresh water inflow regulation. Ecological Modelling 221 (7): 986-996. https://doi. org/10.1016/j.ecolmodel.2009.01.024.

Zheng, L., and R.H. Weisberg. 2012. Modeling the west Florida coastal ocean by downscaling from the deep ocean, across the continental shelf and into the estuaries. Ocean Modelling 48: 10-29. https://doi.org/10.1016/j.ocemod.2012.02.002.

Zhong, Y., A. Bracco, and T.A. Villareal. 2012. Pattern formation at the ocean surface: Sargassum distribution and the role of the eddy field. Limnology and Oceanography: Fluids and Environments 2 (1): 12-27. https://doi.org/10.1215/21573689-1573372.

Zhong, Y., and A. Bracco. 2013. Submesoscale impacts on horizontal and vertical transport in the Gulf of Mexico. Journal of Geophysical Research: Oceans 118 (10): 5651-5668. https://doi.org/ 10.1002/jgrc. 20402 .

\section{Authors and Affiliations}

\section{Dubravko Justić ${ }^{1}\left[\right.$ (]) Villy Kourafalou ${ }^{2}$. Giulio Mariotti ${ }^{1,3} \cdot$ Songjie He $^{1} \cdot$ Robert Weisberg $^{4} \cdot$ Yannis Androulidakis $^{2}$. Christopher Barker ${ }^{5}$. Annalisa Bracco ${ }^{6}$. Brian Dzwonkowski ${ }^{7}$. Chuanmin $\mathrm{Hu}^{4}$. Haosheng Huang ${ }^{1}$. Gregg Jacobs ${ }^{8}$. Matthieu Le Hénaff ${ }^{9,10}$. Yonggang Liu ${ }^{4}$. Steven Morey ${ }^{11}$. Jeffrey Nittrouer ${ }^{12}$. Edward Overton ${ }^{1}$. Claire B. Paris ${ }^{2}$. Brian J. Roberts ${ }^{13} \cdot$ Kenneth Rose $^{14} \cdot$ Arnoldo Valle-Levinson $^{15}$. Jerry Wiggert ${ }^{16}$}

1 Department of Oceanography and Coastal Sciences, Louisiana State University, 1002-Y Energy, Coast \& Environment Building, Baton Rouge, LA 70803, USA

2 Department of Ocean Sciences, University of Miami/RSMAS, Miami, FL 33149, USA

3 Center for Computation and Technology, Louisiana State University, 340 E Parker Blvd, Baton Rouge, LA 70803, USA

4 College of Marine Science, University of South Florida, 140 Seventh Ave. South, St. Petersburg, FL 33701, USA

5 National Oceanic and Atmospheric Administration Emergency Response Division, 7600 Sand Point Way NE, Seattle, WA 98115-6349, USA

6 School of Earth and Atmospheric Sciences, Georgia Institute of Technology, 311 Ferst Dr., Atlanta, GA 30332-0340, USA

7 Dauphin Island Sea Lab, University of South Alabama, Dauphin Island, AL 36528, USA

8 Naval Research Laboratory, Stennis Space Center, 1005 Balch Boulevard, Hancock County, MS 39529, USA

9 Cooperative Institute for Marine and Atmospheric Studies, University of Miami/CIMAS, Miami, FL 33149, USA
10 NOAA Atlantic Oceanographic and Meteorological Laboratory (AOML), 4301 Rickenbacker Causeway, Miami, FL 33149, USA

11 School of the Environment, Florida Agricultural and Mechanical University FSH Science Research Center, 1515 S. Martin Luther King Jr. Blvd, Tallahassee, FL 32307, USA

12 Department of Earth Science, Rice University, MS-126, 6100 Main Street, Houston, TX 77005, USA

13 Louisiana Universities Marine Consortium, 8124 Highway 56, Chauvin, LA 70344, USA

14 Horn Point Laboratory, Center for Environmental Science, University of Maryland, PO Box 775, Cambridge, MD 21613, USA

15 Civil and Coastal Engineering Department, University of Florida, Gainesville, FL 32611, USA

16 Department of Marine Science, University of Southern Mississippi, 1020 Balch Blvd, Kiln, MS 39556, USA 